US Army Corps

of Engineers ${ }_{\circledast}$

Engineer Research and

Development Center
INNOVATIVE SOLUTIONS

for a safer, better world

Installation Technology Transition Program (ITTP)

\title{
ROOFER Inventory Procedures and Inspection Manual for Metal Panel Roofing
}

David M. Bailey, Joseph E. Karbarz, and Katharine E. Sweeton

December 2012

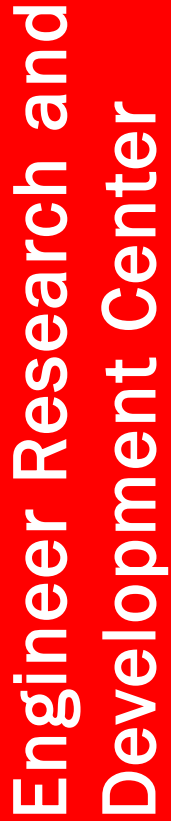

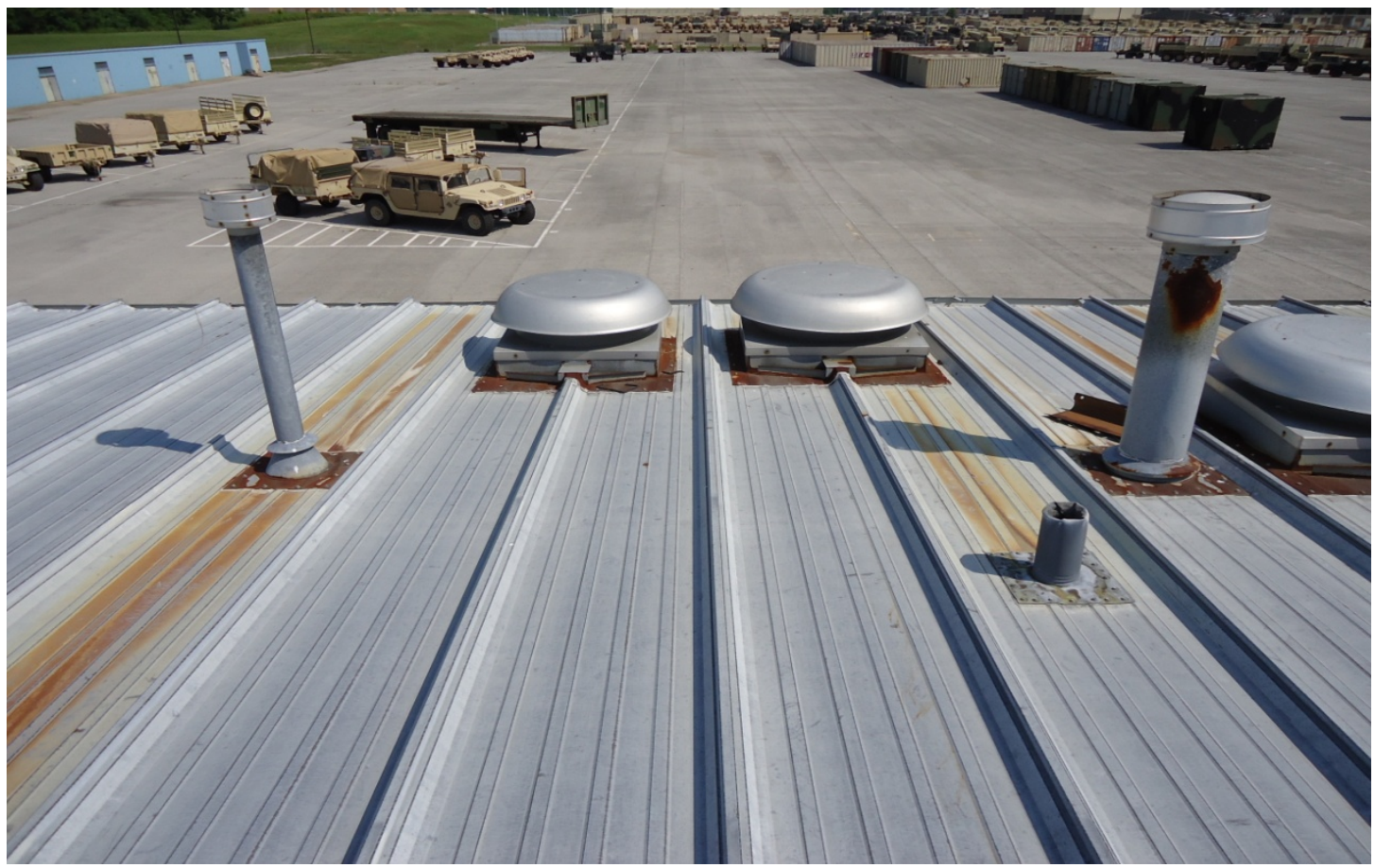


The US Army Engineer Research and Development Center (ERDC) solves the nation's toughest engineering and environmental challenges. ERDC develops innovative solutions in civil and military engineering, geospatial sciences, water resources, and environmental sciences for the Army, the Department of Defense, civilian agencies, and our nation's public good. Find out more at www.erdc.usace.army.mil.

To search for other technical reports published by ERDC, visit the ERDC online library at http://acwc.sdp.sirsi.net/client/default. 


\section{ROOFER Inventory Procedures and Inspection Manual for Metal Panel Roofing}

David M. Bailey

Construction Engineering Research Laboratory

US Army Engineer Research and Development Center

2902 Newmark Drive

Champaign, IL 61822

Joseph E. Karbarz

Information Technology Laboratory

US Army Engineer Research and Development Center

3909 Halls Ferry Road

Vicksburg, MS 39180-6199

Katharine E. Sweeton

US Army Engineer District, Louisville

600 Dr. M L King Jr Place

Louisville, KY 40202-0059

Final report

Approved for public release; distribution is unlimited.

Prepared for Office of the Assistant Chief of Staff for Installation Management (ACSIM) Arlington, VA 22202

Under Project FY10-04, "ROOFER Condition Assessment Procedures for Metal Roofing" 


\section{Abstract}

The US Army is responsible for maintaining millions of square feet of metal panel roofing on a wide variety of facilities. This type of roofing system shares a number of general characteristics with other types, but they use certain distinct types of materials that have their own specialized distress and degradation mechanisms.

Dedicated inspection guidance and condition index calculation methods are needed to quantify the condition of an installation's metal panel roofing assets in order to make the best use of Army maintenance and repair resources. This manual was developed to serve as a standard reference for performing inspections and calculating a flashing condition index (FCI) and panel condition index (PCI) for use in facility maintenance management activities. This guidance represents a new implementation of the widely used ROOFER Sustainment Management System.

DISCLAIMER: The contents of this report are not to be used for advertising, publication, or promotional purposes. Citation of trade names does not constitute an official endorsement or approval of the use of such commercial products. All product names and trademarks cited are the property of their respective owners. The findings of this report are not to be construed as an official Department of the Army position unless so designated by other authorized documents. 


\section{Contents}

Abstract...................................................................................................................................... i

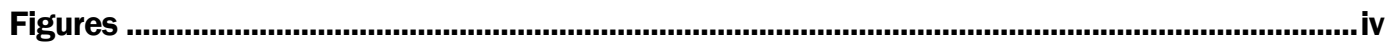

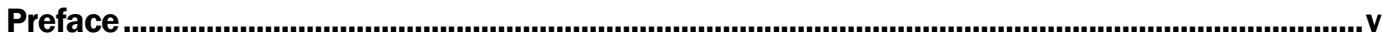

Unit Conversion Factors........................................................................................................ vi

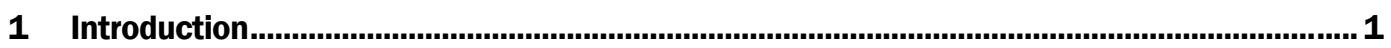

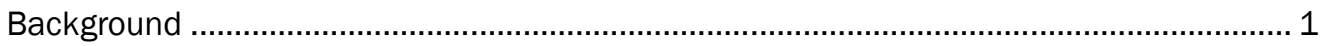

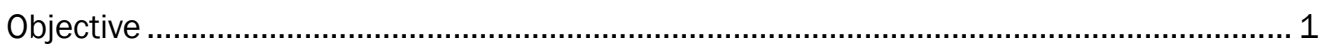

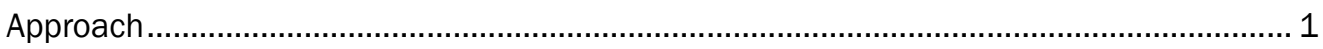

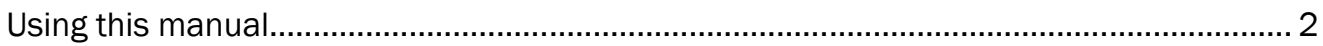

Mode of technology transfer..................................................................................... 2

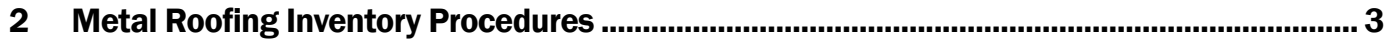

Metal panel roofing system categorization ............................................................... 3

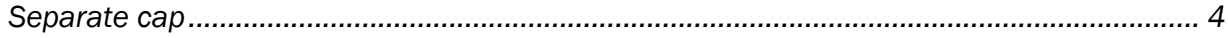

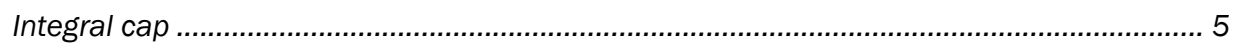

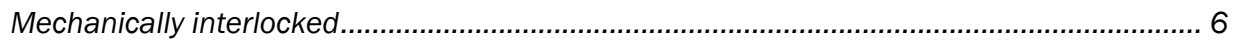

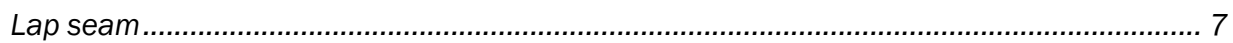

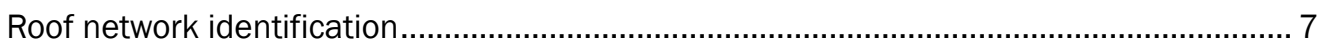

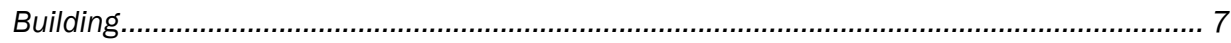

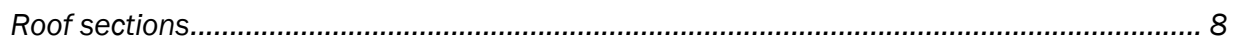

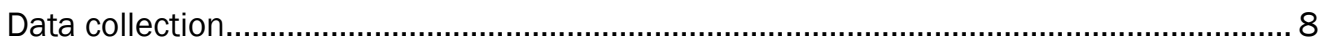

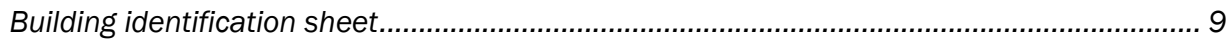

Roof section identification worksheet ............................................................................ 9

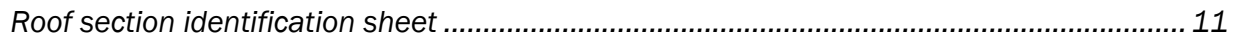

Roof inspection worksheet.............................................................................................. 12

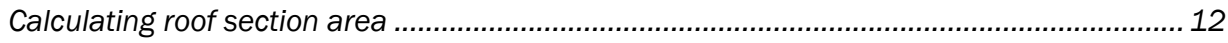

3 Metal Roofing Inspection Procedures ............................................................................21

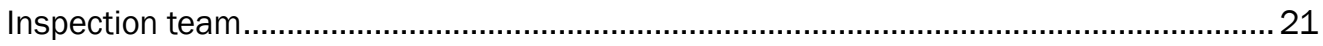

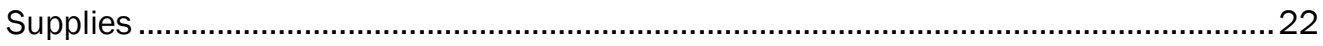

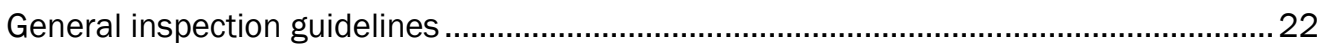

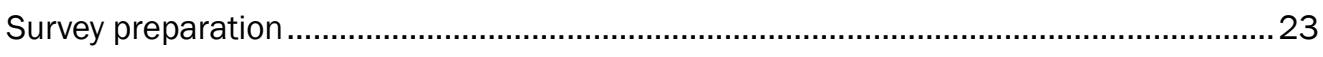

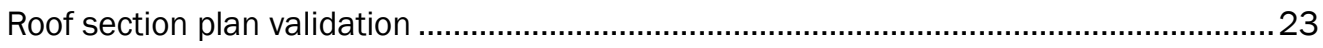

Determining total length of flashed perimeter and curb flashings ......................................23

Determining total number of through-panel fasteners ...................................................... 24

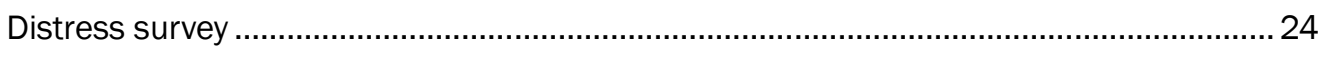

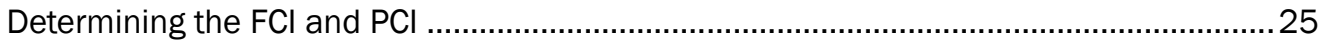




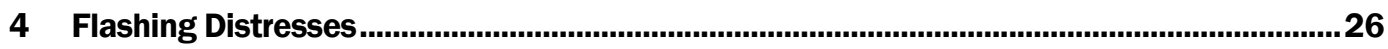

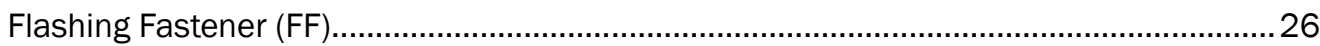

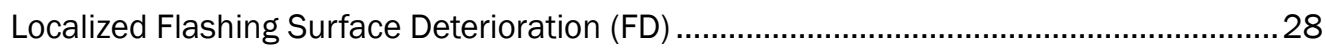

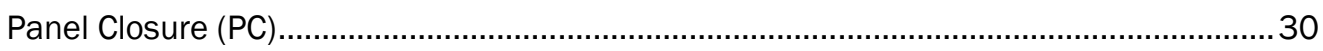

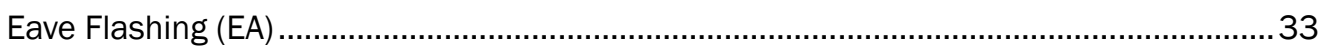

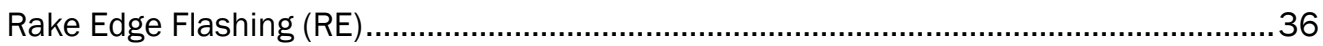

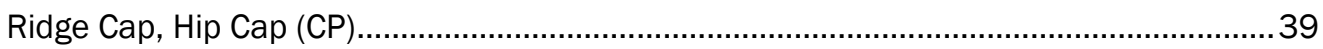

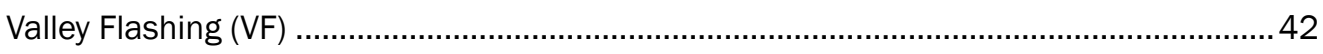

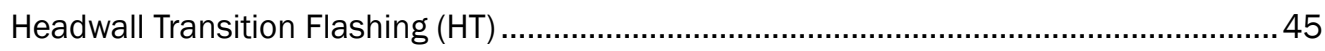

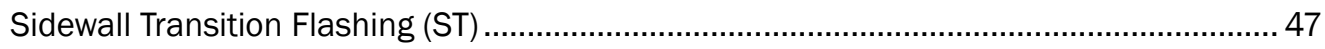

Continuous Roof-to-Wall Panel Transition Flashing (RW) ..............................................50

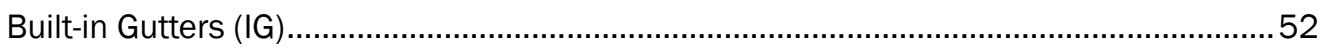

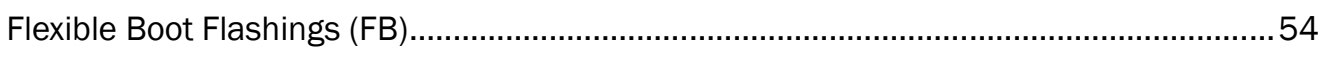

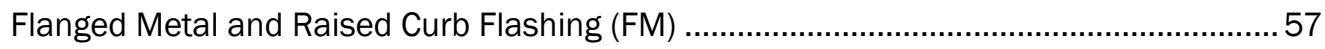

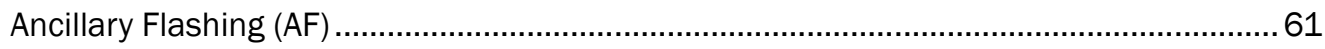

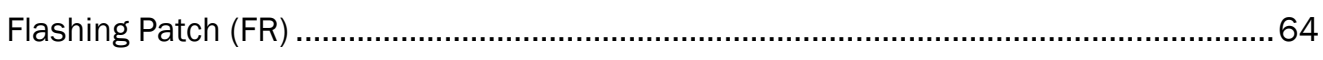

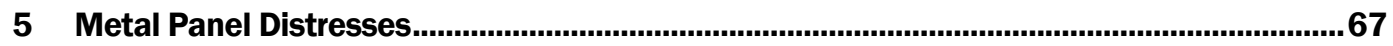

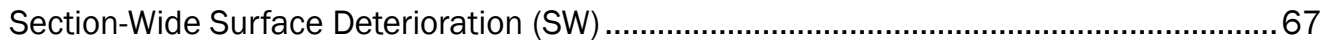

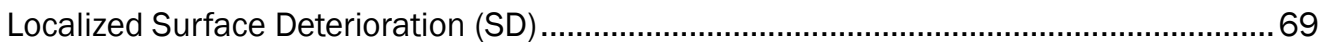

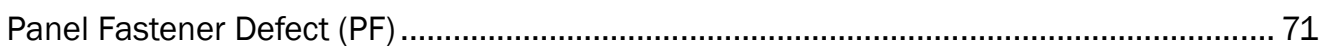

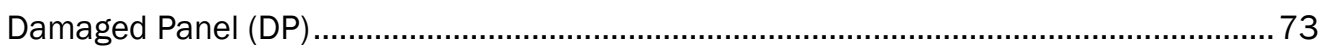

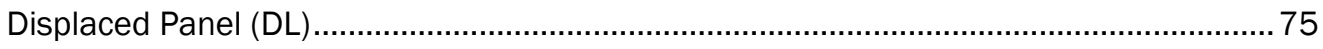

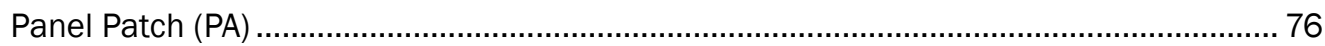

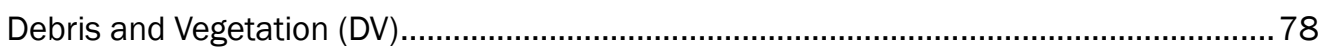

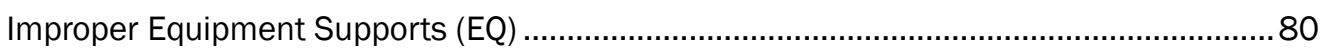

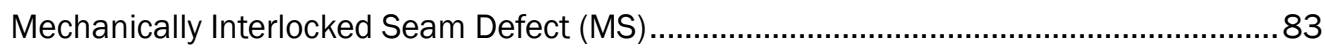

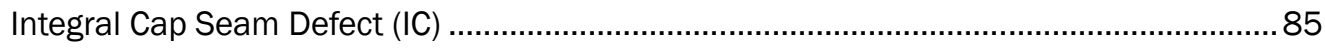

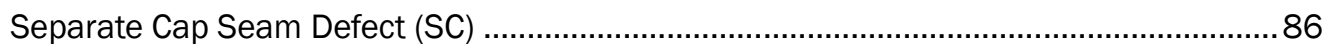

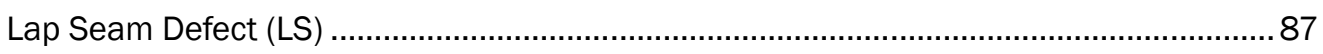

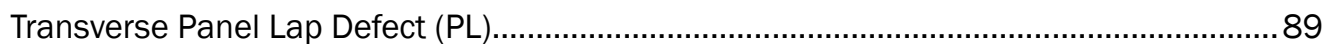

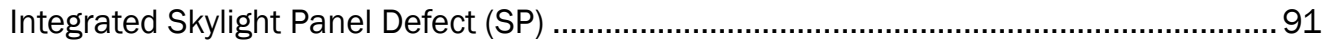

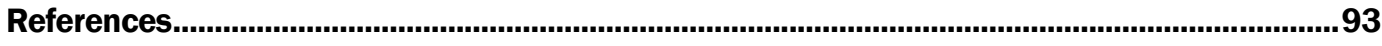

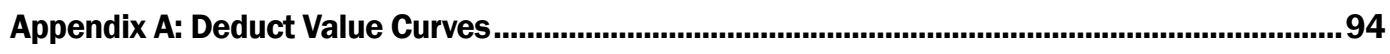

Appendix B: Condition Index Calculation Methodology..................................................... 109

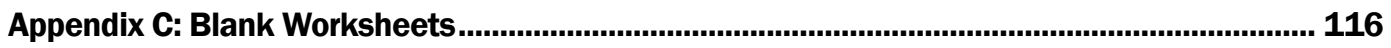

Report Documentation Page 


\section{Figures}

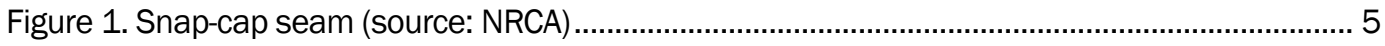

Figure 2. Traditional batten seam (source: NRCA) ……….......................................................... 5

Figure 3. Snap-on batten cap with clip (source: NRCA) ……….................................................. 5

Figure 4. Capped standing seam (source: NRCA) ....................................................................... 5

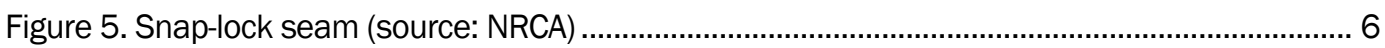

Figure 6. Mechanically seamed single-lock seam (source: NRCA)................................................... 6

Figure 7. Mechanically seamed double-lock seam (source: NRCA) ………………........................ 6

Figure 8. Trapezoidal seam (source: NRCA)................................................................................ 6

Figure 9. Raised lap seam (source: NRCA) ............................................................................ 7

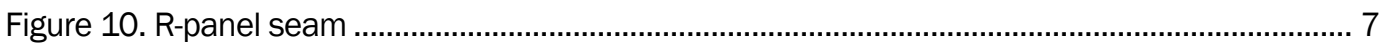

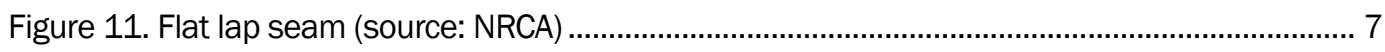

Figure 12. Building Identification Worksheet with sample data..................................................... 13

Figure 13. Roof Section Identification Worksheet (page 1) with sample data................................... 14

Figure 14. Roof Section Identification Worksheet (page 2) with sample data................................. 15

Figure 15. Roof Section Identification Worksheet (page 3) with sample data................................... 16

Figure 16. Roof Section Identification Sheet with sample data. .................................................... 17

Figure 17. Roof Inspection Worksheet with roof section plan....................................................... 18

Figure 18. Standard symbols for roof section plan.................................................................... 19

Figure 19. Roof Inspection Worksheet with inspection data. ........................................................2 20 


\section{Preface}

This study was conducted for the Office of the Assistant Chief of Staff for Installation Management (OACSIM) under the Installation Technology Transition Program (ITTP); Project FY10-04, "ROOFER Condition Assessment Procedures for Metal Roofing." The ITTP Program Manager was Debbie J . Lawrence, CEERD-CV-T, and the Technical Monitor was Philip R. Columbus, DAIM-ODF.

The work was performed by the Materials and Structures Branch (CF-M) of the Facilities Division (CF), US Army Engineer Research and Development Center, Construction Engineering Research Laboratory (ERDCCERL). At the time of publication, Vicki L. Van Blaricum was Chief, CEERD-CF-M; L. Michael Golish was Chief, CEERD-CF; and Martin J . Savoie was the Technical Director for Installations. The Deputy Director of ERDC-CERL was Dr. Kirankumar Topudurti and the Director was Dr. Ilker Adiguzel.

The illustrations of seam details in Chapter 2 and illustrations of the flashing details in Chapter 4 are adapted from the NRCA Roofing Manual: Metal Panel and SPF Roof Systems - 2012, with the permission of the National Roofing Contractor Association (NRCA).

Special acknowledgement is given to following individuals, who were key members of the development team and participated in all field testing and validation efforts:

- Mark deOgburn, Naval Facilities Engineering Command (NAVFAC)

- Tim Benzie, Inspec, Inc., Minneapolis, MN

- Dane Bradford, Bradford Roof Management, Billings, MT

- Mike Quinn, Conley Group Inc., Irving, TX.

COL Kevin J . Wilson was the Commander of ERDC, and Dr. J effery P. Holland was the Director. 


\section{Unit Conversion Factors}

\begin{tabular}{|l|l|l|}
\hline Multiply & By & To Obtain \\
\hline feet & 0.3048 & meters \\
\hline inches & 0.0254 & meters \\
\hline mils & 0.0254 & millimeters \\
\hline pounds (mass) & 0.45359237 & kilograms \\
\hline square feet & 0.09290304 & square meters \\
\hline square inches & $6.4516 \mathrm{E}-04$ & square meters \\
\hline square yards & 0.8361274 & square meters \\
\hline yards & 0.9144 & meters \\
\hline
\end{tabular}




\section{Introduction}

\section{Background}

The US Army Engineer Research and Development Center, Construction Engineering Research Laboratory (ERDC-CERL) has developed the ROOFER Sustainment Management System (SMS) for low-slope membrane and asphalt shingle roofs. The ROOFER SMS provides installations with standardized procedures for performing the inventory, inspection, condition assessment, and network and project analyses for managing their roof assets and making decisions on repair and replacement requirements. ERDC-CERL also developed Micro ROOFER (Bailey 2003), to an automated tool for performing asset management using ROOFER procedures and collected roof asset data. Recently, ERDC-CERL completed a conversion of that tool to a web-based application.

Using procedures that were developed for bituminous built-up (Shahin, Bailey, and Brotherson 1987b), modified bitumen (Bailey 2010), single-ply membrane (Bailey et al. 1993), and asphalt shingle roofs (Bailey 1999), most of the roofing systems used on Army installations can now be inspected and managed using the ROOFER SMS. Metal roofing, the remaining roof type that comprises a significant portion of the Army's roofing assets, had not been addressed before now. Many ROOFER user requests have indicated the need for a procedure to assess metal panel roofs.

\section{Objective}

The objective of this work was to develop ROOFER inventory, inspection, and condition index procedures based on visual inspection of the metal panels and flashing components of metal panel roofing systems. This report provides roof inspectors with a standard reference for collecting physical and historical roofing system data, conducting inspections, and calculating the flashing condition index (FCI) and panel condition index (PCI) for metal panel systems.

\section{Approach}

The concepts and theory behind the ROOFER condition indexing methodology, and the process used to develop and field-validate the distress definitions and deduct value curves, were documented in Shahin, Bailey, and 
Brotherson (1987a). The developmental process for metal systems included technical contributions by a rating team of experts and field tests at several sites (military and nonmilitary).

\section{Using this manual}

Chapter 2 contains the inventory procedure for metal roofing systems. Chapter 3 provides the inspection procedures for metal panel roofing systems only. The inspection procedures are not applicable to metal shingle panel, flat-locked seam panel, or other hybrid systems that are not as commonly used today. Distresses for flashings and panels are presented in Chapters 4 and 5, respectively. Those two chapters include descriptions of distresses, severity levels, defect definitions, photographs, and measurement criteria. Inspectors should study this manual and carry a copy for reference during inspections.

The inspection procedures require technically qualified determinations related to distress severity and the need to replace failing panels. Therefore, the inspection team should include at least one individual having experience with and technical knowledge of metal panel roofing systems.

Results of roof inspections are to be used in conjunction with the calculation procedures provided in Appendix B, "Condition Index Calculation Methodology," to determine the FCIs and PCIs. Deduct value curves used in the calculations are presented in Appendix A. Appendix C includes blank specimens of both the ROOFER inventory and inspection worksheet, and other forms, which may be photocopied for use in the field.

\section{Mode of technology transfer}

Information about the ROOFER SMS and support are available at the US Army Engineer Research and Development Center online fact sheet navigation page:

$\underline{\text { http://sms.cecer.army.mil/SitePages/ROOFER.aspx }}$

Inquiries about ROOFER may be directed to Chief, Materials and Structures Branch (CEERD-CF-M), US Army Engineer Research and Development Center, Construction Engineering Research Laboratory (ERDCCERL), PO Box 9005, Champaign, IL 61826-9005, 217-352-6511. 


\section{Metal Roofing Inventory Procedures}

The roofing inventory is the foundation of ROOFER. It provides the information needed by engineering personnel to manage their roofing assets. Well maintained inventory data, when combined with inspection data (discussed in Chapters 3, 4, and 5), will provide a construction history of each roof, identification of problems that require repair, and a performance record that can be used to determine repair and replacement strategies.

This chapter presents the inventory procedures for metal roofing systems. Two sets of inventory procedures were previously developed for the ROOFER SMS - one for low-slope membrane roofs (Bailey 1990) and another for steep roofs (Bailey 1999). Before development of the procedures presented here, metal roofs were inventoried using the procedures for steep roofs.

\section{Metal panel roofing system categorization}

The inspection procedures presented in this report are used to evaluate the more common metal panel systems. They do not apply to metal shingle panel, flat-locked seam panel, or other hybrid metal roofing systems, which are not used in high numbers today on military installations.

To be able to inspect and assess the condition of metal panel roofing systems, it was necessary to develop a standardized method for classifying the many different systems that are available. There are many ways of categorizing metal panel roofing systems. One common method classifies metal roof systems as being either hydrokinetic (water-shedding) or hydrostatic (waterproof). Hydrokinetic systems provide watertightness by applying slope and gravity. These systems are designed and installed to eliminate the potential for ponding and quickly shed water from the roof. With hydrostatic systems, the panel seams and other joinery between components and at junctures are designed and installed to be able to tolerate minimal hydrostatic pressure without leaking. These systems often rely on greater seam heights and more extensive use of sealants to prevent water penetration than do hydrokinetic systems. 
Metal panel systems may also be categorized as architectural or structural. Architectural systems are usually installed over a solid or closely spaced substrate. They are typically hydrokinetic systems, and their supporting substrates are covered with waterproof underlayments that provide additional protection. Architectural metal systems are used on steep slopes, so they contribute significantly to the visual appearance of the building façade. Structural metal systems do not require the support of a solid substrate; the panels can span framing members, which for most systems are spaced at 5 foot intervals. These systems are most often hydrostatic, and can be used on low-slope applications. It should be noted, however, that the terminology used in metal panel marketing literature may not be consistent with the descriptions offered here. Some systems marketed as architectural may be designed to span purlins, and some systems marketed as structural may be specified for fastening onto a structural deck.

Another basis for categorizing metal panel roofing systems is the method used to fasten and secure the panels to the substructure. For a concealed fastener system, primary attachment is achieved by using concealed clips integrated with the panel seams and fastened to the structure or substrate below. With a through-fastener system, the fasteners are placed through the panel and fastened to the structural system below, requiring a means of making the fastener hole watertight.

The type of seam used for joining adjacent panels is another characteristic that differentiates metal panel roofing systems. For the ROOFER inventory procedure, a simplified method for categorizing seams is most useful. Four panel seam types are used: separate cap, integral cap, mechanically interlocked, and lap. The first three types are used primarily with concealed fastener systems while the lap seam is typically used on throughfastener metal panel systems.

\section{Separate cap}

For separate cap seams, panel joinery is accomplished with a separate cover. Variations of this seam type include a snap cap (Figure 1), batten cover (Figure 2 and Figure 3) and capped standing seam (Figure 4). These systems use concealed clips as their primary method of attachment. 


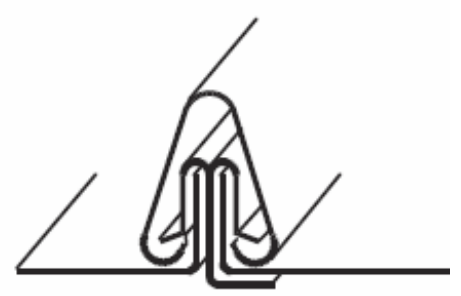

Figure 1. Snap-cap seam (source: NRCA)

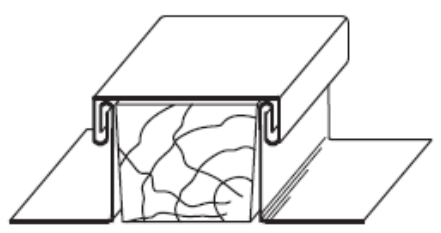

Figure 2. Traditional batten seam (source: NRCA)

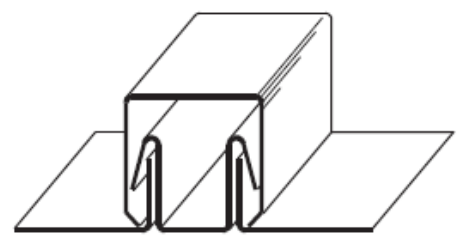

Figure 3. Snap-on batten cap with clip (source: NRCA)

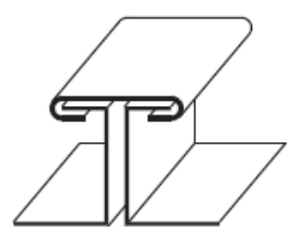

Figure 4. Capped standing seam (source: NRCA)

\section{Integral cap}

Integral cap seams join panels by using a seam cover integrated into one of two adjoining panels. Typically the seam has a "snap-lock" configuration (Figure 5). These systems use concealed clips as their primary method of attachment. 


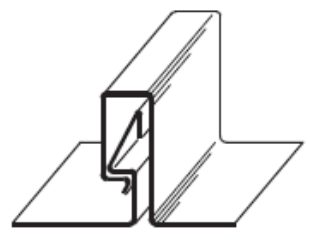

Figure 5. Snap-lock seam (source: NRCA)

\section{Mechanically interlocked}

Mechanically interlocked seams join panels by mating the legs of two adjacent panels and bending or folding. The seaming is typically performed by hand or automated equipment. Figure 6 depicts a single-lock seam that has a fold of 90 degrees. Figures 7 and 8 depict double-lock seams that have 180 degree folds. Mechanically interlocked seam systems use concealed clips as their primary method of attachment.

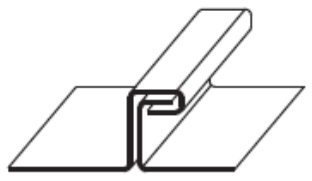

Figure 6. Mechanically seamed single-lock seam (source: NRCA)

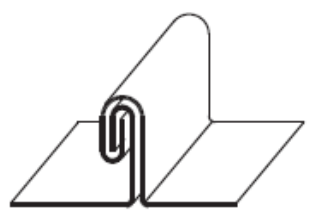

Figure 7. Mechanically seamed double-lock seam (source: NRCA)

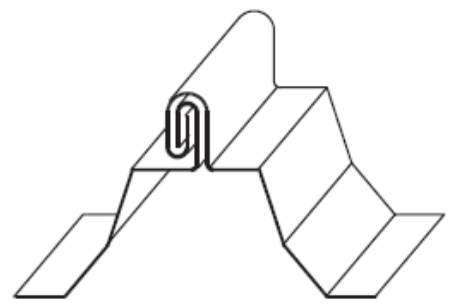

Figure 8. Trapezoidal seam (source: NRCA) 


\section{Lap seam}

Lap seam systems use through fasteners as their primary method of attachment. Panels are joined by simply overlapping adjacent panels and securing them to the substrate with fasteners that penetrate the panels (Figure 9, Figure 10, and Figure 11).

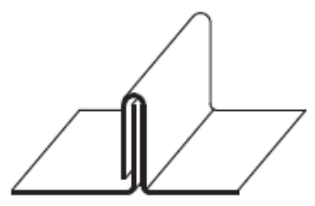

Figure 9. Raised lap seam (source: NRCA)

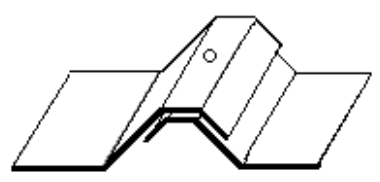

Figure 10. R-panel seam

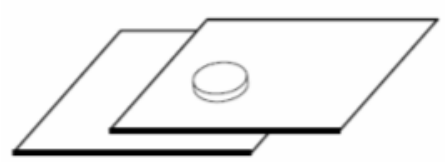

Figure 11. Flat lap seam (source: NRCA)

\section{Roof network identification}

A roof network, as defined within the ROOFER system, consists of all the building roofs maintained by an installation or facility manager. A network is generally divided into the following manageable components:

\section{Building}

A building consists of one distinct structure that may include several wings or sections, but generally has one building number or designation. Buildings connected by covered walks or enclosed passageways should be considered separately unless they are designated by the same building num- 
ber. Facility complexes with only one building number or designation should be given sub-designations for easier identification.

\section{Roof sections}

Building roofs are managed by units called roof sections for which all repair and replacement decisions can be made. To achieve this, each roof section is inspected and evaluated independently of other roof sections. As a rule, a building having a single roofing system type that was all installed at the same time and measuring less than approximately 10,000 square feet should be managed as one section. Roofing on dormers and similar projections should be included with the main roof section. For buildings with larger roof areas, the roof may be divided into two or more sections. For those buildings, the inspector should inspect and rate each section independently. Using this approach, a roof section in poor condition does not detract from the assessment of a roof section on the same building that is performing well. Also, it may be possible to replace only those sections that have reached the end of their service life while making necessary repairs to the remaining sections.

Roof sections are assigned letter designations (A, B, C, etc.). For building roofs requiring multiple sections, the sections are generally delineated by:

- different weather exposure (e.g., north side and south side of a gabled roof)

- perimeter details such as firewalls, expansion joints, valleys, hips, or ridges

- different roof slopes or levels

- areas having different roof covering types, different amounts of rooftop equipment, or significantly different conditions below the roof

- areas that were constructed at different times.

If a roof is physically divided into many small areas, strong consideration should be given to combining these areas with a larger adjacent roof area to comprise one roof section.

\section{Data collection}

The information needed to successfully manage a roof network must be stored in a way that makes the data accessible and usable. The data collection system described in this report allows easy input into the web-based 
ROOFER application. Once a database is established, a facility manager can perform analyses and develop reports that are needed to effectively manage large networks of building roofs or individual roof projects.

The physical and historical information about buildings and roof sections are recorded on standardized forms. The information can come from a variety of sources. At installations that have complete building records, most of the data can be taken from as-built drawings, record drawings, and specifications. Because these drawings and specifications often do not show actual conditions, all the data should be verified during the visual inspection.

It is important that the collected information be as complete as possible. Missing data will make analysis and planning difficult. Although this phase does require some investment of time and effort, it needs to be done only once and then updated when a roof system is modified.

\section{Building identification sheet}

The Building Identification Sheet (Figure 12) provides general information that includes building name, number, location, occupancy, and the date of original construction of the building. It also lists each roof section and its area. A space is also provided on the sheet for placing a building roof plan that shows overall dimensions and identifies each roof section. The plan should be drawn to a scale that will fully utilize the space available on the sheet. For large buildings, a scale of $1 \mathrm{in} .=30 \mathrm{ft}$ or $1 \mathrm{in}$. $=60 \mathrm{ft}$ will probably be necessary to show the entire roof.

\section{Roof section identification worksheet}

The three-page Roof Section Identification Worksheet (Figures 13, 14, and 15) simplifies the task of collecting the inventory data for a metal roof section and ensures uniformity in reporting terminology. Most of the items are self-explanatory, and the collection process uses checklists for identifying the various system components. Data can be obtained from specifications, drawings, and visual inspection.

The worksheet has a header section and additional sections for seven categories: 10 - General; 20 - Structural Frame; 30 - Roof Deck; 40 - Underlayment; 50 - Roof Covering; 60 - Flashings; and 70 - Remarks. Descriptions of the collected inventory data follow: 
10-General

Section 11 - Type. Slope configurations for the roofing system.

Section 12 - Access. The method used to gain access to the roof section. Note whether the ladder is inside or outside the building and if it is permanently attached to the building. If it is not, a portable ladder may be necessary for inspection. If access is from an adjacent roof section, identify the section.

\section{0-Structural Frame}

Section 21 - Type. The structural framing system that supports the roof.

30-Roof Deck

Section 31 - Structural Deck. The roof deck construction supporting the roof covering.

Section 32 - Attachment Surface. For roof coverings that are not attached directly to the structural deck, the intermediate structure or substrate to which attachment is made.

Section 33 - Slope. The predominant slope of the roof section. Slopes are to be recorded in 1/ 8 inch increments up to a slope of 1 inch per foot. For slopes greater than 1 inch per foot, the slopes are to be recorded in $1 / 2$ inch increments. The roof plan will generally indicate the slope (e.g., 4 inches in 12). If the slope is not noted on the roof plan, the section drawings may indicate the slope. If such information is not available, field measurement will be required.

Section 34 - Drainage. The existing means of removing rainwater from the roof section. ROOF EDGE should be selected if the roof water flows over the building edge without gutters or scuppers to the ground or to a lower roof area. Check the roof section for gutters, downspouts, and interior drains.

40-Underlayment

Section 41 - Type. Any material course placed beneath the roof covering to provide additional protection to the deck, shed water, and provide a secondary weather protection. 
50-Roof Covering

Section 51 - Type. The type of metal panel roofing system. It is necessary to categorize standing seam panel systems by the seam type.

Section 52 - Base Metal. The base metal of the roofing panel and any metallurgical coating.

Section 53 - Panel Finish. The type of polymeric coating added to the exposed surface of the metal panels.

Section 54 - Panel Attachment. The method used for attachment of the metal panels to the substrate.

\section{0-Flashings}

Section 61 - Type. Measure and record total amount of the various existing flashing details (i.e. eave, rake, ridge, hip, valley, headwall transition etc). For reference purposes, see the description sections and detail illustrations of the various flashing distresses in Chapter 4. Check the Roof Inspection Worksheet to ensure that all of the existing flashing, including penetrations, pitch pans, and pipe supports are shown and/ or labeled on the roof section plan (see Figure 17).

Section 62 - Accessories. Types of roof accessories on the roof surface.

Section 63 - Overlay. Underlying layers of previous roofing systems.

70-Remarks

Additional information that will be useful to inspectors or facility managers.

\section{Roof section identification sheet}

The inventory data for a roof section can be entered directly into a computerized database using the web-based ROOFER application or compiled onto a Roof Section Identification Sheet (Figure 16). 


\section{Roof inspection worksheet}

Each roof section should have a roof plan drawn to a scale that fits on the Roof Inspection Worksheet (Figure 17). The plan should show all physical roof features using the standard symbols and acronyms that are depicted on Figure 18. Locations of all termination flashings (i.e. eave, rake, ridge cap / hip cap) are to be indicated on the roof section plan using leader lines and the appropriate acronyms. Note that the total lengths of each of the types of termination flashings are to be recorded in section 61 of the Roof Section Identification Worksheet. Once completed, a master Roof Inspection Worksheet with a roof section plan can be scanned and saved in a JPEG digital image format and uploaded to the web-based ROOFER database. A copy can then be printed for use when performing future inspections.

\section{Calculating roof section area}

The roof section area that is required as part of the condition rating procedure should represent actual exposed surface area, not just the projected horizontal area. When measuring in the field, lengths taken in the plane of the roof slope should be used when calculating roof area. When dimensions are taken from aerial photographs, horizontal dimensions must be converted from the scaled measurements, and any linear dimensions that represent sloped surfaces need to be adjusted for length in the plane of the slope. 


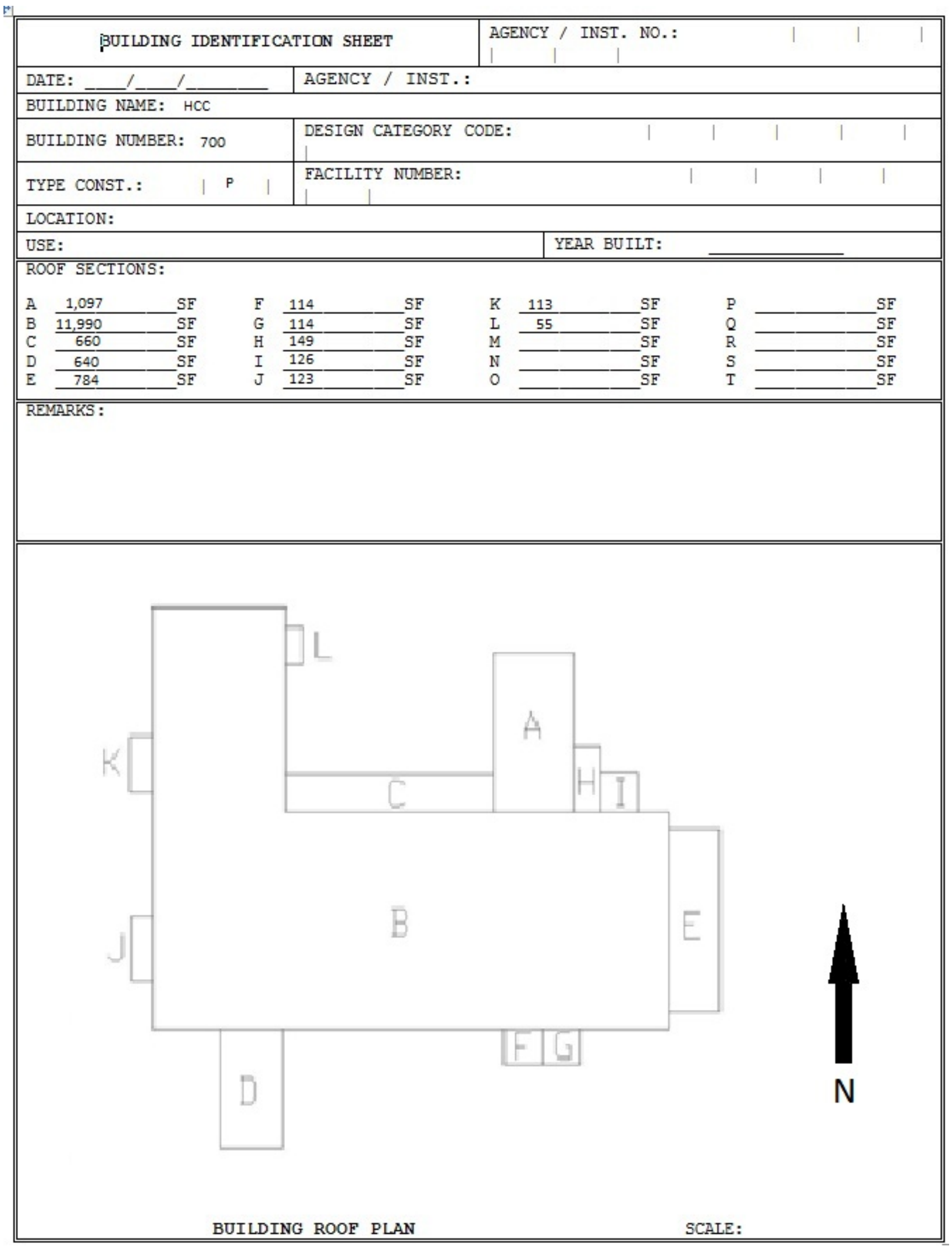

Figure 12. Building Identification Worksheet with sample data. 


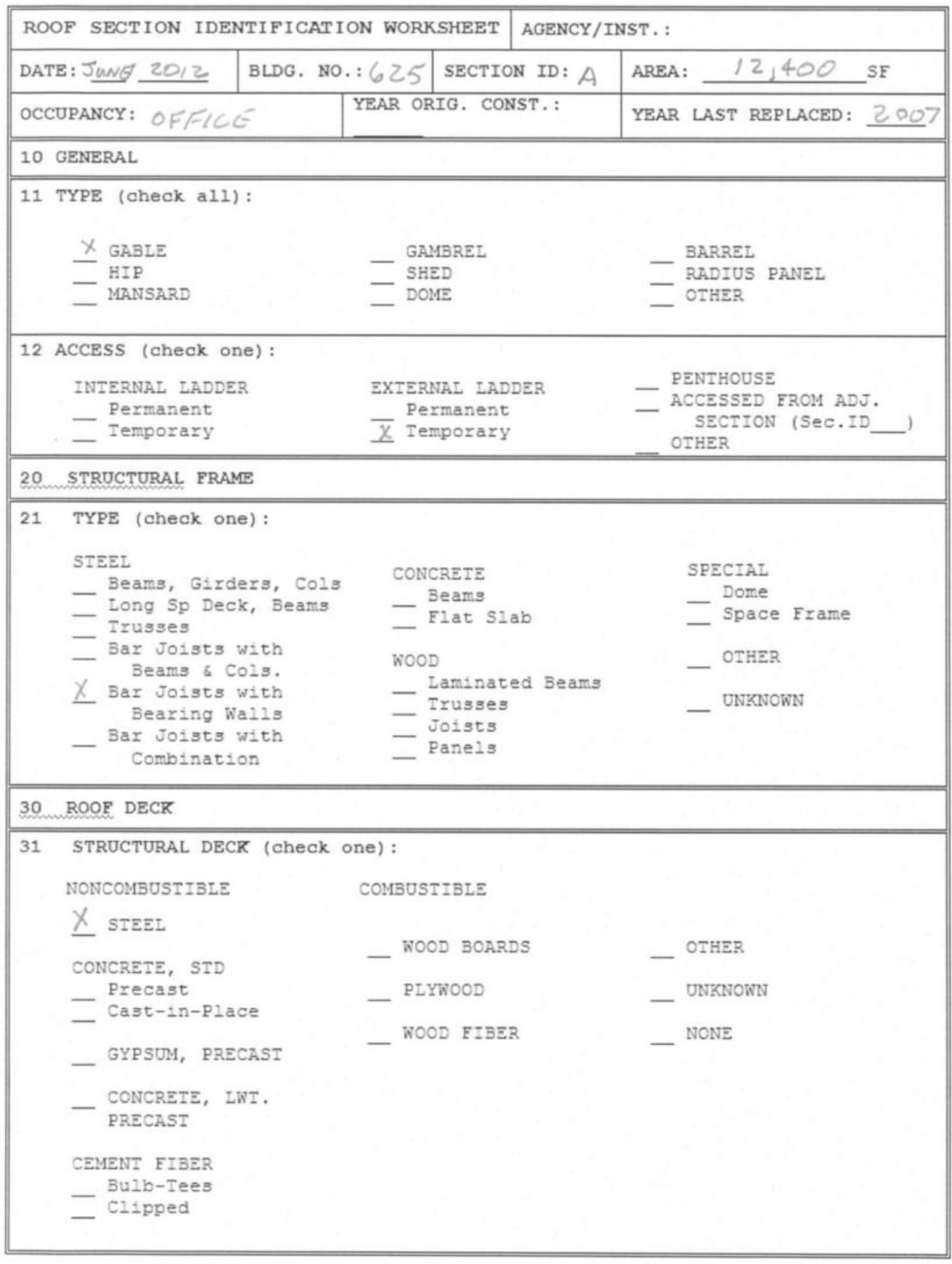

Figure 13. Roof Section Identification Worksheet (page 1) with sample data. 


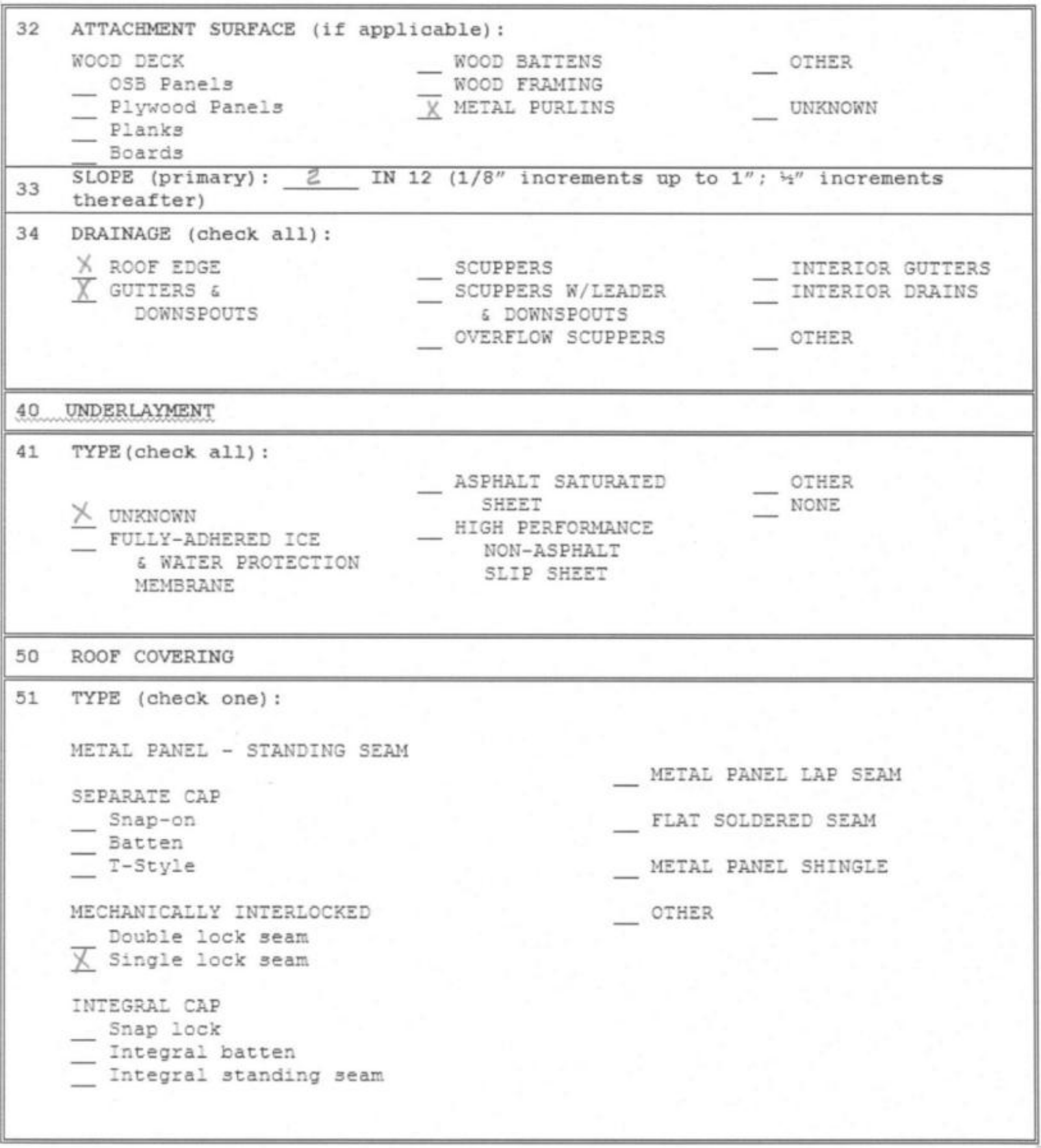

Figure 14. Roof Section Identification Worksheet (page 2) with sample data. 


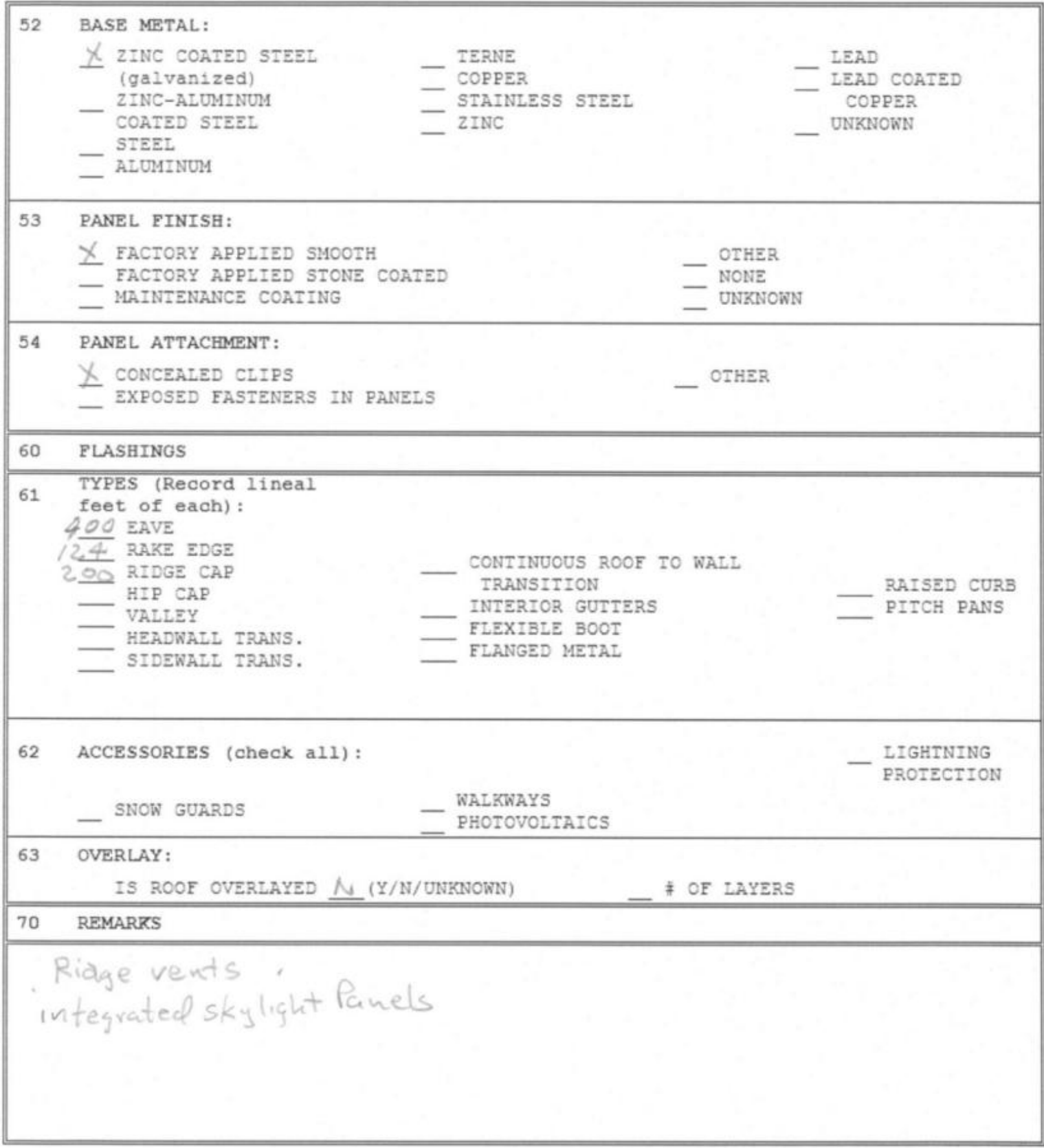

Figure 15. Roof Section Identification Worksheet (page 3) with sample data. 


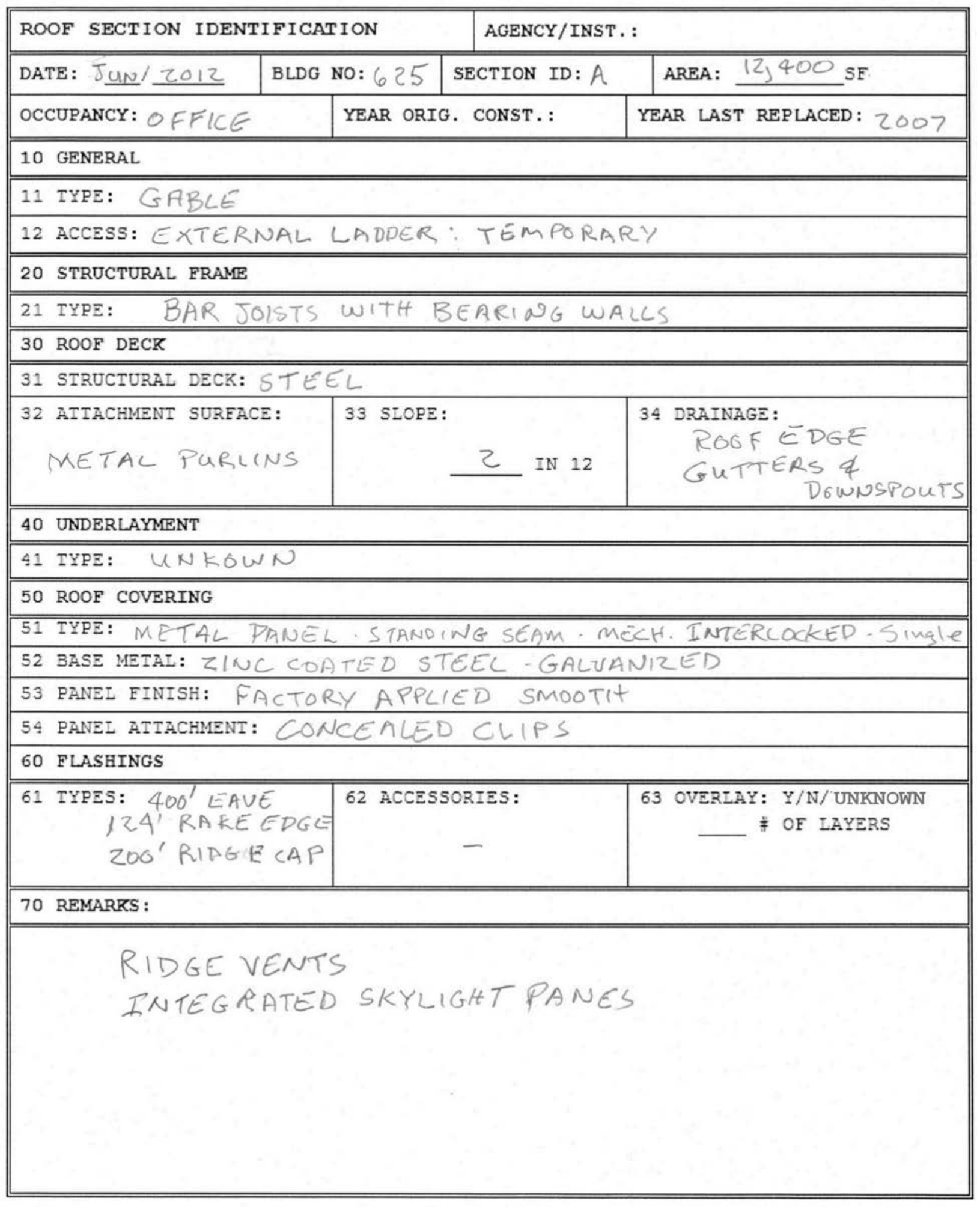

Figure 16. Roof Section Identification Sheet with sample data. 


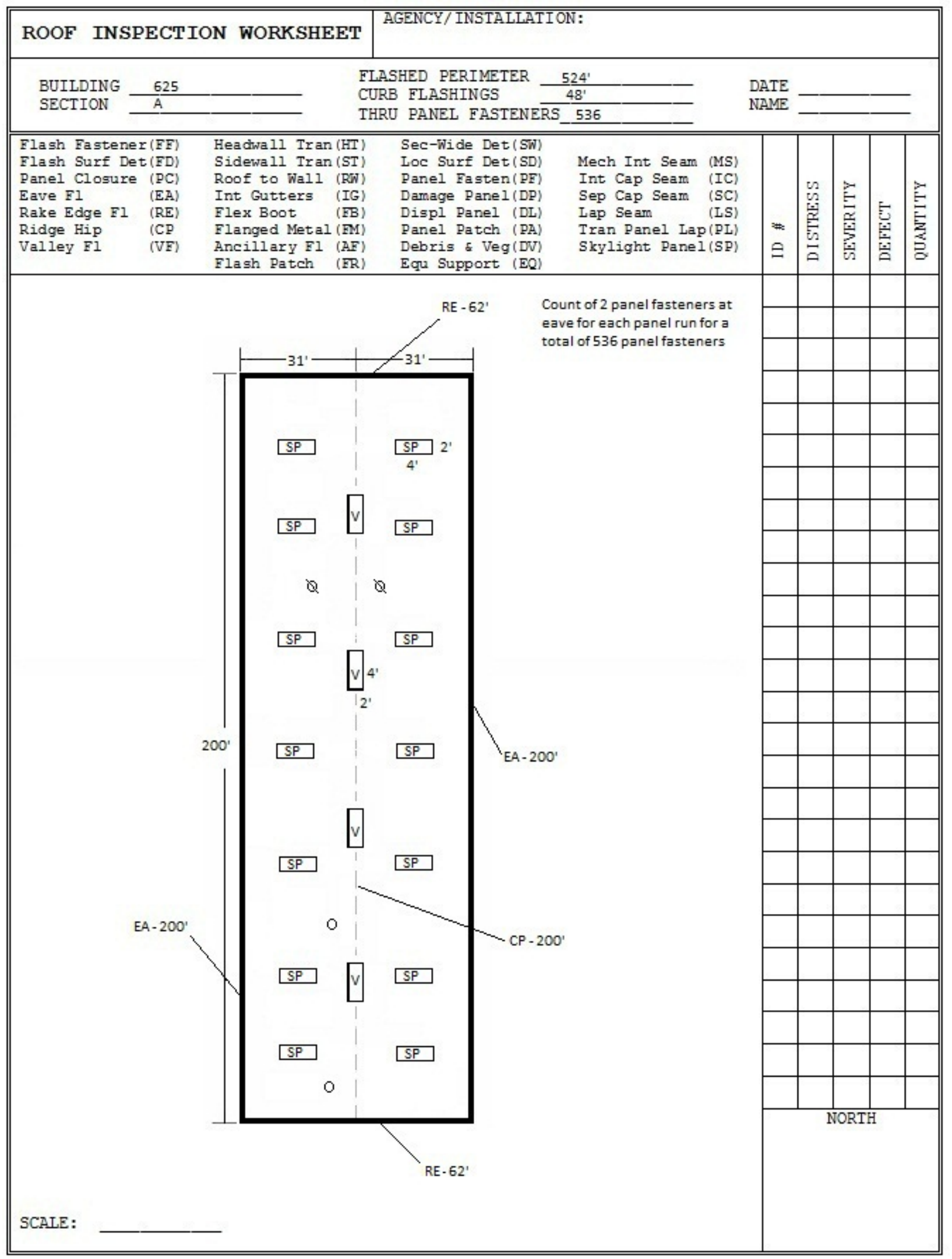

Figure 17. Roof Inspection Worksheet with roof section plan. 


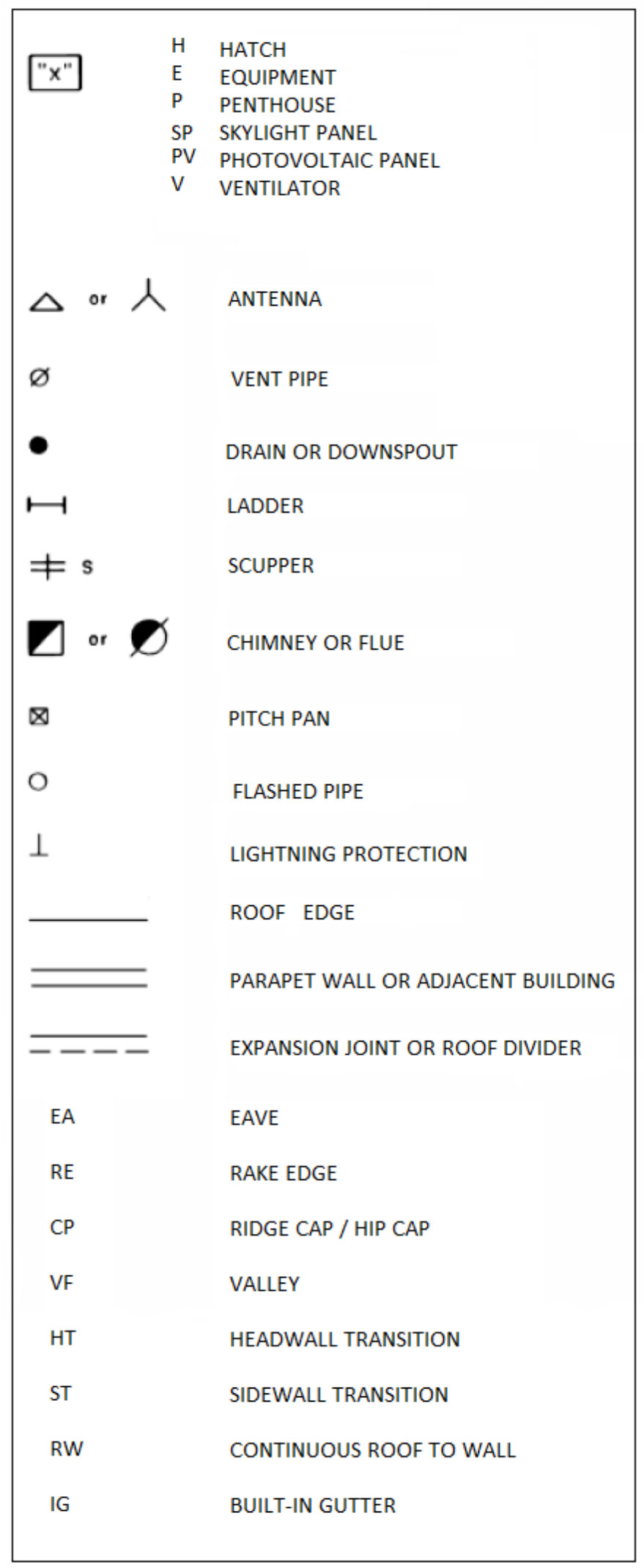

Figure 18. Standard symbols for roof section plan. 


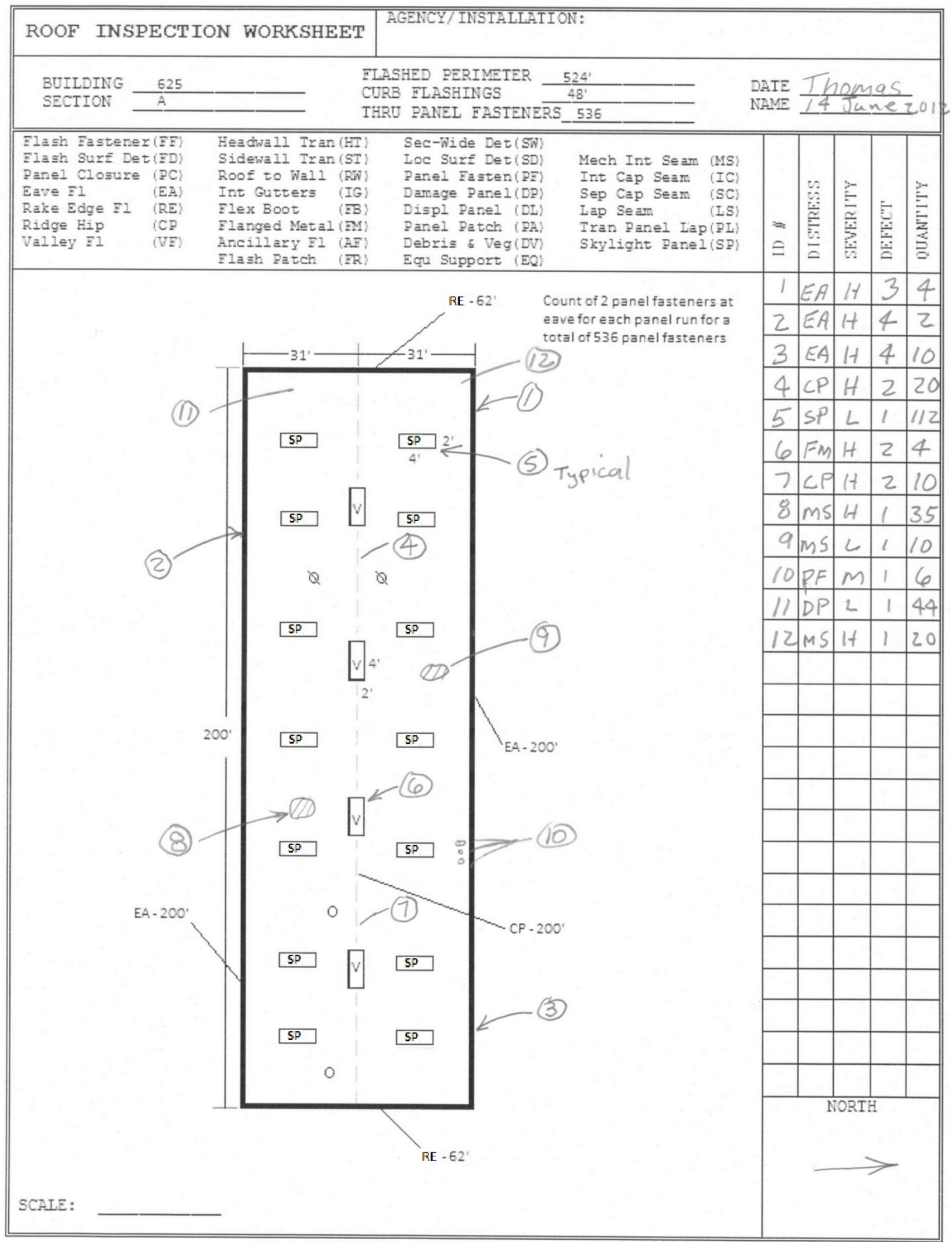

Figure 19. Roof Inspection Worksheet with inspection data. 


\section{Metal Roofing Inspection Procedures}

The inspection procedures presented in this chapter are based on the same concepts and theories used previously in developing the ROOFER inspection procedures for other roofing systems (Shahin, Bailey, and Brotherson 1987a, 1987b; Bailey et al. 1993). As with those systems, the roof covering component (metal panels) and flashing system component are assessed separately based on data collected during a visual distress survey.

For each roof section, a Panel Condition Index (PCI) and a Flashing Condition Index (FCI) are determined using the survey data and the calculation methodology described in Appendix B. The PCI and FCI are numerical values that range from 0 - 100, where 100 means excellent. For both the panel and the flashing, the index represents the roofing component's (1) ability to perform its functions, (2) needed level of maintenance and, (3) waterproof integrity.

The distress survey consists of identifying problems and characterizing them by distress type, severity level (high, medium, low), defect type, and quantity. Definitions and measurement techniques for the flashing distresses are presented in Chapter 4 and for the panel distresses in Chapter 5. A thorough visual inspection must be conducted in strict accordance with these two chapters, using the procedures defined below to ensure that meaningful and valid condition assessment is achieved. The inspection must be carefully organized and planned.

This chapter presents inspection procedures to be used in conducting the visual distress survey for metal panel roofing systems.

\section{Inspection team}

A team of at least two people-an inspector and a recorder-should perform the roof inspection. The inspection procedures require technically qualified determinations related to distress severity and the need to replace failing panels. Therefore, the inspection team should include at least one member having experience with and technical knowledge of metal panel roofing systems. The inspector surveys the roof, identifying distresses and determining severity levels, specific defects, and quantities. The recorder logs the data on the worksheet and assists in measuring distress 
quantities when required. The recorder must also serve as the safety observer for the team.

\section{Supplies}

The following supplies are required to perform the inspection and can be carried in a satchel when on the rooftop:

- inspection and distress manual (this document)

- pencil and clipboard

- copies of the Roof Inspection Worksheet (photocopy from Appendix C)

- small hacksaw blade (for probing)

- lumber crayon or wax pencil

- measuring tapes (12 ft and $100 \mathrm{ft}$ recommended)

- large plastic bag (for collecting rooftop debris)

- binoculars

- slope meter.

\section{General inspection guidelines}

The following is a list of general guidelines for the roof inspection:

- Walk the outside of the building and look for water stains, efflorescence, missing mortar, spalling brick, and gutter and downspout problems. Note any findings in the Remarks Section on the reverse side of the Roof Inspection Worksheet.

- Ask facility manager or building occupants if there are any known water leakage problems.

- Walk the interior of the building and examine the ceiling for water marks or other evidence of problems. Note rusting or other signs of water penetration in the Remarks Section. Occupants can often provide valuable information.

- If accessible, inspect attic space to verify type of deck and identify problems.

- When on the rooftop, be careful not to damage the roof. Do not step on unsupported flashings or seams.

- If snow, frost, or visible moisture is present on the roof, postpone the inspection until the roof is clear and dry.

- Wherever possible, measure lengths and areas to determine distress quantities. Using estimates in place of measurements compromises the rating accuracy. Pacing to find lengths, measuring number of panels 
and counting the quantity of fasteners per panel, or other numerical estimating techniques are preferable to "eyeball" estimates.

- If more than one distress severity level is found in a localized area, count the entire area at the highest severity level present.

- Note in the Remarks Section any other problems that are not included in the lists of flashing and panel distresses.

- Once a panel has been determined to have a defect that by its definition requires panel replacement (e.g., Localized Surface Deterioration high severity defect \#2, SD-H-2), do not count other distresses on that same panel.

\section{Survey preparation}

It may be necessary for the survey team to contact the building superintendent or custodian for assistance in gaining access to the roof. When accessing the roof, the inspectors should assess safety conditions and determine if they can walk on the roof surface safely. If the roof cannot be walked safely (e.g., slopes rising more than 5 inches in 12 inches), alternative inspection methods should be used, such as use of a lift or chicken ladders. The inspectors should always be aware of and abide by all safety requirements of governing authorities.

\section{Roof section plan validation}

Before beginning the inspection, the existing roof section plan on the Roof Inspection Worksheet should be checked for completeness and accuracy. Any missing, extraneous, or inaccurate depictions of physical roof features should be revised before proceeding with the survey (see Chapter 2). All section area and roof feature dimensions should be checked for accuracy as deemed necessary. If a roof section plan has not been drawn on the worksheet at the time of the inspection, it should be developed following the guidelines described Chapter 2 .

\section{Determining total length of flashed perimeter and curb flashings}

The calculations used in the roof condition rating procedures require a total quantity of flashed perimeter length and curb flashing lengths for the section being evaluated. For a typical roof section, the flashed perimeter length is the total perimeter length of the roof section. Curb flashings are the flashed terminations around platforms that support raised rooftop equipment and features such as access hatches. The team should measure 
and establish these two quantities before starting the distress survey. Both quantities should be entered in the appropriate fields in the header section of the Roof Inspection Worksheet (see Figure 19). If values were entered on the sheet before the inspection, the team should verify for accuracy.

\section{Determining total number of through-panel fasteners}

For this inspection procedure, through-panel fasteners are defined as fasteners that penetrate any part of a metal panel. These fasteners can be screws that may have gaskets and/ or washers, or various types of rivets and nails. Fasteners that do not penetrate any part of a system panel (such as those that have their head or washer in contact with the flashing metal) are considered flashing fasteners, and are not included in this count.

The inspection team should count and record the total number of exposed through panel fasteners on the roof section. The precision of this count is not critical for the assessment process; a 10\% error is acceptable. Counting number of fasteners per panel or per area and extrapolating for the entire roof section will suffice. The total quantity of through-panel fasteners should be entered in the appropriate field in the header section of the Roof Inspection Worksheet (see Figure 18). If a value was entered on the sheet before the inspection, the team should verify it for accuracy.

\section{Distress survey}

Inspectors must be able to identify the various distresses and defects accurately and follow the inspection procedure closely to obtain meaningful, consistent, and repeatable results. When performing the inspection, identify each distress as it is encountered. Using the criteria defined in Chapters 4 and 5, determine its severity level and the specific defect that best defines the problem. Measure the quantity of the defect. A description of the valley flashing distresses and specific defects is shown in Figure 18.

For each encountered distress, enter the two-letter distress abbreviation, the letter representing the severity level ( $\mathrm{L}$ - low, $\mathrm{M}$ - medium, $\mathrm{H}$ - high), the specific defect number, and the quantity information in the columns on the right side of the Roof Inspection Worksheet. Each individual distress entry is assigned an identification number, starting with 1 (ID \# in column 1) and numbering consecutively. Record the location of each distress on the roof plan using the identification number, as shown in Figure 16. If, during the inspection, the worksheet becomes filled, continue re- 
cording on a second worksheet. Appendix B contains an abbreviated list of identifiers for all the distress/ severity level/ defect combinations. The list is designed to help inspectors rapidly identify and record defects. A copy of the list can be attached to the bottom of a long [ $8 \mathrm{x} 14 \mathrm{in}$.] clipboard so it is visible below Roof Inspection Worksheet.

Perform the distress survey of each roof section using the following steps:

1. Inspect the perimeter. Establish a starting point at one corner of the roof section. Walk the perimeter, examining all eave, rake, and other termination flashings. Fill in the worksheet as the inspection proceeds.

2. After inspecting the perimeter, walk the roof area, using an established pattern, inspecting all other flashings. This includes ridges, hips, valleys, transitions, flanged metal, curb, and penetration flashings. Establish a starting point at one corner of the roof section. Covering 10- to $15-\mathrm{ft}$ wide strips, walk back and forth across the roof section surveying the entire area.

3. When specific defects occur uniformly on a large area, the following representative sampling technique can be used. Select a portion of the roof (e.g., number of panels, $1000 \mathrm{sq} \mathrm{ft}$ of panels, or 20 lineal $\mathrm{ft}$ of flashing) and measure the distress in the sample area. Then, by extrapolation, estimate the quantity of that distress for the total portion of the panels or flashing affected. Record the distress information as a single entry with one identification number on the Roof Inspection Worksheet. The boundaries of the overall area or length, which is represented by the sampling, should be shown on the roof section plan.

\section{Determining the $\mathrm{FCl}$ and $\mathrm{PCI}$}

The FCI and PCI of a roof section are determined from the information recorded on the Roof Inspection Worksheet. The condition indexes can be calculated by entering the distress information into the web-based ROOFER application. The indexes can also be determined manually using the methodology described in Appendix B. 


\section{Flashing Distresses}

\section{Flashing Fastener (FF)}

\section{Description}

This distress pertains to all flashing securement fasteners that do not penetrate the roof panel. Fasteners can be screws that may have gaskets and/ or washers, or various types of rivets and nails.

Note: Flashing fasteners that penetrate the roof panel are considered panel fastener distresses.

Note: Flashing fasteners that do not penetrate the roof panel but penetrate the valley flashing are considered valley flashing distresses.

\section{Severity levels}

\section{Medium}

1. Fastener has no flexible gasket (where one was originally installed) or has a flexible gasket that is deteriorating but appears to be watertight; or fastener is corroded, improperly seated, or has a sealant repair but appears to be watertight.

High

1. Fastener or flexible gasket (where one was originally installed) is loose, deteriorated or missing and is allowing water to penetrate the roofing system; or fastener has an enlarged hole that is allowing water to penetrate the roofing system.

\section{Measurement}

Count the total number of defective fasteners. 


\section{Density}

$$
\text { Problem Density }=\frac{A}{B} \times 100
$$

$A=$ Number of defective fasteners.

$\mathrm{B}=$ Total length of roof section perimeter and metal curb flashings ( $\mathrm{ft}$ ).

Note: The problem density is calculated for each observed severity level.

\section{FF reference photographs}

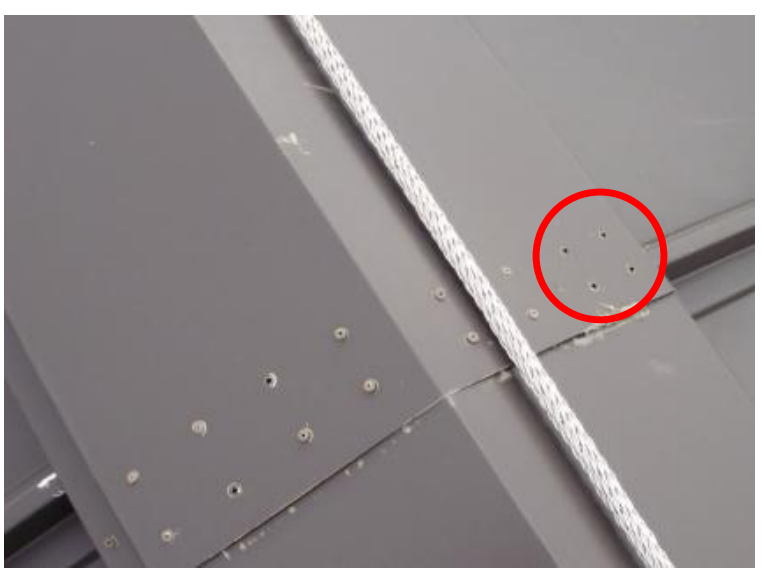

FF-H-1: Fastener or flexible gasket (where one was originally installed) is loose, deteriorated or missing and is allowing water to penetrate the roofing system; or fastener has an enlarged hole that is allowing water to penetrate the roofing system.

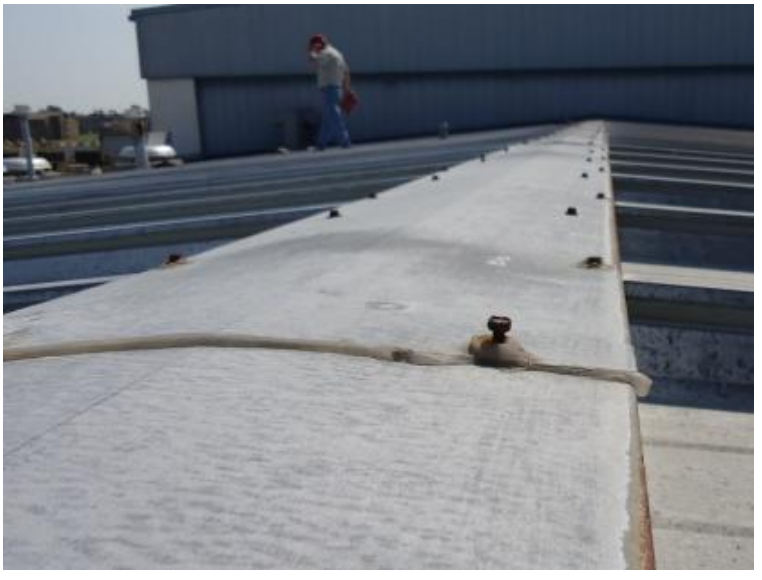

FF-H-1: Fastener or flexible gasket (where one was originally installed) is loose, deteriorated or missing and is allowing water to penetrate the roofing system; or fastener has an enlarged hole that is allowing water to penetrate the roofing system. 


\section{Localized Flashing Surface Deterioration (FD)}

\section{Description}

Degradation of finish on the flashing, such as colored paint, clear coat, anodized finish; degradation of the field-applied coating; or metal corrosion, and only as it differs from remainder of roof.

Note: If SD-M-2 is determined for the roof section, then this defect does not apply separately; it is captured in the defect for the panel.

\section{Severity levels}

Medium

1. Flashing has localized loss of applied finish, or localized metal corrosion.

\section{Measurement}

Measure the lineal feet of defective flashing.

\section{Density}

$$
\text { Problem Density }=\frac{A}{B} \times 100
$$

A = Length of defective flashing ( $\mathrm{ft}$ ).

$\mathrm{B}=$ Total length of roof section perimeter and metal curb flashings ( $\mathrm{ft}$ ).

Note: The problem density is calculated for each identified severity level. 


\section{FD reference photograph}

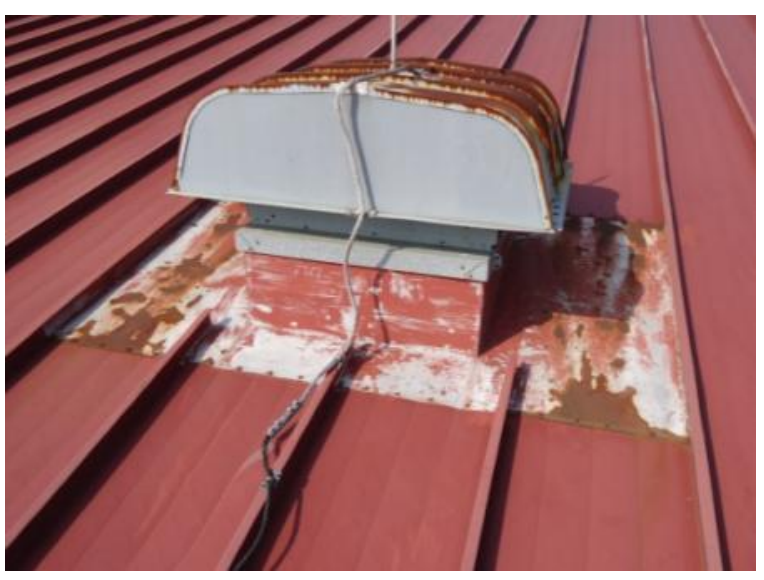

FD-M-1: Flashing has localized loss of applied finish or localized metal corrosion. 


\section{Panel Closure (PC)}

\section{Description}

Pre-formed nonmetallic insert or metal panel closure (Z-clip or boxed end closure) that seals the openings in the panel profile. Panel closures are found on ridges, hips, eaves, walls-wherever panels terminate.
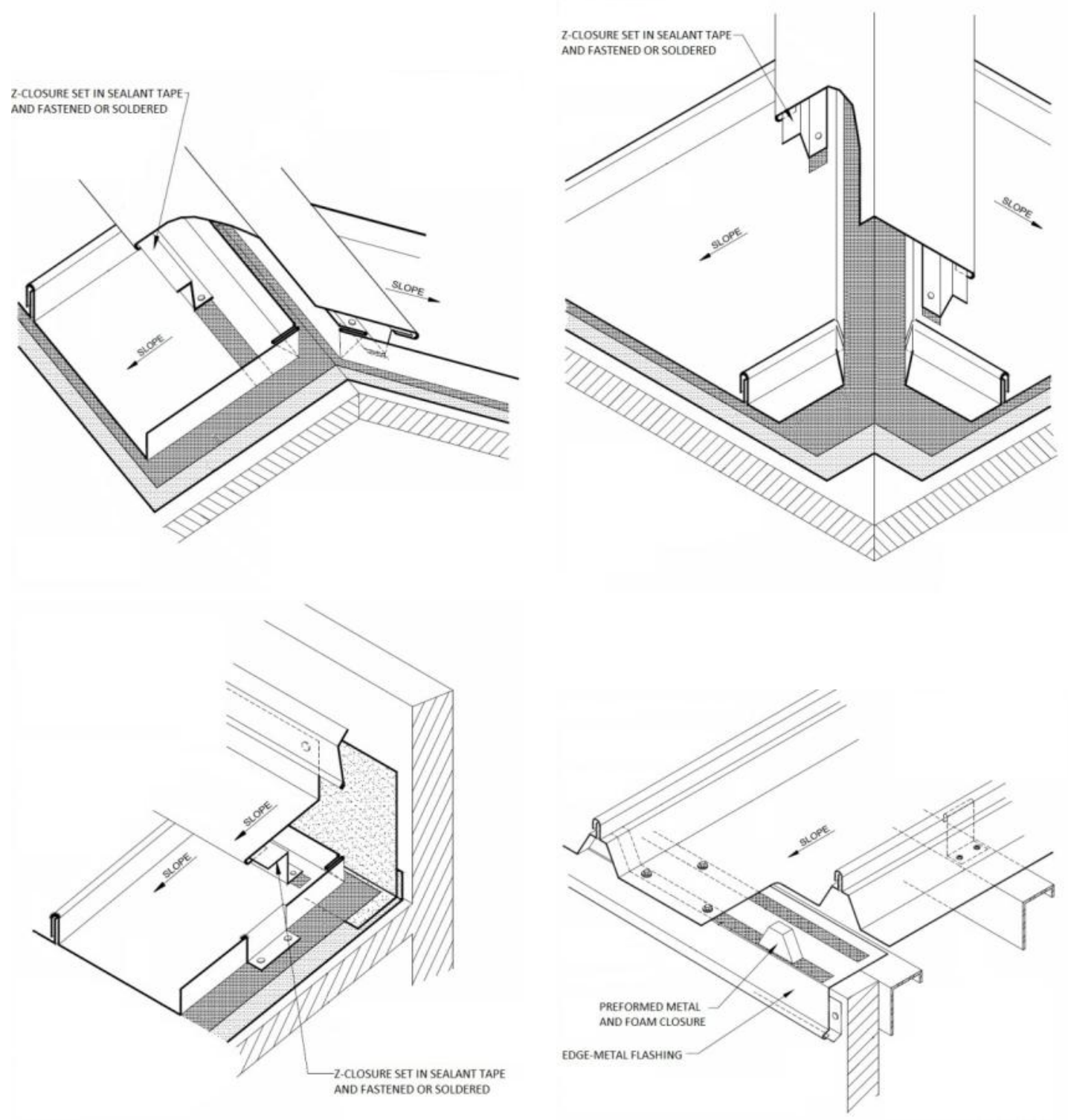

Panel closure details (source: NRCA). 


\section{Severity levels}

Medium

1. Panel closure is misaligned but appears to be watertight.

2. Pre-manufactured seam cap does not fit properly.

High

1. Non-metal panel closure is deformed, misaligned, damaged, or missing; allowing water to penetrate the roofing system.

2. Metal panel closure is deformed, misaligned, or missing; allowing water to penetrate the system.

\section{Measurement}

Measure the lineal feet of defective panel closures. Count individual defective panel closures as a minimum of 1 foot.

\section{Density}

$$
\text { Problem Density }=\frac{A}{B} \times 100
$$

A $=$ Length of defective closures ( $\mathrm{ft}$ ).

$\mathrm{B}=$ Total length of roof section perimeter and metal curb flashings ( $\mathrm{ft}$ ).

Note: The problem density is calculated for each observed severity level. 


\section{PC reference photographs}

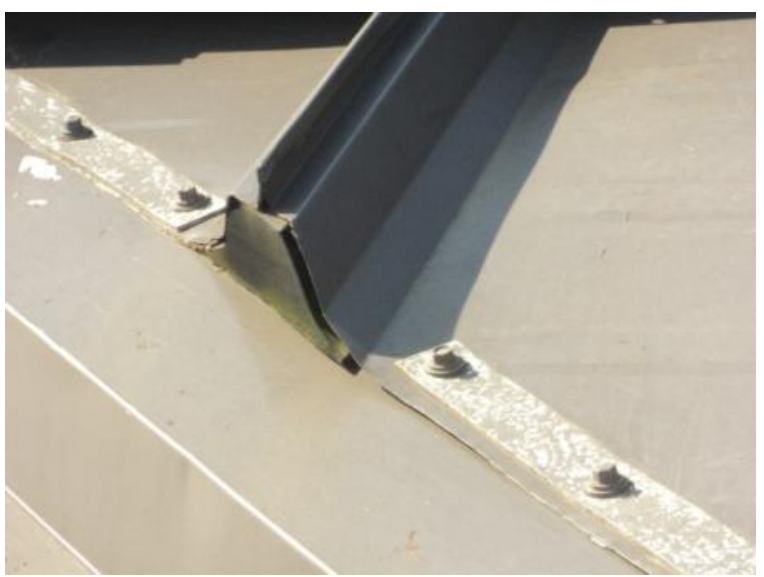

PC-M-1: Panel closure is misaligned but appears to be watertight.

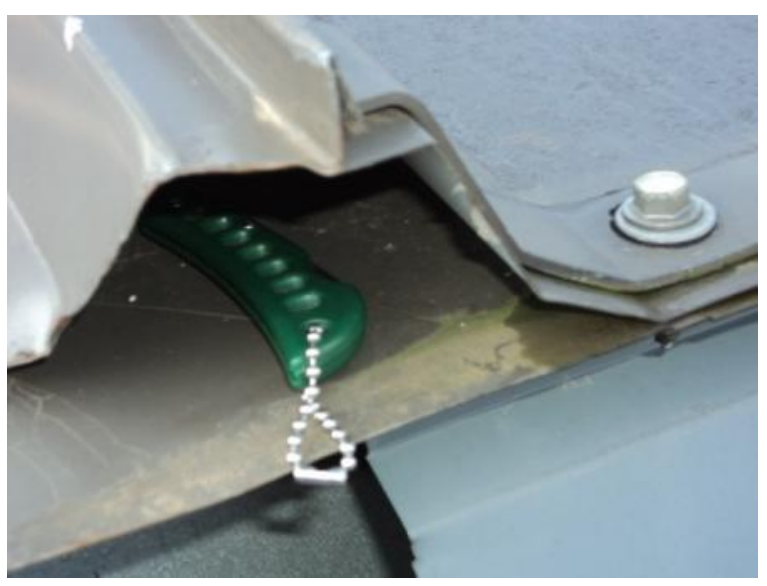

PC-H-1: Non-metal panel closure is deformed, misaligned, damaged or missing; allowing water to penetrate the roofing system.

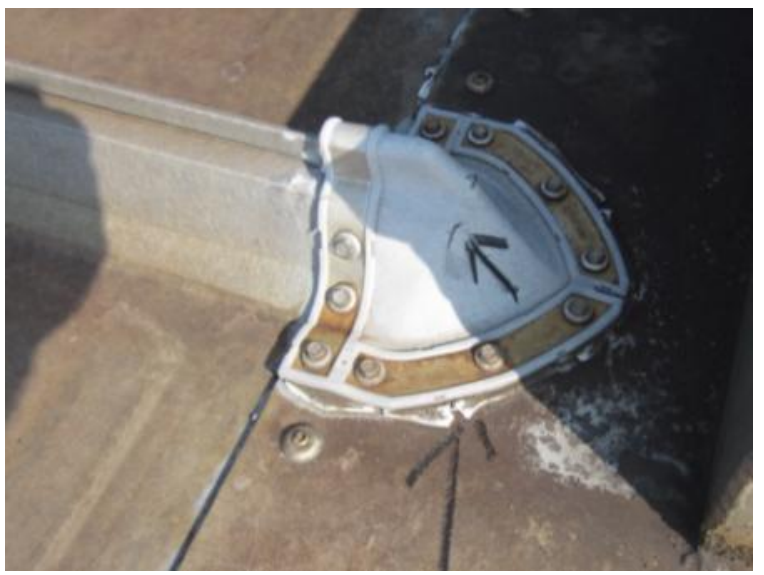

PC-H-2: Metal panel closure is deformed, misaligned, or missing; allowing water to penetrate the system.

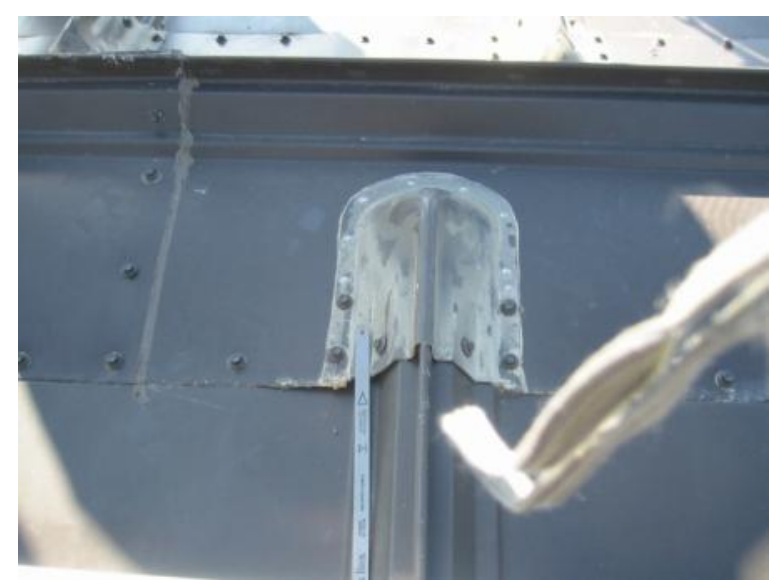

PC-M-2: Pre-manufactured seam cap does not fit properly.

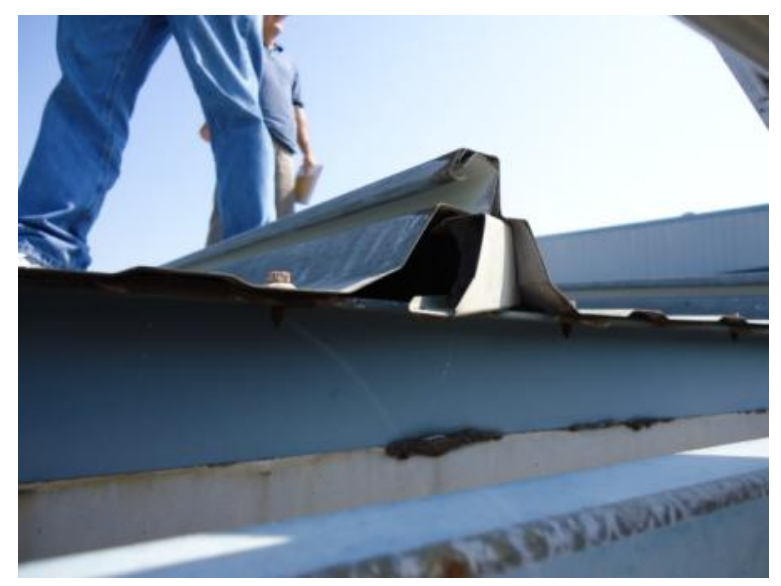

PC-H-1: Non-metal panel closure is deformed, misaligned, damaged or missing; allowing water to penetrate the roofing system. 


\section{Eave Flashing (EA)}

\section{Description}

Eave flashing is the metal flashing at the draining edge of a roof.
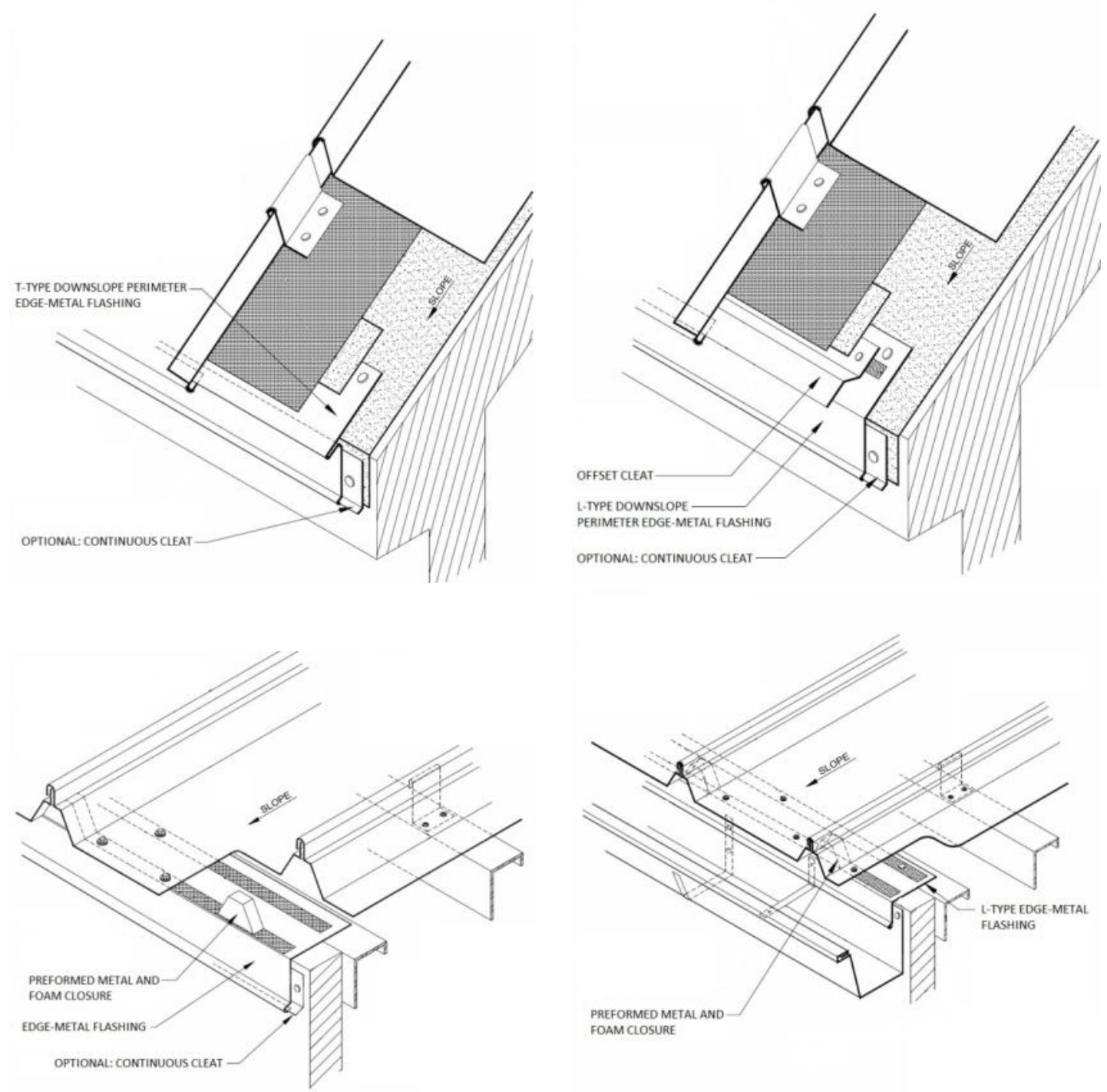

Eave flashing details (source: NRCA). 


\section{Severity levels}

Medium

1. Eave flashing is displaced but appears to be watertight.

High

1. Eave flashing has holes.

2. Non-cleated eave flashing is displaced and allowing water to penetrate the system.

3. Cleated eave flashing is displaced or disengaged.

4. Eave flashing has open joints or butt joints.

5. Eave flashing is missing.

\section{Measurement}

For $\mathrm{H}-1, \mathrm{H}-2, \mathrm{H}-3, \mathrm{H}-4$, and $\mathrm{H}-5$ defects, measure the lineal feet of defective flashing. Individual defects shall be counted as a minimum of 1 foot. If the distance between defects is less than 1 foot, include the length between defects.

For M-1 defect, count the entire length of each defective flashing piece (typically 10 feet).

\section{Density}

$$
\text { Problem Density }=\frac{A}{B} \times 100
$$

A $=$ Length of eave flashing defects ( $\mathrm{ft}$ ).

$\mathrm{B}=$ Total length of roof section perimeter and metal curb flashings ( $\mathrm{ft}$ ).

Note: The problem density is calculated for each observed severity level. 


\section{EA reference photograph}

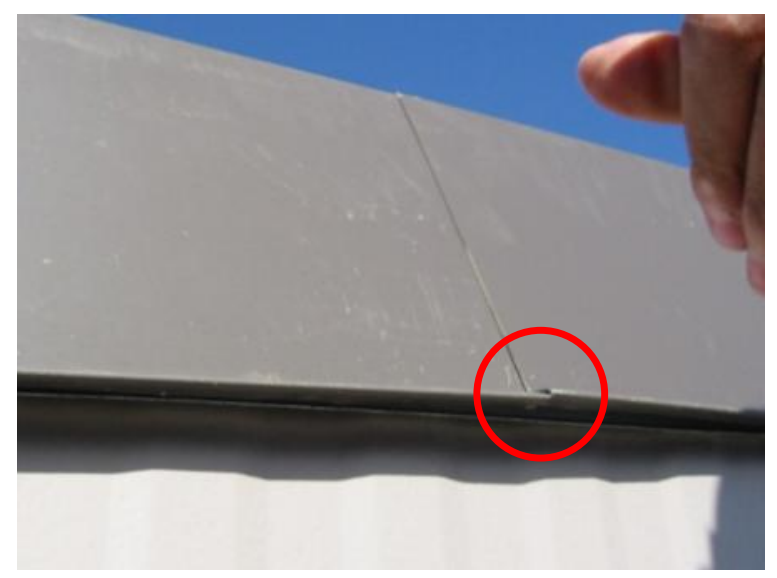

EA-H-3: Cleated eave flashing is displaced or disengaged. 


\section{Rake Edge Flashing (RE)}

\section{Description}

Rake edge metal flashing is installed along the inclined edge of a sloped roof. It can be similar to eave flashing, providing protection for underlying building surfaces, and allows water to drip away from vertical surfaces. In addition, some panel profiles have a raised rake cap.
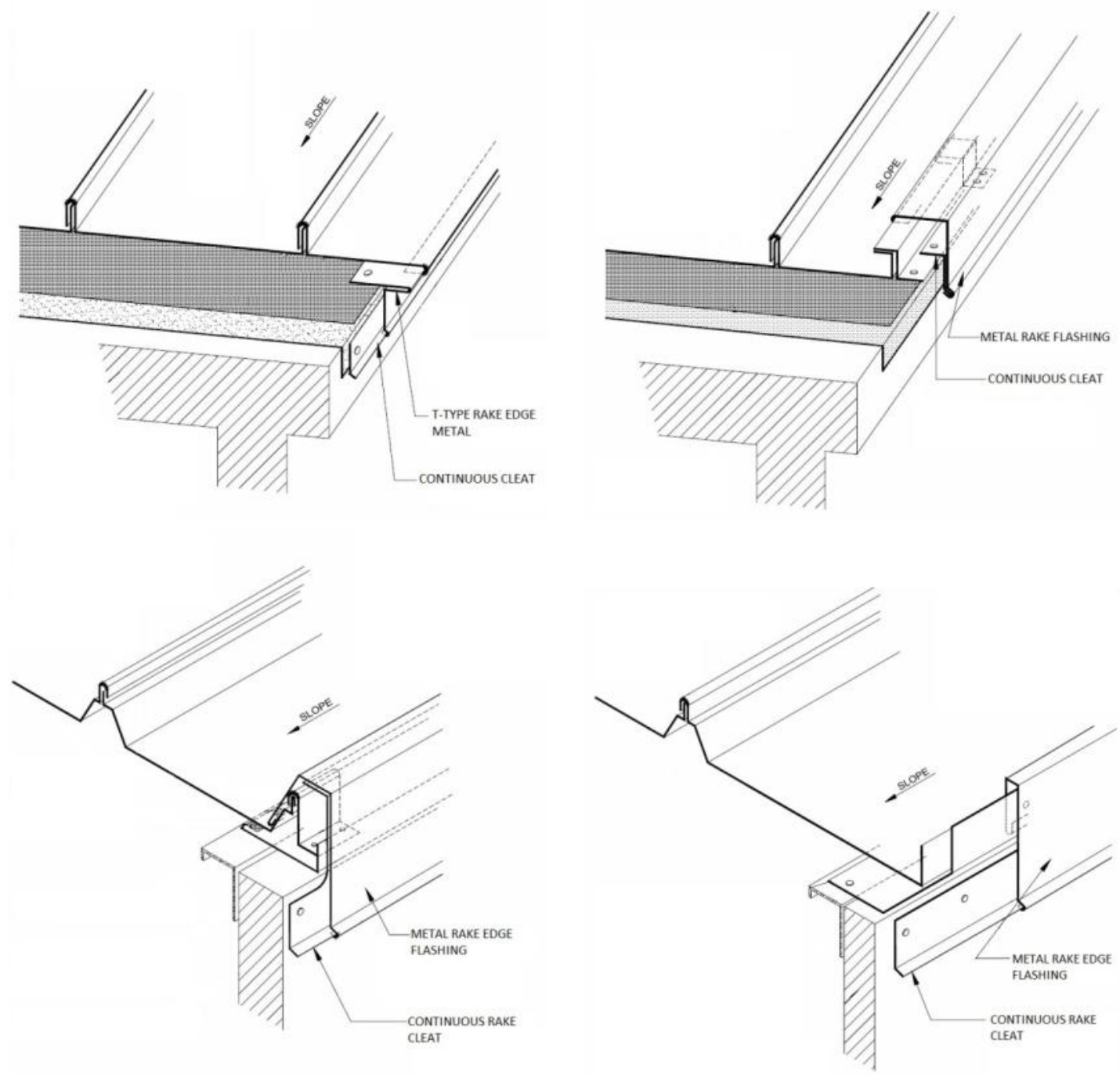

Rake edge flashing details (source: NRCA). 


\section{Severity levels}

Medium

1. Rake flashing is loose or displaced but appears to be watertight and does not compromise panel securement.

High

1. Rake flashing has holes.

2. Rake flashing is loose, displaced, or missing; allowing water to penetrate the roofing system and/ or compromising panel securement.

3. Rake flashing is installed so that water is running against lap.

4. Rake flashing has open joints or butt joints.

\section{Measurement}

For $\mathrm{H}-1$ and $\mathrm{H}-4$ defect, measure the lineal feet of defective flashing. Individual defects shall be counted as a minimum of 1 foot. If the distance between defects is less than 1 foot, include the length between defects.

For M-1, H-2, and H-3 defects; count the entire length of each defective flashing piece (typically 10 feet).

\section{Density}

$$
\text { Problem Density }=\frac{A}{B} \times 100
$$

A = Length of rake edge flashing defects ( $\mathrm{ft}$ ).

$\mathrm{B}=$ Total length of roof section perimeter and metal curb flashings ( $\mathrm{ft}$ ).

Note: The problem density is calculated for each observed severity level. 
RE reference photographs

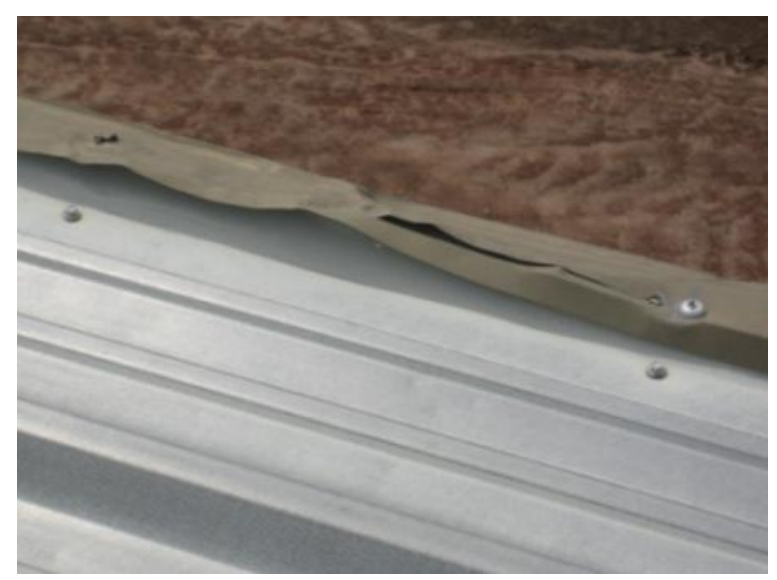

RE-H-1: Rake flashing has holes.

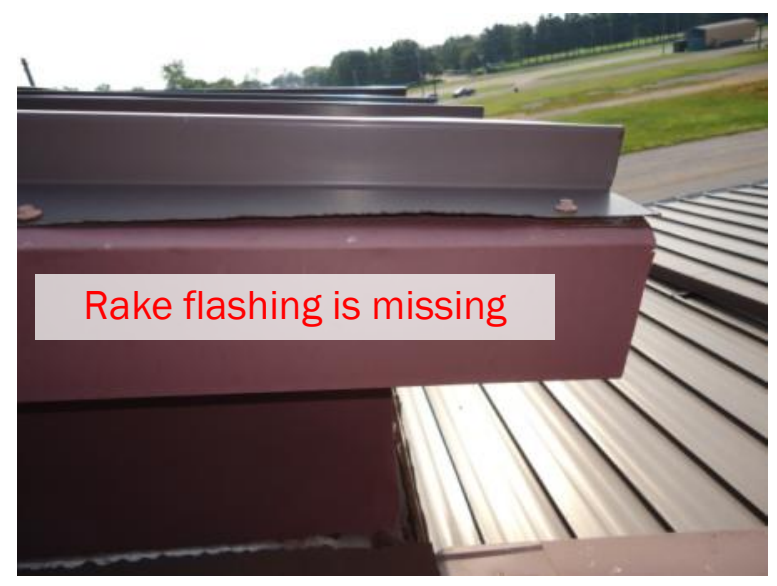

RE-H-2: Rake flashing is loose, displaced or missing, allowing water to penetrate the roofing system and/or compromising panel securement.

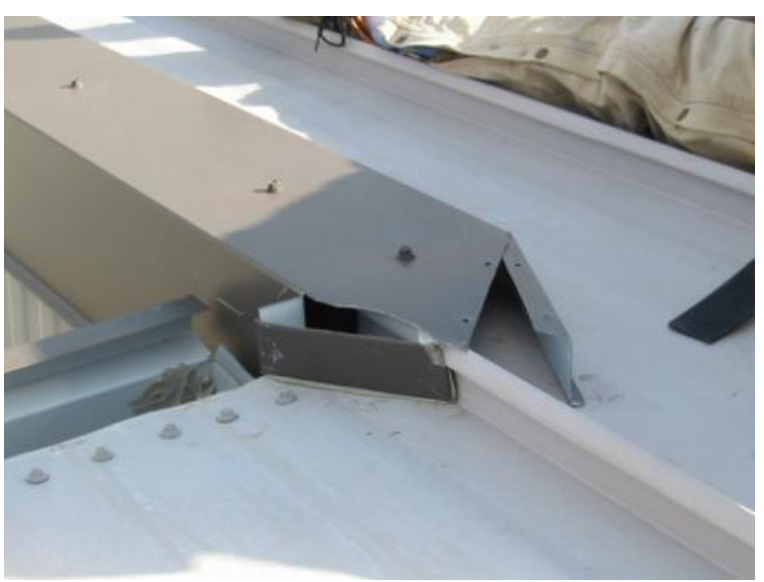

RE-H-2: Rake flashing is loose, displaced, or missing, allowing water to penetrate the roofing system and/or compromising panel securement.

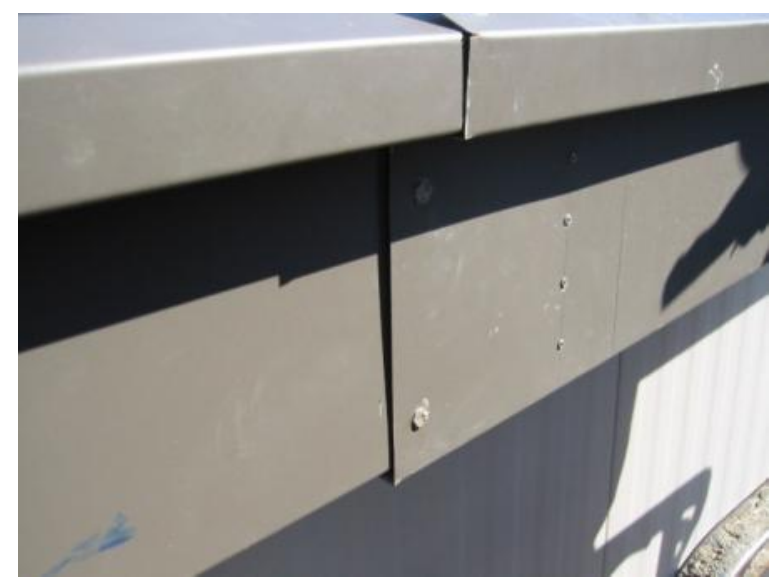

RE-H-4: Rake flashing has open joint or butt joints. 


\section{Ridge Cap, Hip Cap (CP)}

\section{Description}

Ridge caps and hip caps provide roofing protection at the terminations of adjoining, sloping roof planes. The ridge cap protects the uppermost, horizontal external angle; the hip cap covers the inclined external angle formed by the intersection of two sloping roof planes. Venting and nonventing applications determine the fastening and sealing requirements.
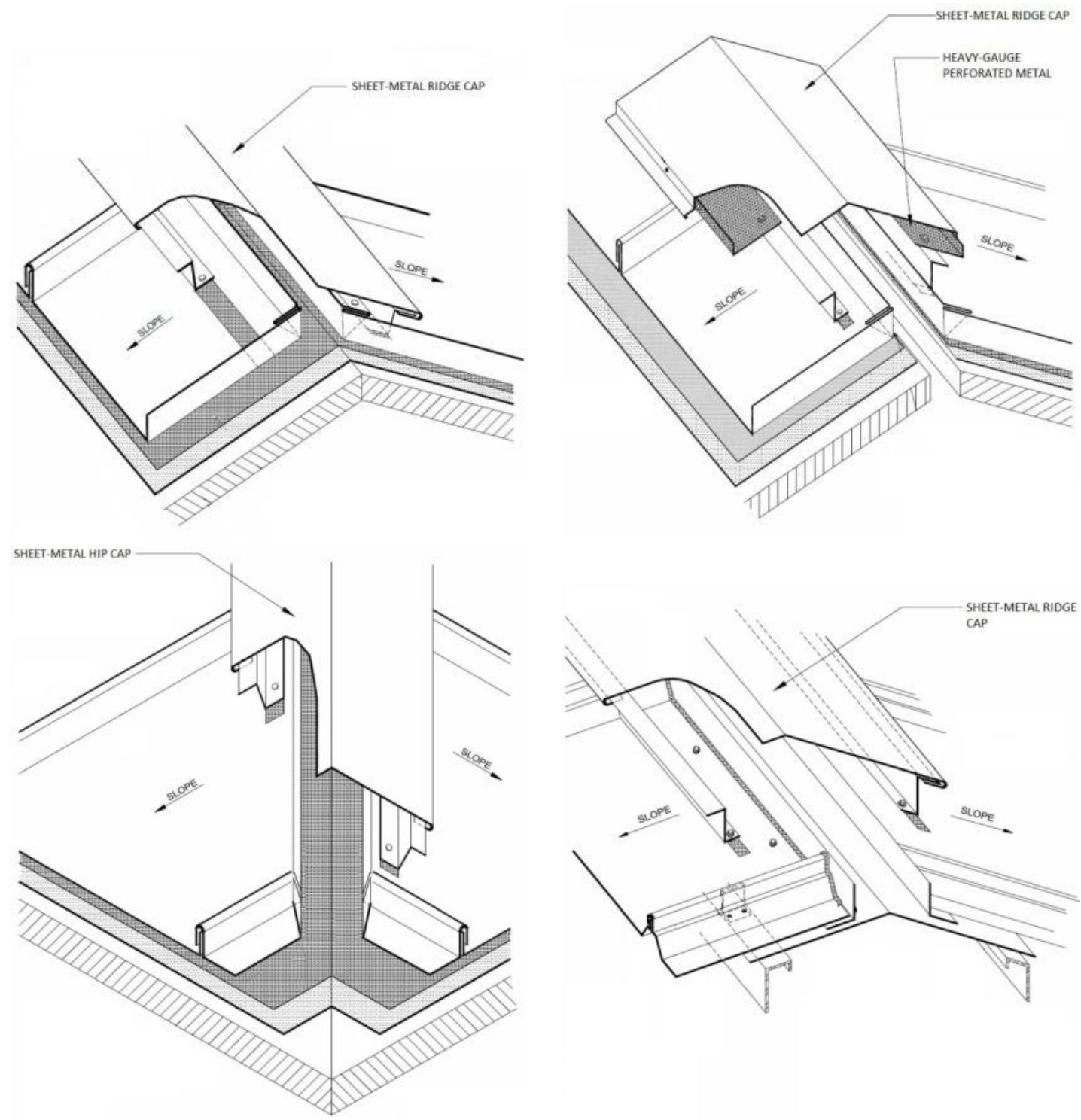

Ridge cap and hip cap flashing details (source: NRCA) (cont'd). 

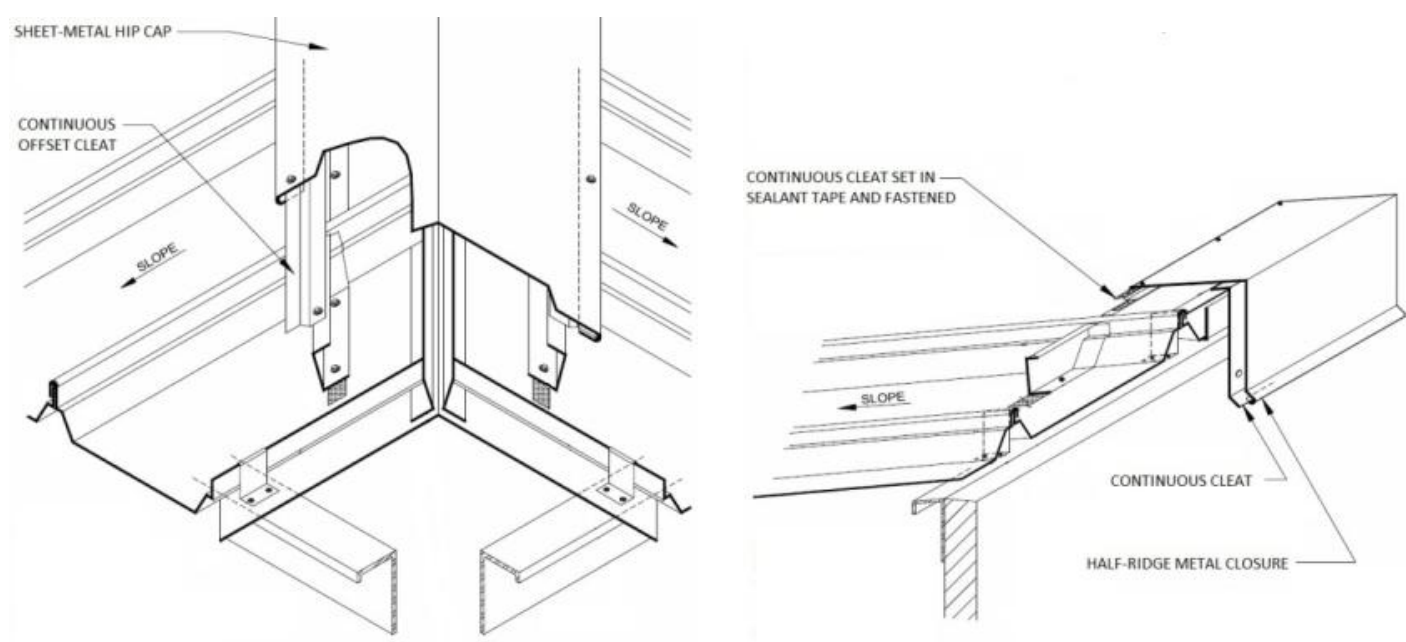

Ridge cap and hip cap flashing details (source: NRCA) (concluded).

\section{Severity levels}

\section{Medium}

1. Ridge or hip cap flashing is disengaged but appears to be watertight.

\section{High}

1. Ridge or hip cap flashing has holes that require localized repair.

2. Ridge or hip cap flashing is deformed or disengaged and allowing water to penetrate the roofing system; or evidence of ponding at a lap or seam.

3. Ridge or hip cap flashing is missing.

4. Hip cap flashing has joints that are bucking water.

5. Ridge or hip cap flashing has open joints or butt joints.

\section{Measurement}

For $\mathrm{H}-1$ and $\mathrm{H}-5$ defects, measure the lineal feet of defective flashing. Individual defects shall be counted as a minimum of 1 foot. If the distance between defects is less than 1 foot, include the length between defects.

For M-1, H-2, H-3, and H-4 defects; count the entire length of each defective flashing piece (typically 10 feet). 


\section{Density}

$$
\text { Problem Density }=\frac{A}{B} \times 100
$$

$A=$ Length of ridge or hip cap flashing defects ( $\mathrm{ft}$ ).

$\mathrm{B}=$ Total length of roof section perimeter and metal curb flashings ( $\mathrm{ft}$ ).

Note: The problem density is calculated for each observed severity level.

\section{CP reference photographs}

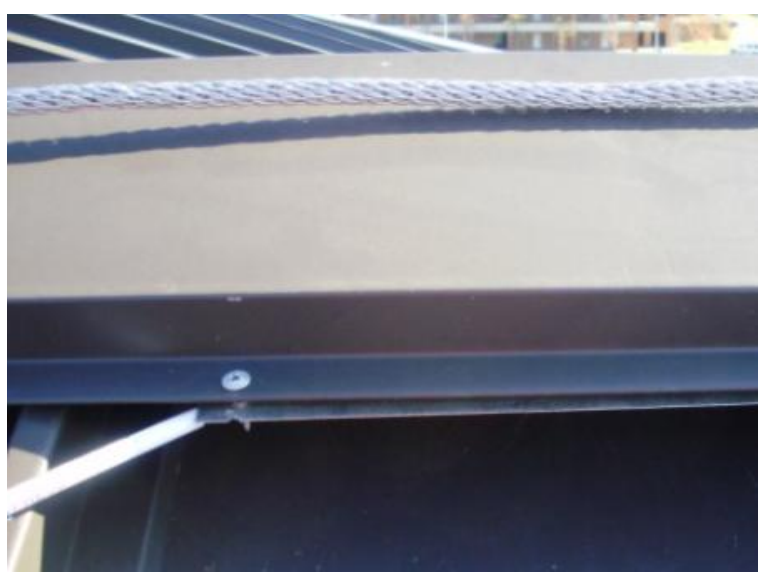

CP-M-1: Ridge or hip cap flashing is disengaged but appears to be watertight.

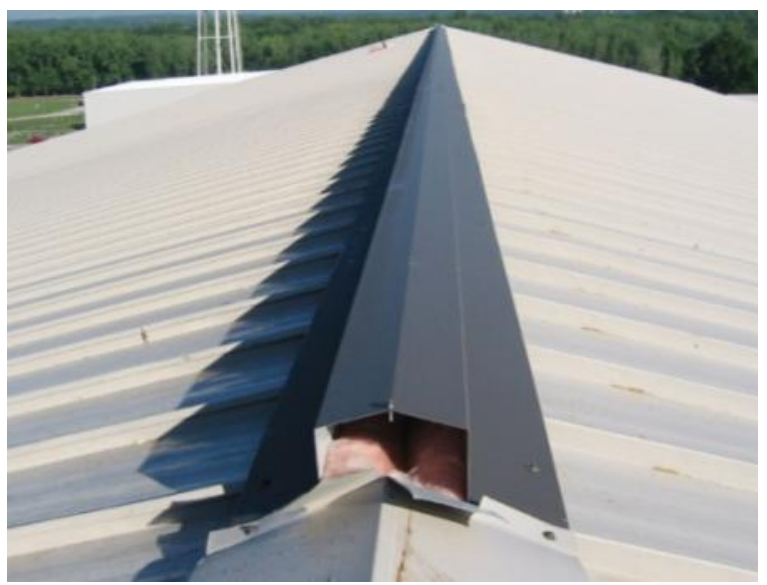

CP-H-3: Ridge or hip cap flashing is missing.

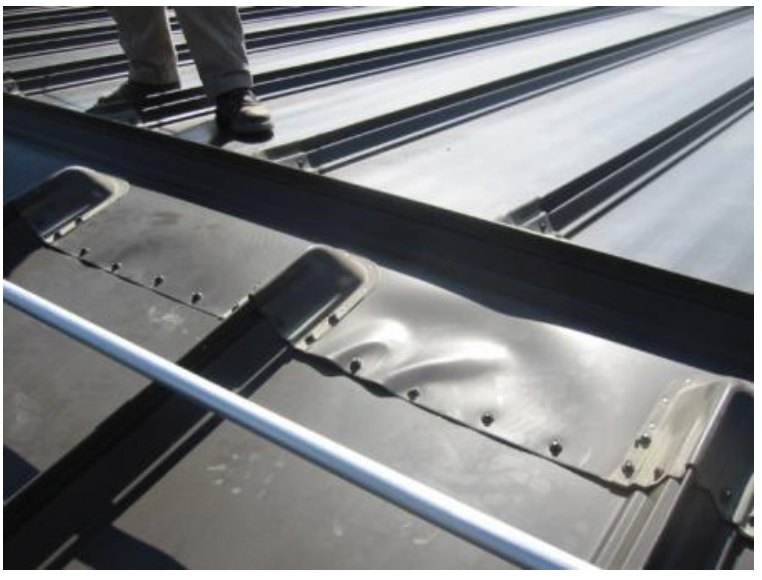

$\mathrm{CP}-\mathrm{H}-2$ : Ridge or hip cap flashing is deformed or disengaged and allowing water to penetrate the roofing system; or evidence of ponding at a lap.

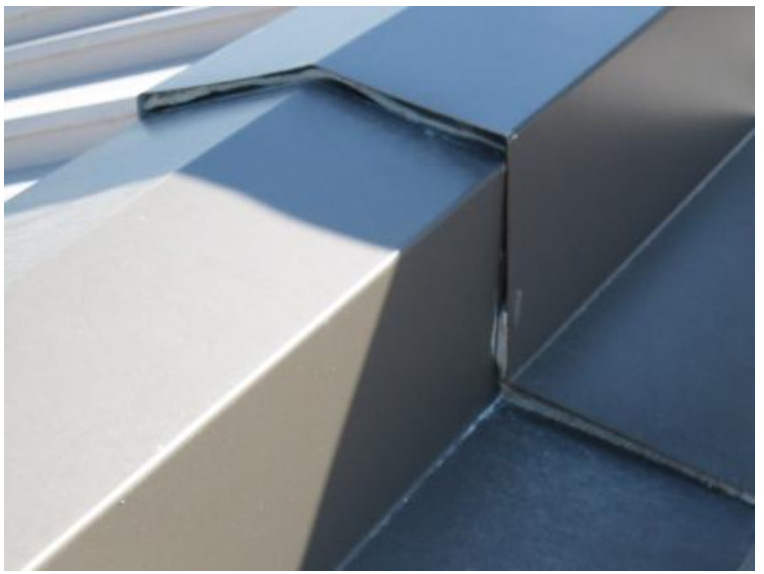

CP-H-5: Ridge or hip cap flashing has open joint or butt joints. 


\section{Valley Flashing (VF)}

\section{Description}

Valley flashing is flashing where the intersection of two sloping roof planes forms a "V". Fasteners that penetrate the valley flashing but do not penetrate the roof panel shall be considered as valley flashing defects and not flashing fastener defects. Patches in the valley flashings shall be considered as valley flashing defects and not flashing patch defects.

Note: If fasteners penetrate the roof panel, the distress is considered a panel fastener distress.
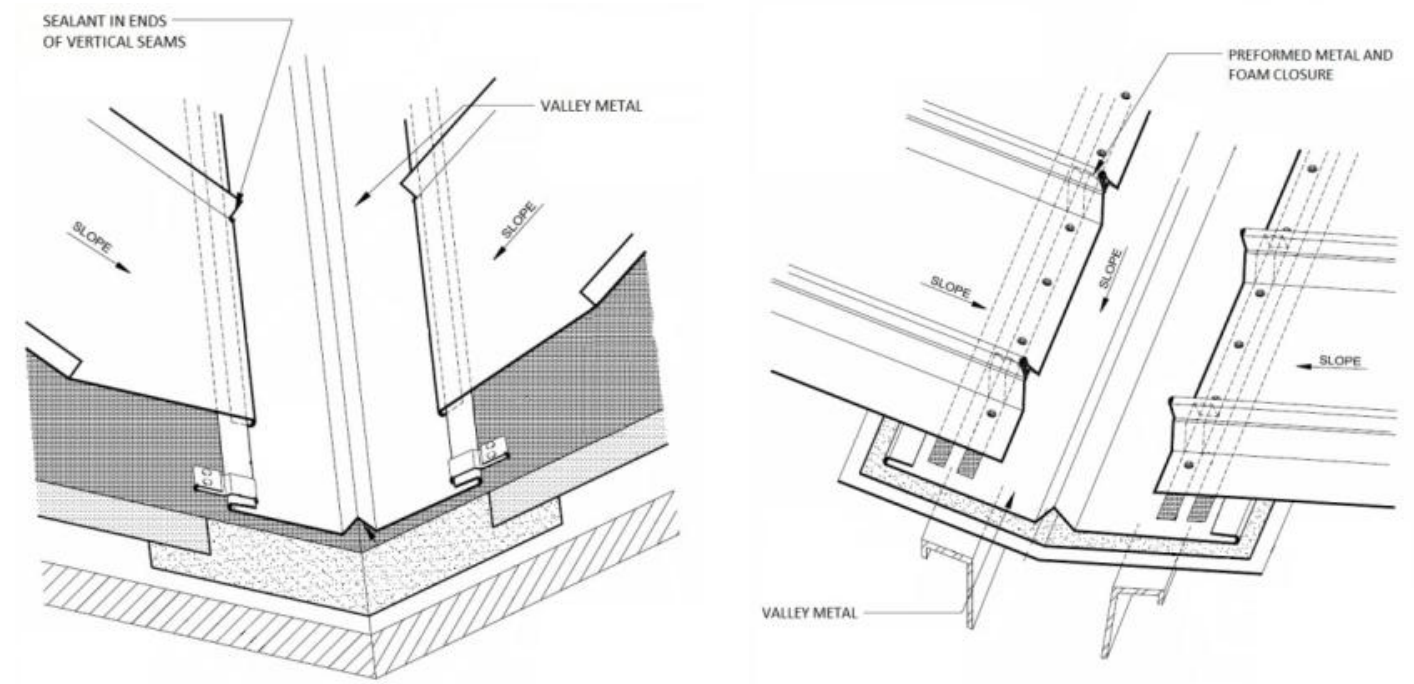

Valley flashing details (source: NRCA).

\section{Severity levels}

Low

1. Valley flashing fastener is located in the valley but appears to be watertight.

2. Valley flashing patch appears to be watertight

\section{Medium}

1. Valley flashing fastener has no flexible gasket or has a flexible gasket that is deteriorating but appears to be watertight; or fastener is corroded, improperly seated, or has a temporary repair but appears to be watertight. 
High

1. Valley flashing fastener or flexible gasket is loose, deteriorated, or missing and is allowing water to penetrate the roofing system; or fastener has an enlarged hole that is allowing water to penetrate the roofing system.

2. Valley flashing has holes.

3. Valley flashing has open joints or butt joint, or joints that are bucking water.

4. Panel end that terminates in valley has become disengaged.

5. Valley flashing patch is allowing water to penetrate the roofing system or is inappropriate.

6. Valley flashing is missing.

\section{Measurement}

For L-2, H-2, H-3, H-4, H-5, and H-6 defects, measure the lineal feet of defective flashing. Individual defects shall be counted as a minimum of 1 foot. If the distance between defects is less than 1 foot, include the length between defects.

For L-1, M-1, and H-1 defects; count the total number of defective fasteners.

\section{Density}

$$
\text { Problem Density }=\frac{A}{B} \times 100
$$

A = Length of valley flashing defects ( $\mathrm{ft}$ ).

$\mathrm{B}=$ Total length of roof section perimeter and metal curb flashings ( $\mathrm{ft}$ ).

Note: The problem density is calculated for each observed severity level. 


\section{VF reference photographs}

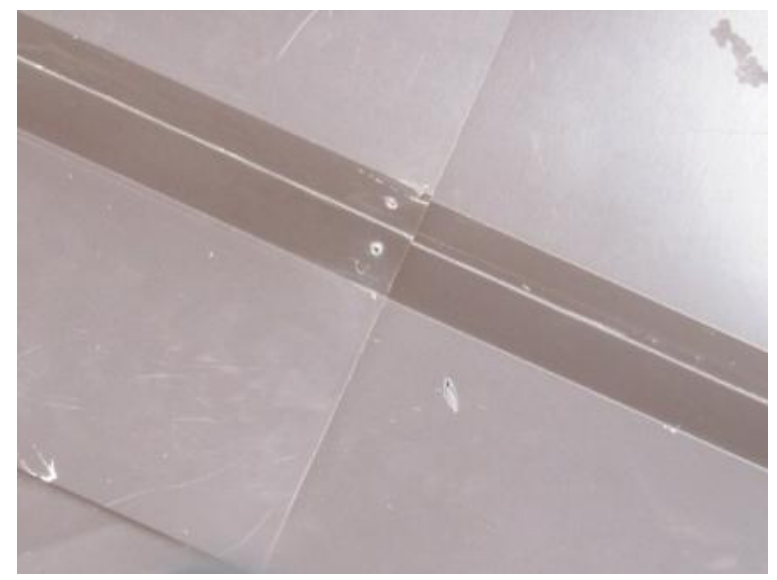

VF-L-1: Valley flashing fastener is located in the valley but appears to be watertight.

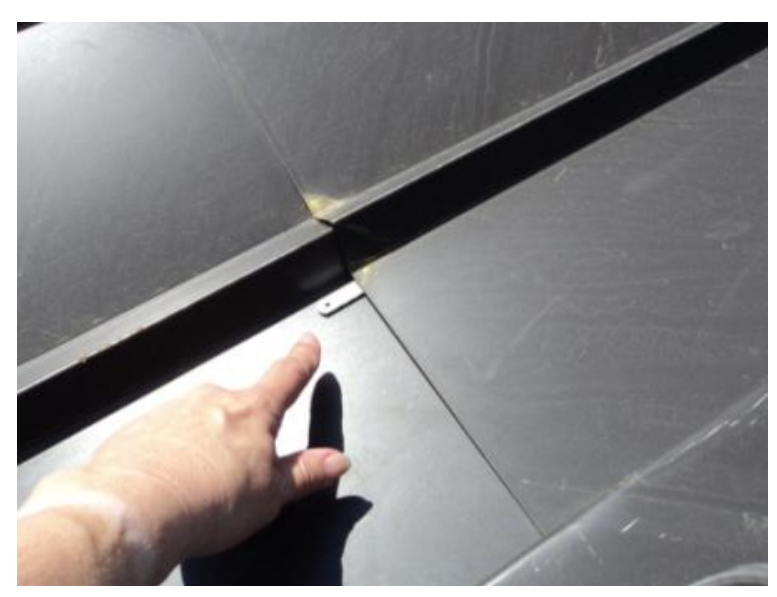

VF-H-3: Valley flashing has open joints or butt joint, or joints that are bucking water.

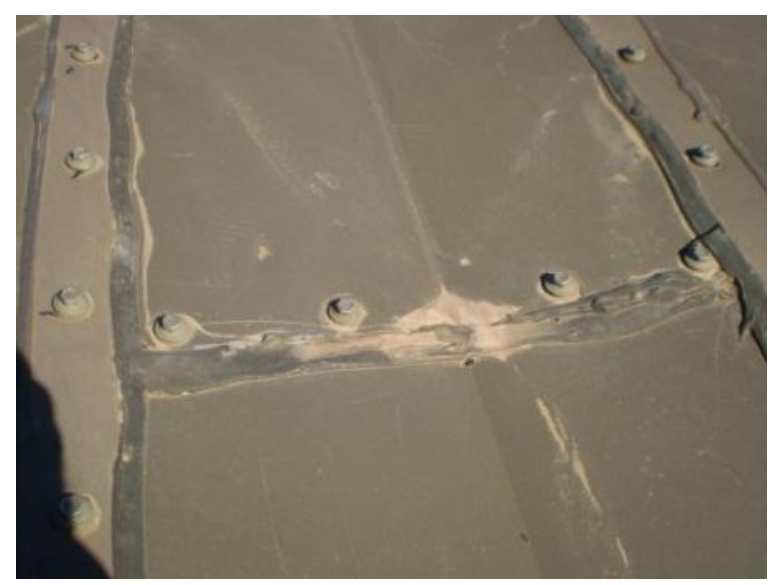

VF-L-1: Valley flashing fastener is located in the valley but appears to be watertight.

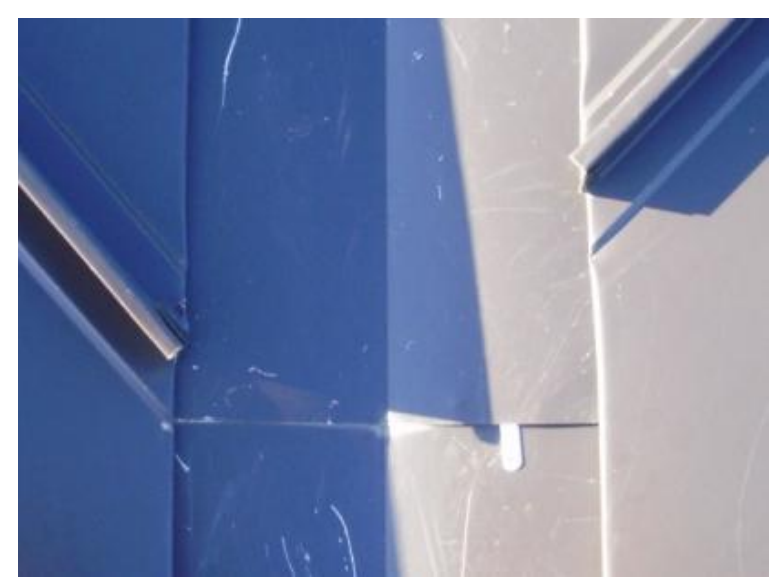

VF-H-3: Valley flashing has open joints or butt joint, or joints that are bucking water. 


\section{Headwall Transition Flashing (HT)}

\section{Description}

Flashing for a roof section that transitions to a headwall. This flashing requires roof-to-wall flashing, positively attached to the roofing system. A similar flashing detail is used to transition from a metal roof plane to another metal roof plane on the upslope side that is at a steeper slope.
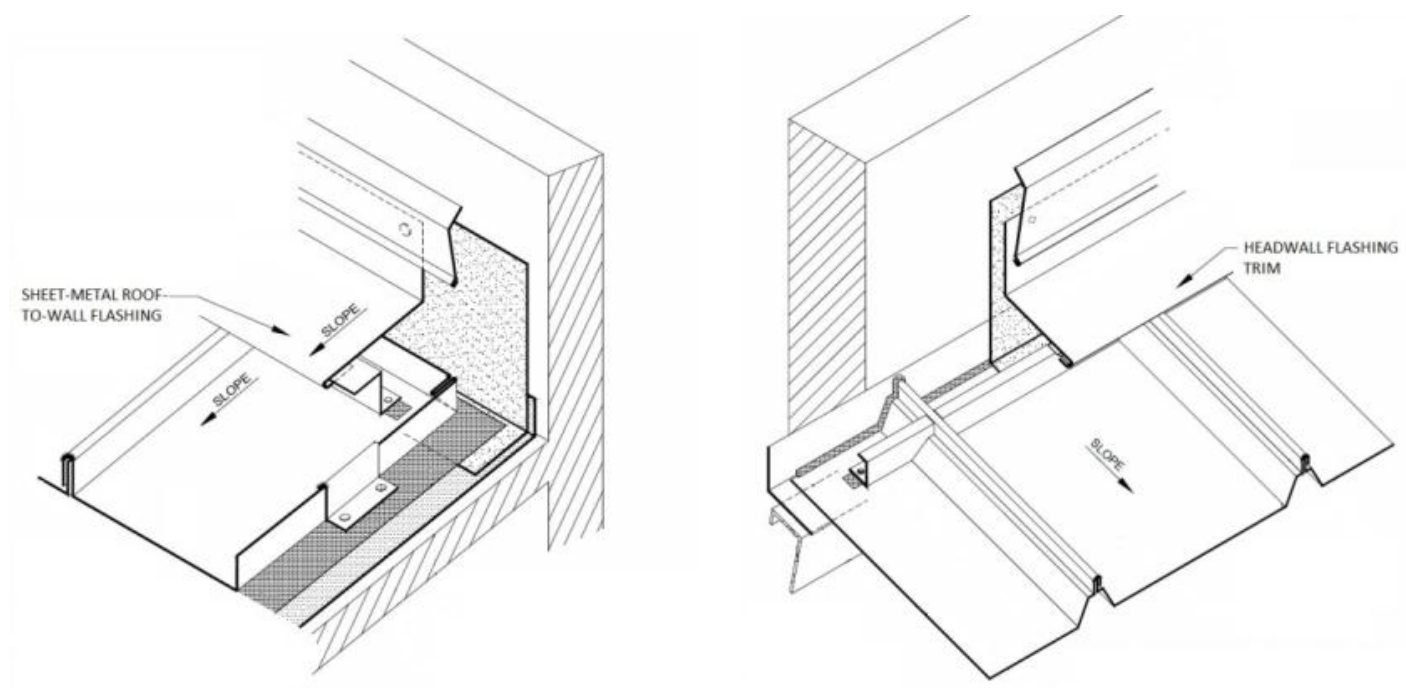

Headwall transition flashing details (source: NRCA).

\section{Severity levels}

Medium

1. Transition flashing is disengaged or loose but appears to be watertight.

High

1. Transition flashing has holes.

2. Transition flashing is disengaged or loose and is allowing water to penetrate the roofing system.

3. Transition flashing is missing or deformed and is allowing water to penetrate the roofing system.

4. Transition flashing has open joints or butt joints, or joints that are bucking water. 


\section{Measurement}

For $\mathrm{H}-1$ and $\mathrm{H}-4$ defects, measure the lineal feet of defective flashing. Individual defects shall be counted as a minimum of 1 foot. If the distance between defects is less than 1 foot, include the length between defects.

For M-1, H-2, and $\mathrm{H}-3$ defects, count the entire length of each defective flashing piece (typically 10 feet).

\section{Density}

$$
\text { Problem Density }=\frac{A}{B} \times 100
$$

A = Length of roof to headwall transition flashing defects ( $\mathrm{ft}$ ).

$\mathrm{B}=$ Total length of roof section perimeter and metal curb flashings ( $\mathrm{ft}$ ).

Note: The problem density is calculated for each observed severity level. 


\section{Sidewall Transition Flashing (ST)}

\section{Description}

A roof panel that transitions to a sidewall and requires a roof-to-wall flashing.
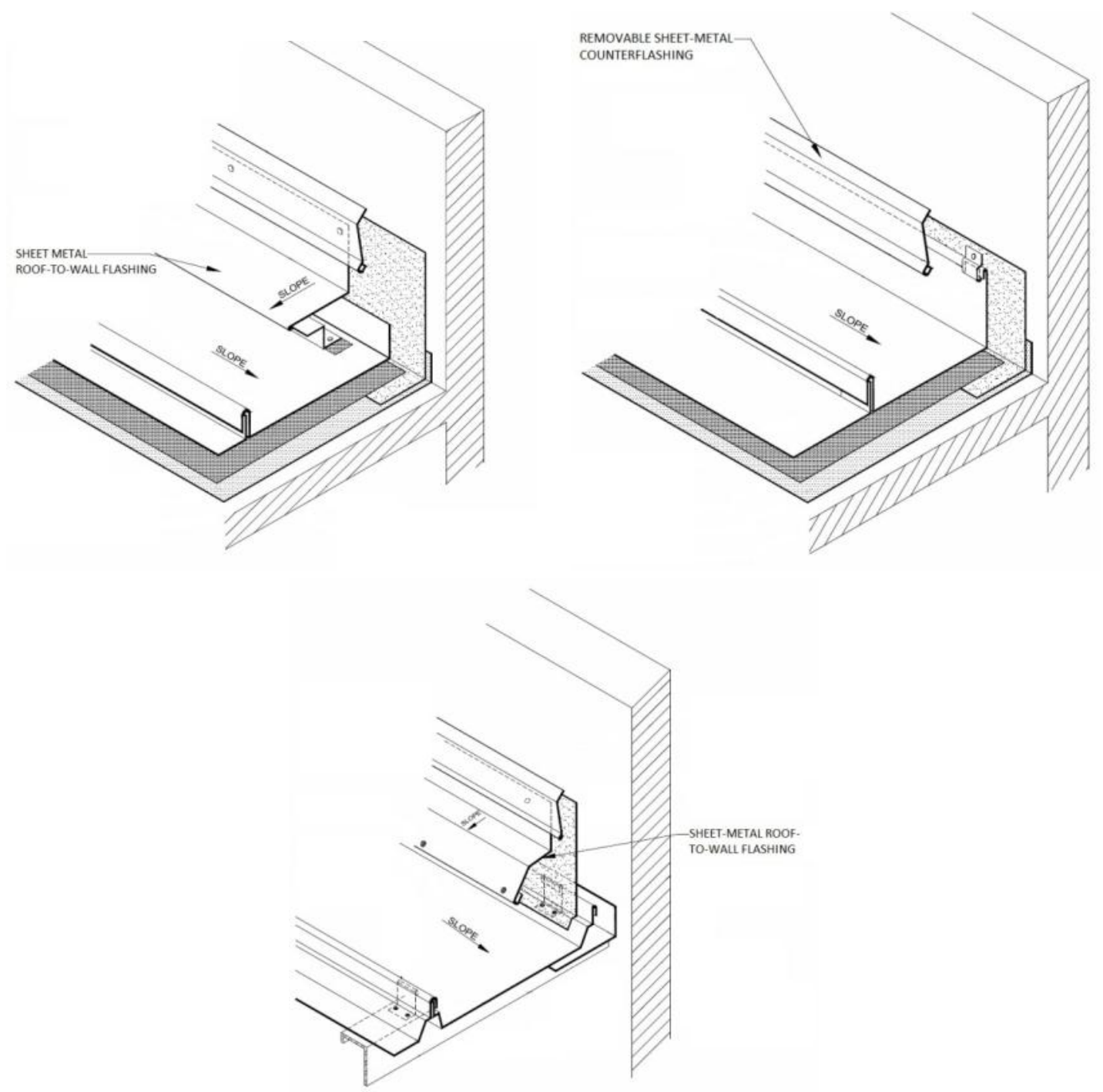

Sidewall transition flashing details (source: NRCA).

\section{Severity levels}

Medium

1. Transition flashing is disengaged or loose but appears to be watertight. 
High

1. Transition flashing has holes.

2. Transition flashing is disengaged or loose and is allowing water to penetrate the roofing system.

3. Transition flashing has open joints or butt joints, or joints that are bucking water.

4. Transition flashing is missing or deformed and is allowing water to penetrate the roofing system.

\section{Measurement}

For H-1, and H-3 defects, measure the lineal feet of defective flashing. Individual defects shall be counted as a minimum of 1 foot. If the distance between defects is less than 1 foot, include the length between defects.

For M-1, H-2 and H-4 defects; count the entire length of each defective flashing piece (typically 10 feet).

\section{Density}

$$
\text { Problem Density }=\frac{A}{B} \times 100
$$

$A=$ Length of roof to sidewall transition flashing defects ( $\mathrm{ft}$ ).

$\mathrm{B}=$ Total length of roof section perimeter and metal curb flashings ( $\mathrm{ft}$ ).

Note: The problem density is calculated for each observed severity level. 


\section{ST reference photographs}

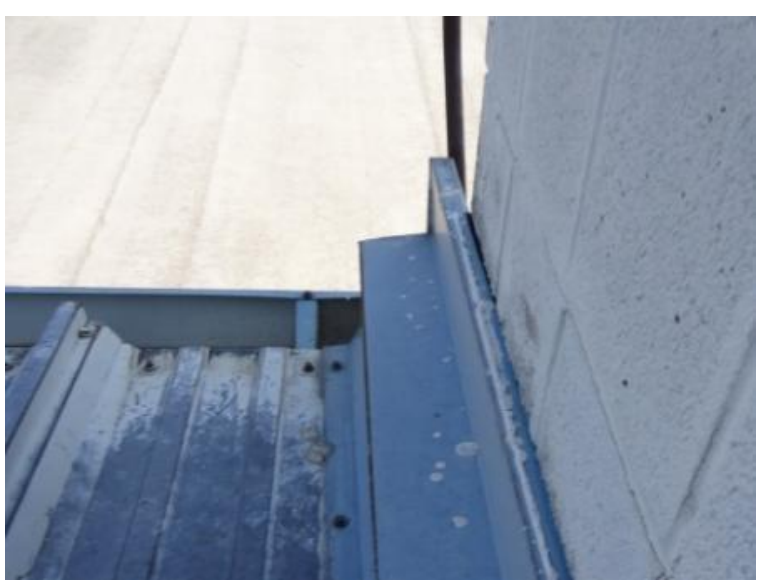

ST-H-2: Transition flashing is disengaged or loose and is allowing water to penetrate the roofing system.

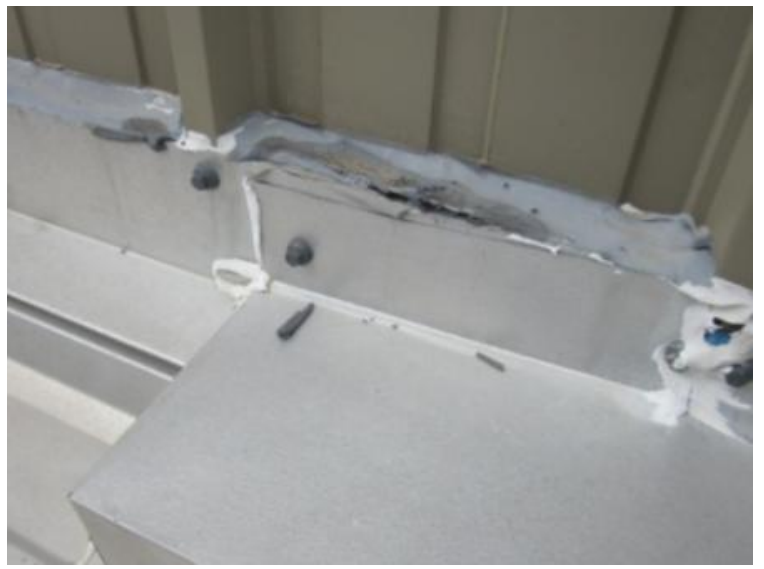

ST-H-3: Transition flashing has open joints or butt joints, or joints that are bucking water. 


\section{Continuous Roof-to-Wall Panel Transition Flashing (RW)}

\section{Description}

All panel profiles that transition from one roof slope to a greater roof slope where the panels are continuous.

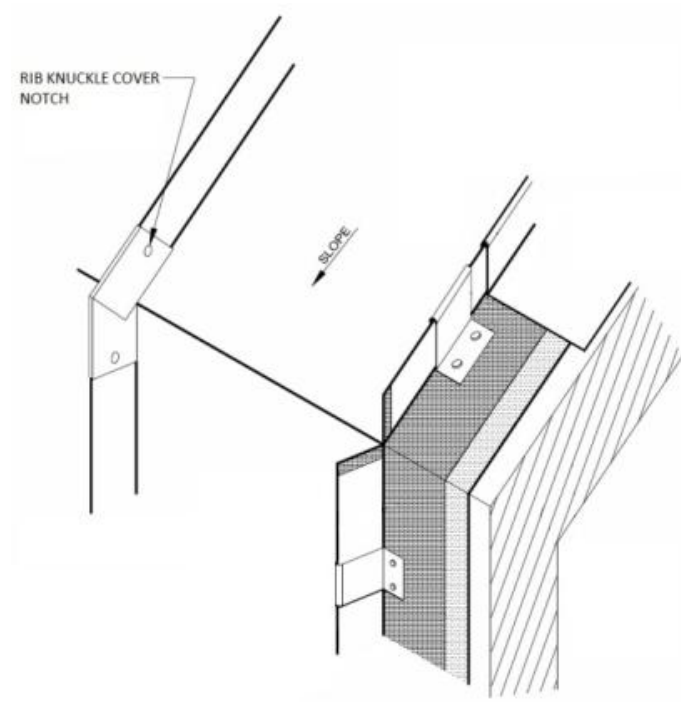

Continuous roof-to-wall panel transition flashing details (source: NRCA).

\section{Severity levels}

Low

1. Continuous roof-to-wall panel transition flashings are rated low severity as a minimum due to the maintenance problems associated with them.

High

1. Transition flashing has loose, deformed, or missing seam cover.

\section{Measurement}

For L-1 defect, measure the lineal feet of defective flashing. Individual defects shall be counted as a minimum of 1 foot. If the distance between defects is less than 1 foot, include the length between defects.

For H-1 defect, count each defective seam covers as one each. 


\section{Density}

$$
\text { Problem Density }=\frac{A}{B} \times 100
$$

$A=$ Length of continuous roof-to-wall panel transition flashing defects ( $\mathrm{ft}$ ). $\mathrm{B}=$ Total length of roof section perimeter and metal curb flashings ( $\mathrm{ft}$ ).

Note: The problem density is calculated for each observed severity level. 


\section{Built-in Gutters (IG)}

\section{Description}

Built-in gutter is a gutter that is flashed at its entire perimeter.

\section{Severity levels}

Low

1. Interior gutter is lined with elastomeric membrane or coating and appears to be watertight.

Medium

1. Interior gutter is not lined with elastomeric membrane or coating and appears to be watertight.

High

1. Interior gutter is not lined with elastomeric membrane or coating and has holes, splits or open joints.

2. Interior gutter having elastomeric membrane or coating has holes splits or open joints.

3. Interior gutter or drain is clogged.

\section{Measurement}

Measure the lineal feet of defective flashing. Individual defects shall be counted as a minimum of 1 foot. If the distance between defects is less than 1 foot, include the length between defects.

\section{Density}

$$
\text { Problem Density }=\frac{A}{B} \times 100
$$

A = Length of interior gutter defects (ft).

$\mathrm{B}=$ Total length of roof section perimeter and metal curb flashings ( $\mathrm{ft}$ ).

Note: The problem density is calculated for each observed severity level. 


\section{IG reference photographs}

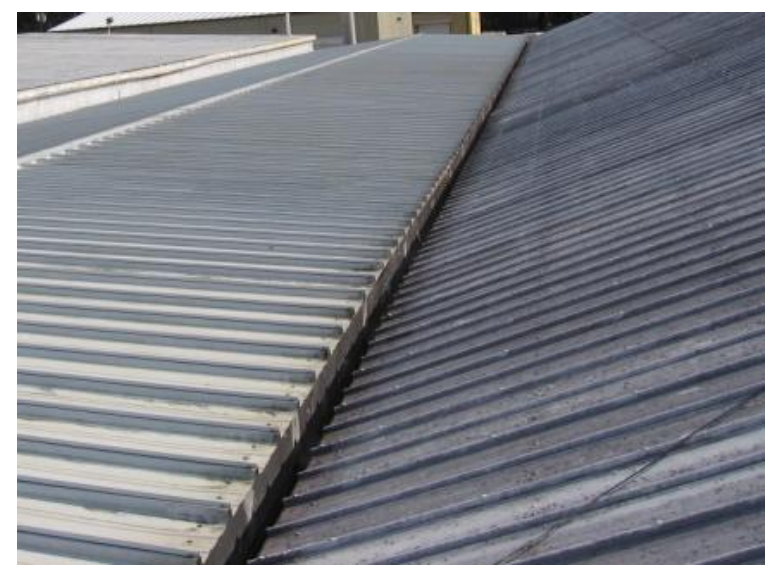

IG-L-1: Interior gutter is lined with elastomeric membrane or coating and appears to be watertight.

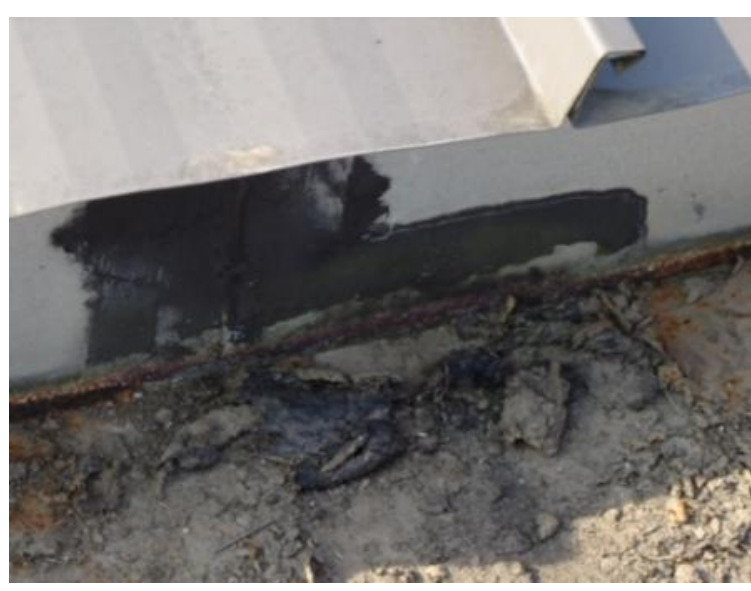

IG-H-1: Interior gutter is not lined with elastomeric membrane or coating and has holes, splits or open joints.

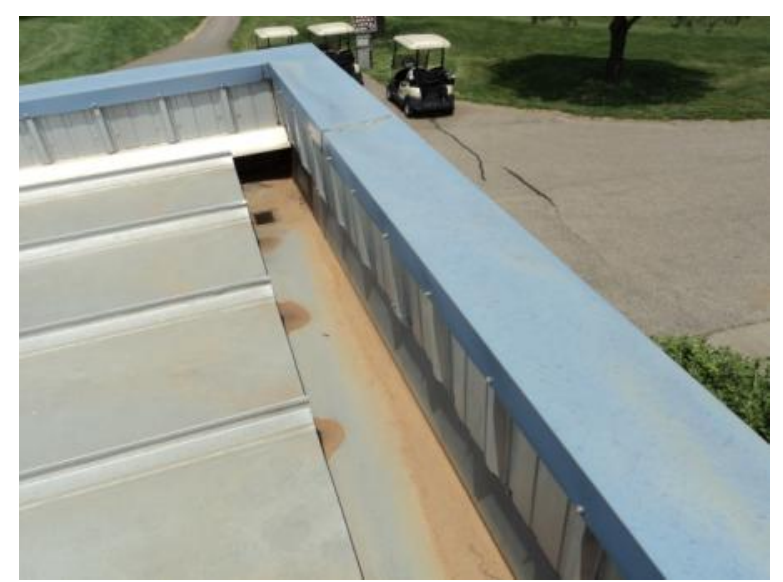

IG-M-1: Interior gutter is not lined with elastomeric membrane or coating and appears to be watertight.

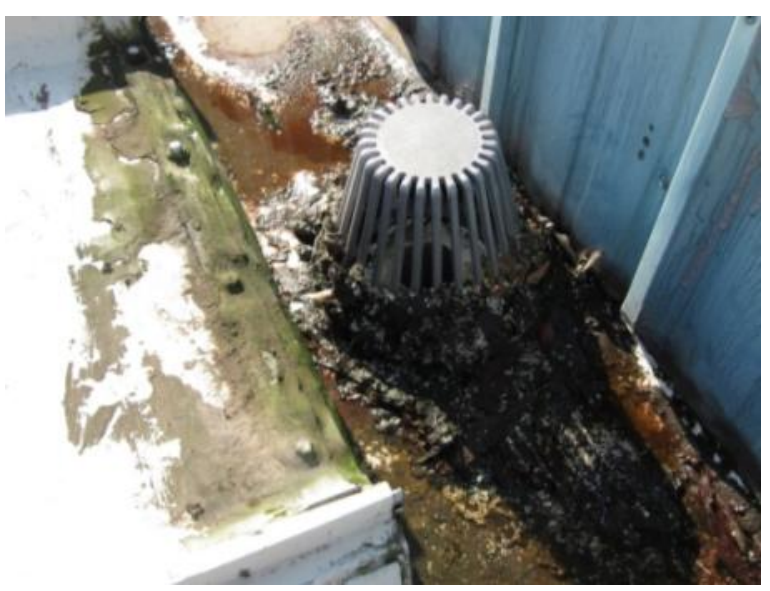

IG-H-3: Interior gutter or drain is clogged. 


\section{Flexible Boot Flashings (FB)}

\section{Description}

A flexible boot flashing is a flashing that extends from the panel surface up the penetration where it seals around the penetration. Typically these flashings are mechanically fastened to the panel surface. The top is typically a friction fit seal which is then made into a compression seal using a drawband.

Note: Penetration that blocks drainage should be addressed in the flanged metal and raised curb flashing distress (FM H-1).

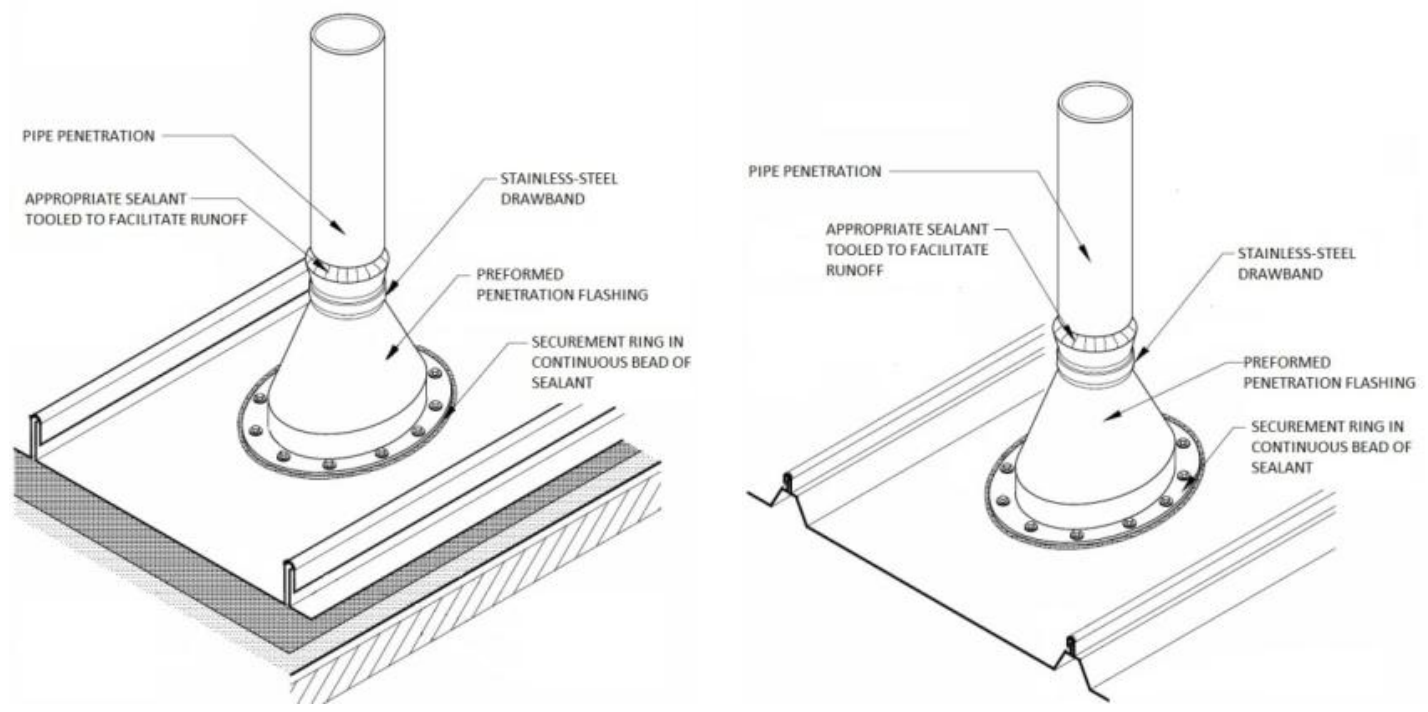

Flexible boot flashing details (source: NRCA).

\section{Severity levels}

Low

1. Flexible boot flashings are rated low-severity as a minimum due to the maintenance problems associated with them.

\section{Medium}

1. Flexible boot flashing has loose, missing, corroded or misaligned drawband. 
High

1. Flexible boot is missing or has holes; or flexible boot flashing interferes with a panel seam and is allowing water to penetrate the system.

2. Flexible boot flashing has deformed securement ring, allowing water to penetrate the roofing system.

3. Flexible boot flashing has failed or missing sealant around the drawband, allowing water to penetrate the roofing system.

\section{Measurement}

Count each flexible boot flashing as $1 \mathrm{ft}$ at the highest observed severity level.

\section{Density}

$$
\text { Problem Density }=\frac{A}{B} \times 100
$$

$\mathrm{A}=$ Length of flexible boot flashing defects ( $\mathrm{ft}$ ).

$\mathrm{B}=$ Total length of roof section perimeter and metal curb flashings (ft).

Note: The problem density is calculated for each observed severity level. 


\section{FB reference photographs}

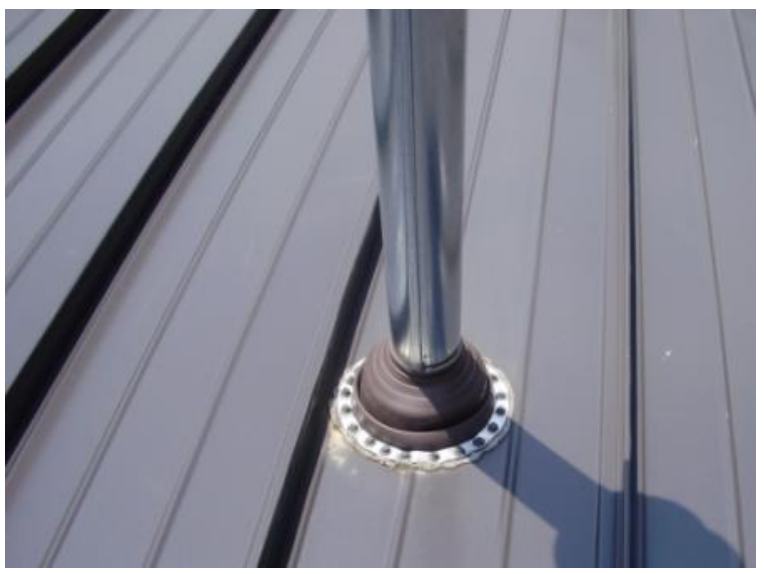

FB-L-1: Flexible boot flashings are rated low-severity as a minimum due to inherent maintenance problems.

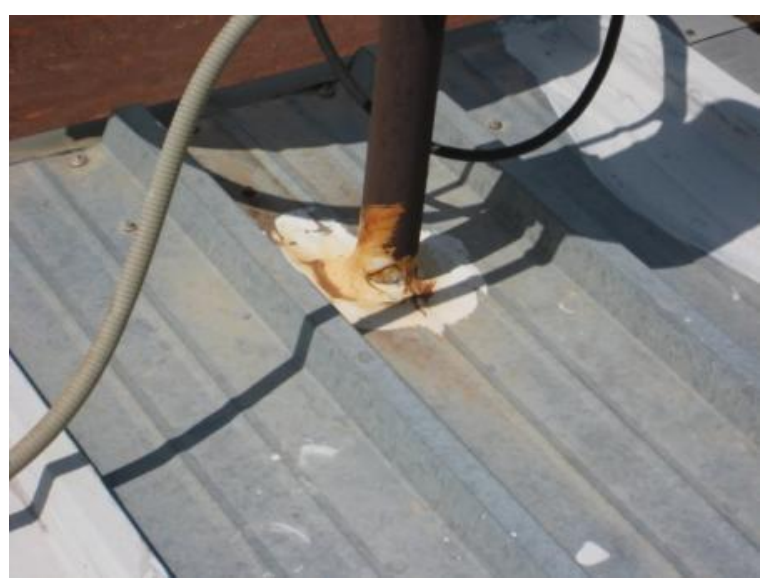

FB-H-1: Flexible boot is missing or has holes; or flexible boot flashing interferes with a panel seam and is allowing water to penetrate the system.

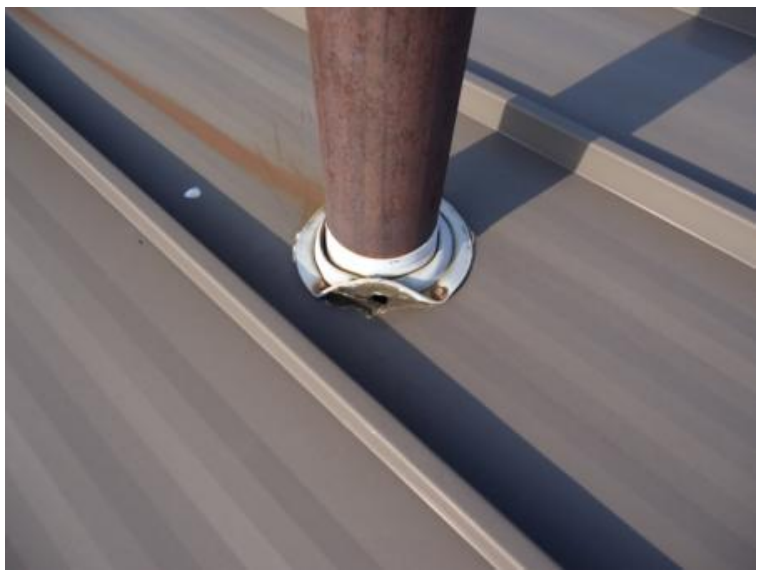

FB-H-2: Flexible boot flashing has deformed securement ring, allowing water to penetrate the roofing system.

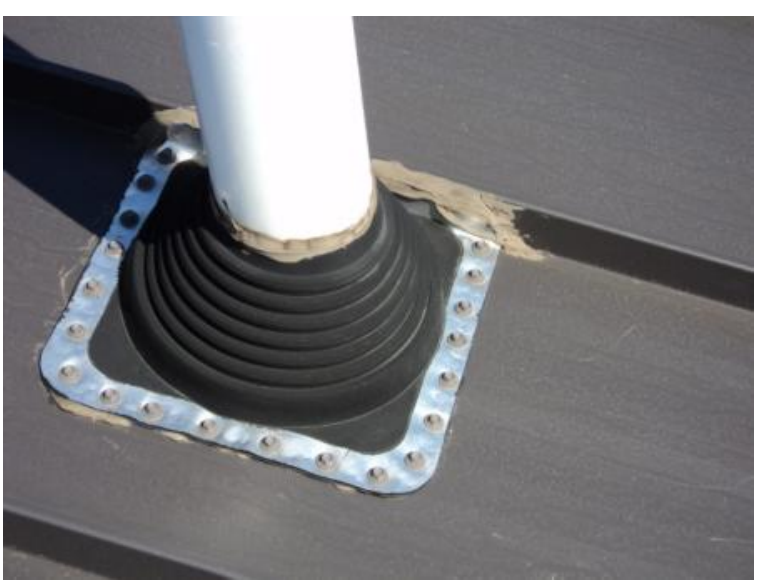

FB-M-1: Flexible boot flashing has loose, missing, corroded or misaligned draw band.

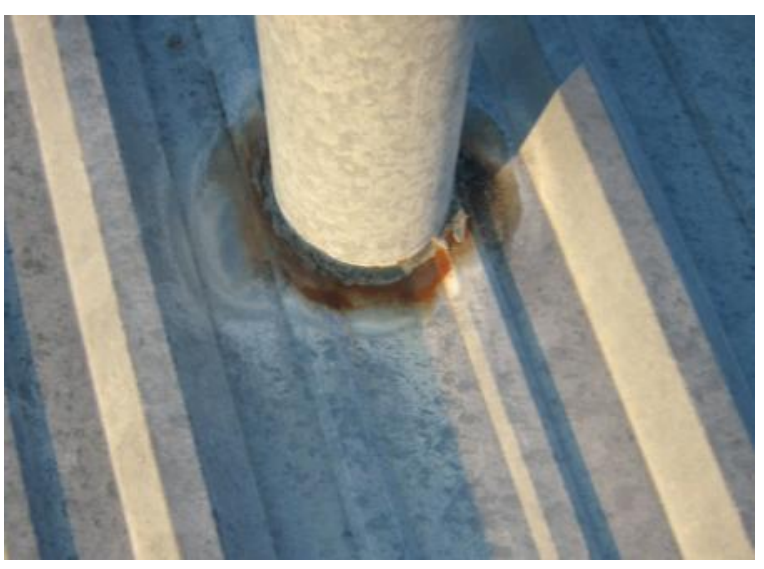

FB-H-1: Flexible boot is missing or has holes; or flexible boot flashing interferes with a panel seam and is allowing water to penetrate the system. 


\section{Flanged Metal and Raised Curb Flashing (FM)}

\section{Description}

A flanged metal or raised flashing extends from the panel surface up the sides of a square, curbed or round penetration. The surface that rests on or under the panel is made of metal with a welded, soldered, or otherwise watertight seal at transitions. These flashings can be mechanically attached to the panel and may require sealant or a membrane of elastomeric seal at the outside of the panel flange. The top may or may not be tight against the penetration. The top may turn down into a pipe penetration, have a separate cap that covers the top, or may rely on an "umbrella" or storm collar to keep water from entering at the top of the flashing. The top may also be counterflashed by a separate cap or a skylight frame or part of the equipment that is mounted to the top of the curb.
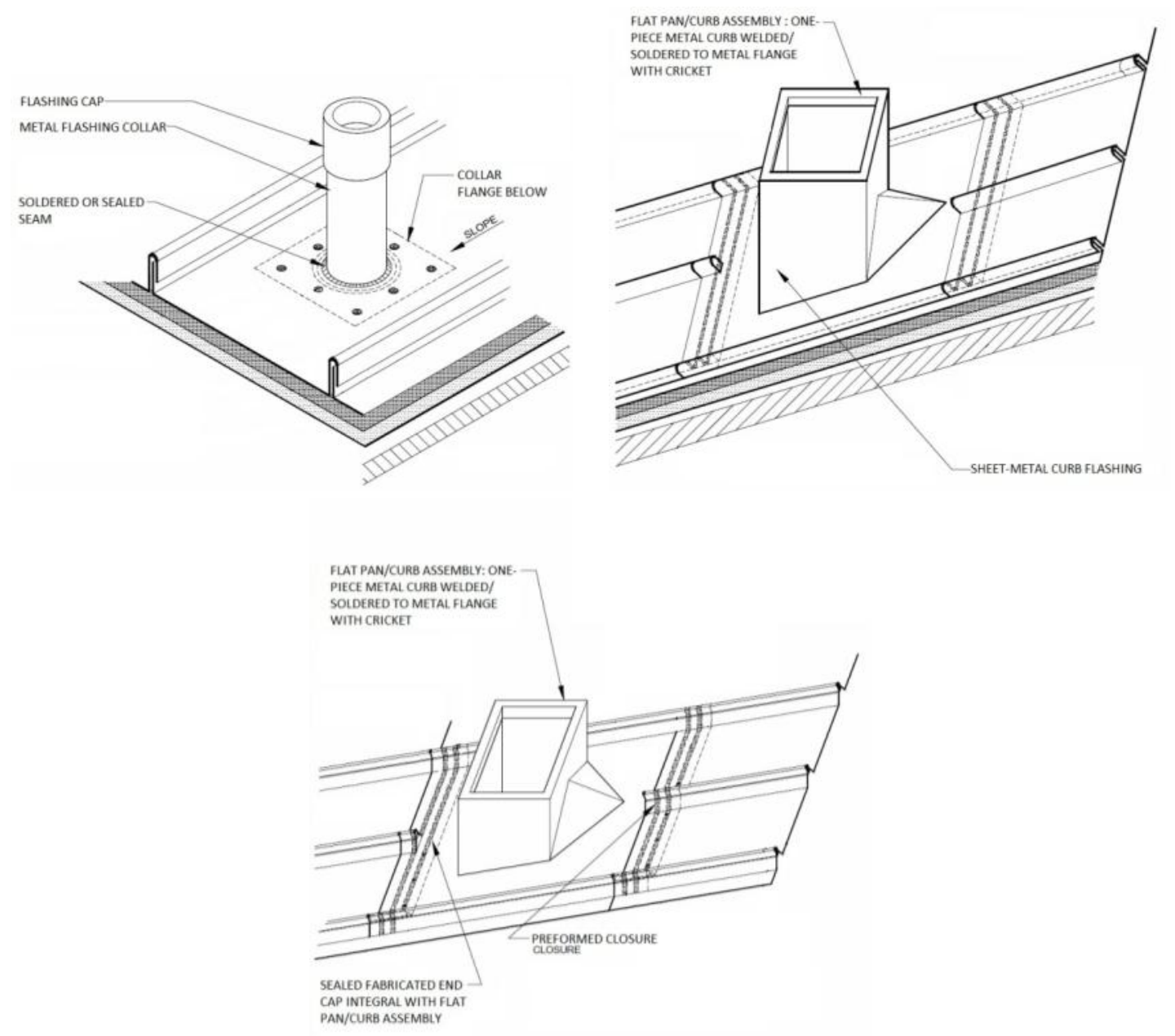

Flanged metal and raised curb flashing details (source: NRCA). 


\section{Severity levels}

Low

1. Flanged metal and raised curb flashings are rated low-severity as a minimum due to the maintenance problems associated with them.

\section{Medium}

1. Flashing flange on upslope side is mounted on top of panel, bucking water, but appears to be watertight

2. Flashing flange on downslope side is mounted below panel, bucking water, but appears to be watertight.

3. Sealant around umbrella is deteriorating, torn, or deformed, but appears to be watertight.

High

1. Flashing impedes drainage.

2. Flashing has holes.

3. Flashing joint has failed and is allowing water to penetrate the roofing system.

4. Flashing flange on upslope side is mounted on top of panel, bucking water, and is allowing water to penetrate the roofing system.

5. Flashing flange on downslope side is mounted below panel, bucking water, and is allowing water to penetrate the roofing system.

6. Flashing has missing seam closure on downslope side.

7. Flashing flange is open or unsealed.

8. Top of pipe flashing is open.

9. Sealant around umbrella is missing or is allowing water to penetrate the roofing system.

\section{Measurement}

Measure the lineal feet of defective flashing. Individual defects shall be counted as a minimum of 1 foot. If the distance between defects is less than 1 foot, include the length between defects.

\section{Density}

$$
\text { Problem Density }=\frac{A}{B} \times 100
$$


$A=$ Length of flanged metal or raised curb flashing defects ( $\mathrm{ft}$ ).

$\mathrm{B}=$ Total length of roof section perimeter and metal curb flashings ( $\mathrm{ft}$ ).

Note: The problem density is calculated for each observed severity level.

\section{FM reference photographs}

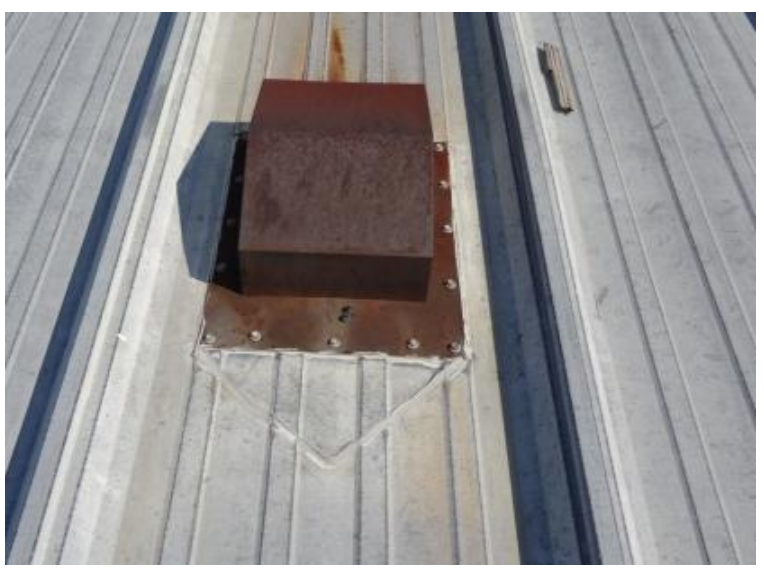

FM-M-1: Flashing flange on upslope side is mounted on top of panel, bucking water, but appears to be watertight.

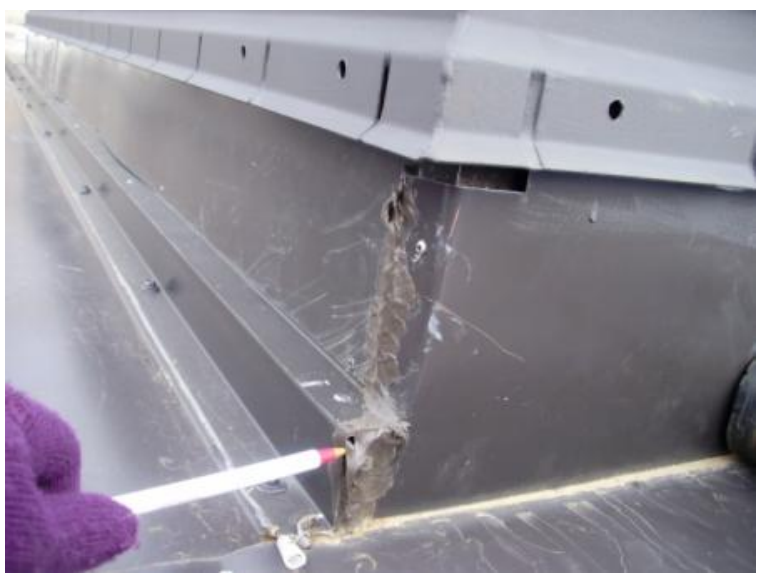

FM-H-2: Flashing has holes.

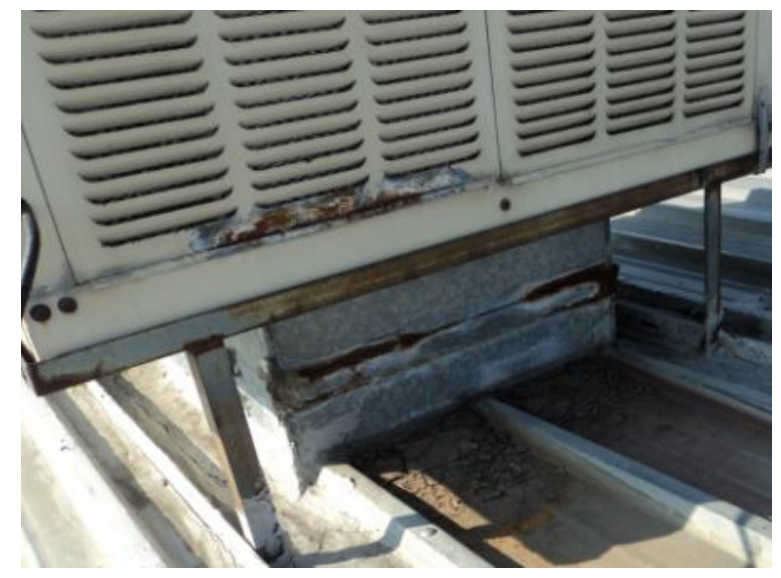

FM-H-1: Flashing impedes drainage.

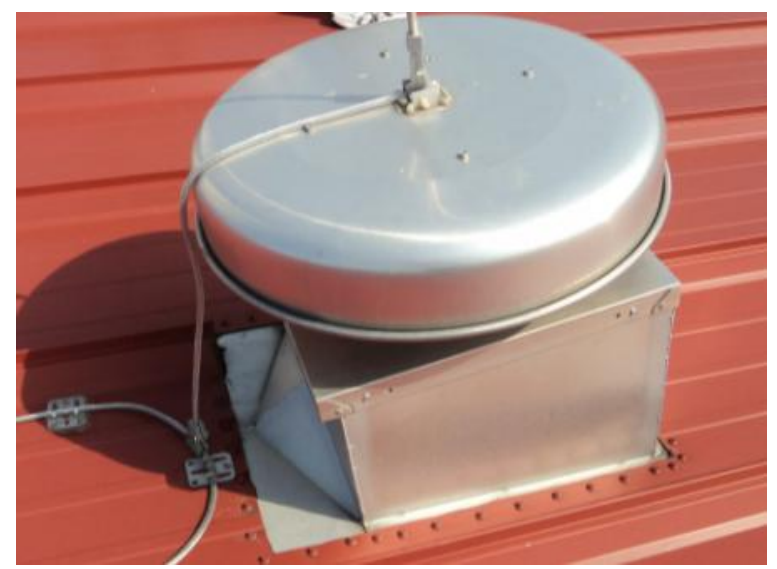

FM-H-5: Flashing flange on downslope side is mounted below panel, bucking water, and is allowing water to penetrate the roofing system. 


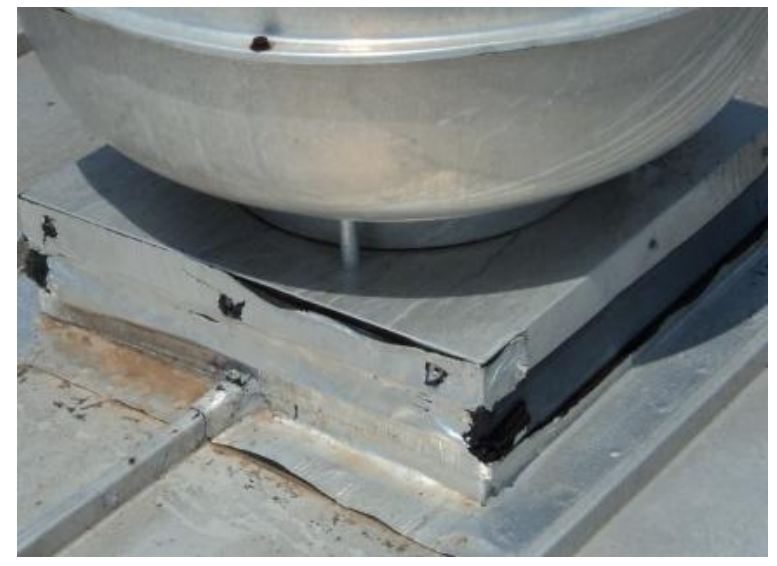

FM-H-7: Flashing flange is open or unsealed.

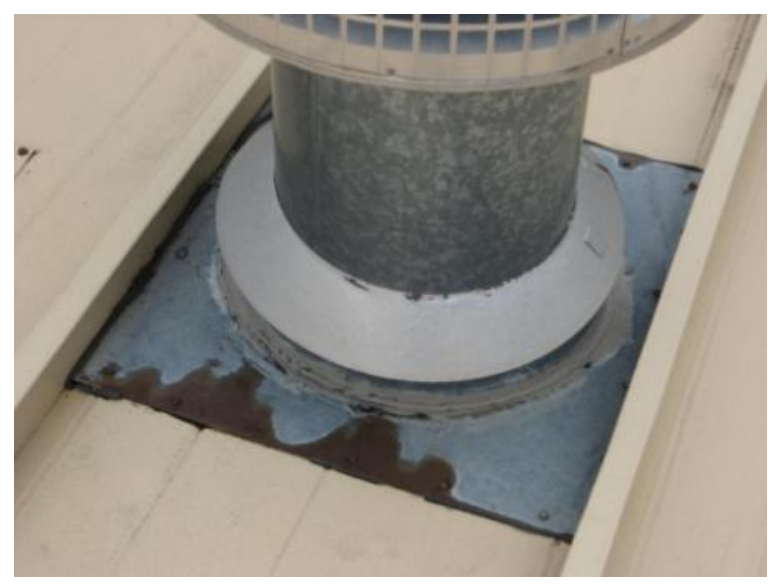

FM-H-9: Sealant around umbrella is missing or is allowing water to penetrate the roofing system. 


\section{Ancillary Flashing (AF)}

\section{Description}

Ancillary flashing includes counterflashing; any sheet metal coping cap or elastomeric bellows expansion joint cover that serves as part of the counterflashing; or cover over a detail such as an equipment curb or termination flashing. Ancillary flashing protects the top termination of the vertical flashing and sheds water away from it. Properly lapped exterior siding or cladding can perform the function of ancillary metal flashing.

Note: Fasteners that do not penetrate the roof panel that is part of the flashing component are treated as a flashing fastener distress. If they do penetrate the roof panel, they are considered a panel fastener distress.
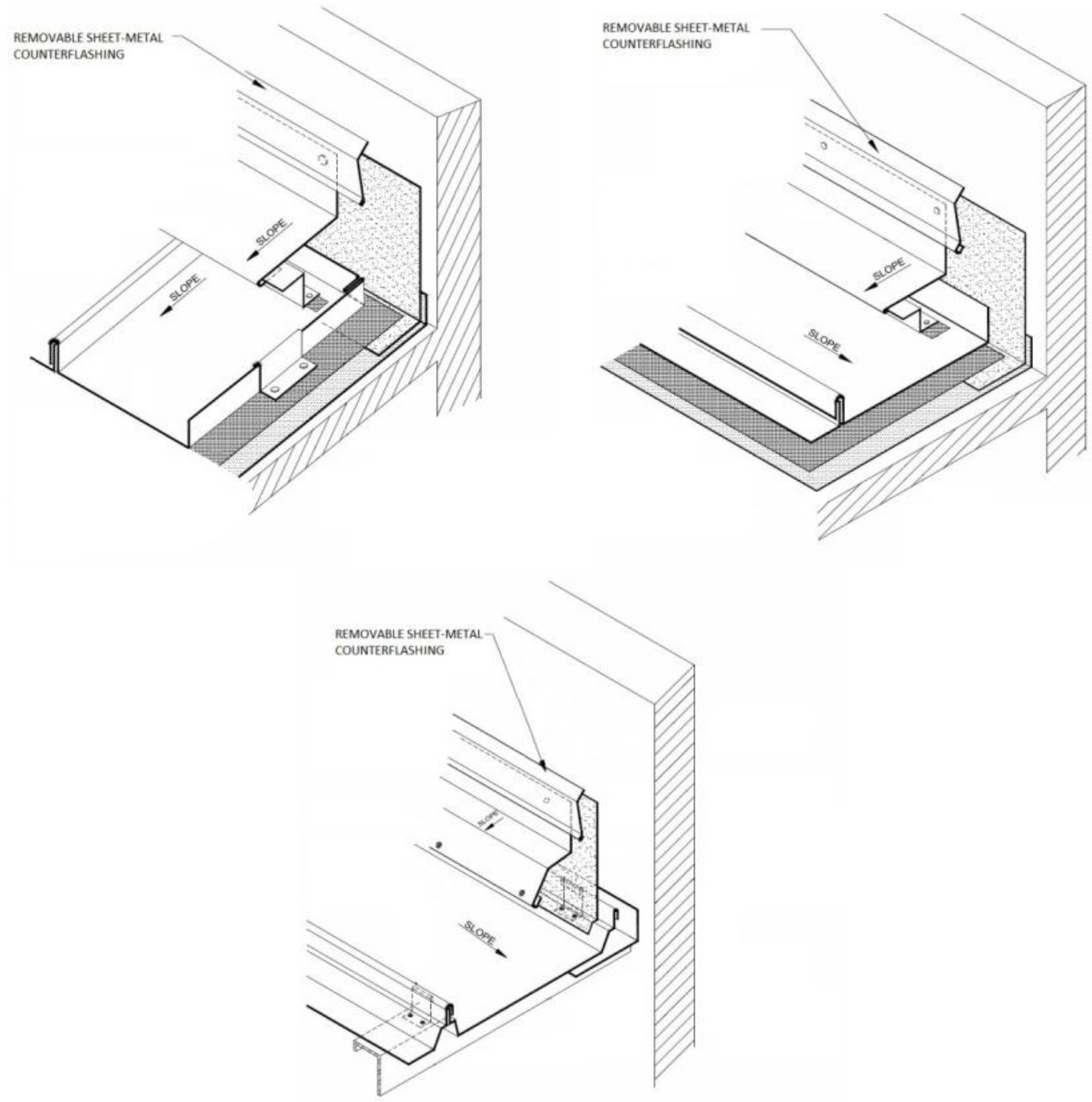

Ancillary flashing details (source: NRCA). 


\section{Severity levels}

Low

1. Curb/ coping cap flashing is deformed with evidence of water ponding at a location that is not adjacent to a lap or seam; or counterflashing is deformed but still functioning.

2. Elastomeric bellows expansion joint cover is used.

\section{Medium}

1. Ancillary flashing has holes on a vertical surface.

2. Curb/ coping cap has unflashed or improperly flashed penetration passing through, but appears to be watertight.

High

1. Ancillary flashing has holes through it or severe deterioration on a horizontal surface.

2. Ancillary flashing is missing or deformed; or there is evidence of water ponding at a lap or seam.

3. Ancillary flashing is displaced.

4. Ancillary flashing has a failed soldered joint, an open joint, a butt joint, or joint covers missing from where originally installed.

5. Ancillary flashing has joints that are bucking water.

6. Sealant at reglet, top of counterflashing, or sealed joint is missing or no longer functioning.

7. Counterflashing, exterior siding, or cladding does not extend over top of transition flashing where originally installed or required.

8. Curb/ coping cap has unflashed or improperly flashed penetration passing through it that is allowing water to penetrate the roofing system.

9. Top of transition flashing is not properly counterflashed or terminated.

\section{Measurement}

For L-1, M-1, H-1, H-4, H-6, and H-9 defects, measure the lineal feet of defective flashing. Individual defects shall be counted as a minimum of 1 foot. If the distance between defects is less than 1 foot, include the length between defects.

For L-2, M-2, H-2, H-3, H-5, H-7, and H-8 defects, count the entire length of each defective flashing piece (typically 10 feet). 


\section{Density}

$$
\text { Problem Density }=\frac{A}{B} \times 100
$$

$\mathrm{A}=$ Length of ancillary flashing defects ( $\mathrm{ft})$.

$\mathrm{B}=$ Total length of roof section perimeter and metal curb flashings ( $\mathrm{ft}$ ).

Note: The problem density is calculated for each observed severity level.

\section{AF reference photographs}

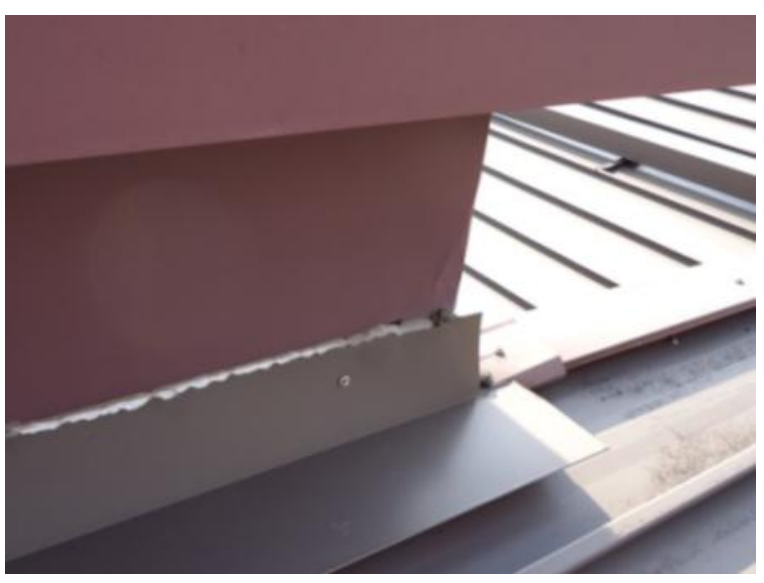

AF-H-6: Sealant at reglet, top of counterflashing, or sealed joint is missing or no longer functioning.

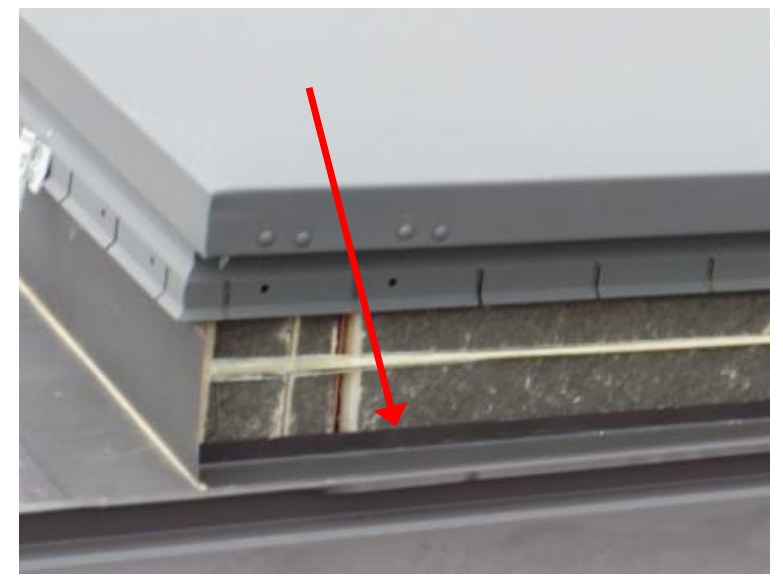

AF-H-9: Top of transition flashing is not properly counterflashed or terminated. 


\section{Flashing Patch (FR)}

\section{Description}

Post-construction application of material applied to the flashing metal that is intended as a repair. Topical application of sealant is an example of a flashing patch. Random application of sealant that is not performing a waterproofing function is not considered as patching. Patches in the valley flashings shall be considered as valley flashing defects and not flashing patch defects.

Note: A flashing fastener that has a sealant repair is counted as a flashing fastener distress.

\section{Severity levels}

Low

1. Flashing patch appears to be watertight and does not require a more permanent repair.

\section{Medium}

1. Flashing patch that appears to be watertight, but requires a more permanent repair.

High

1. Flashing patch is allowing water to penetrate the roofing system.

\section{Measurement}

Measure the lineal feet of flashing component that is patched.

When large quantities of this problem are present, especially on large roofs, the representative sampling technique can be used.

\section{Density}

$$
\text { Problem Density }=\frac{A}{B} \times 100
$$

$\mathrm{A}=$ Length of patched flashing component $(\mathrm{ft})$. 
$\mathrm{B}=$ Total length of roof section perimeter and metal curb flashings ( $\mathrm{ft}$ ).

Note: The problem density is calculated for each observed severity level.

\section{FR reference photographs}

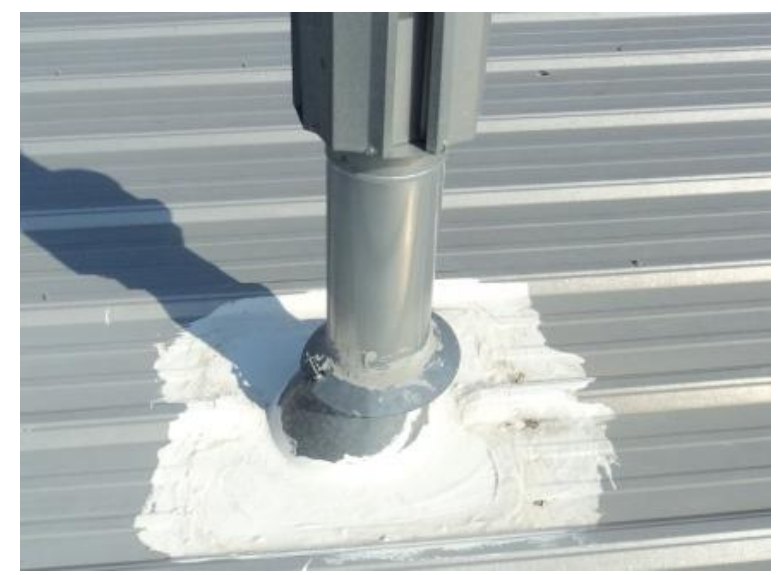

FR-L-1: Flashing patch appears to be performing a waterproofing function and appears to be watertight and does not require a more permanent repair.

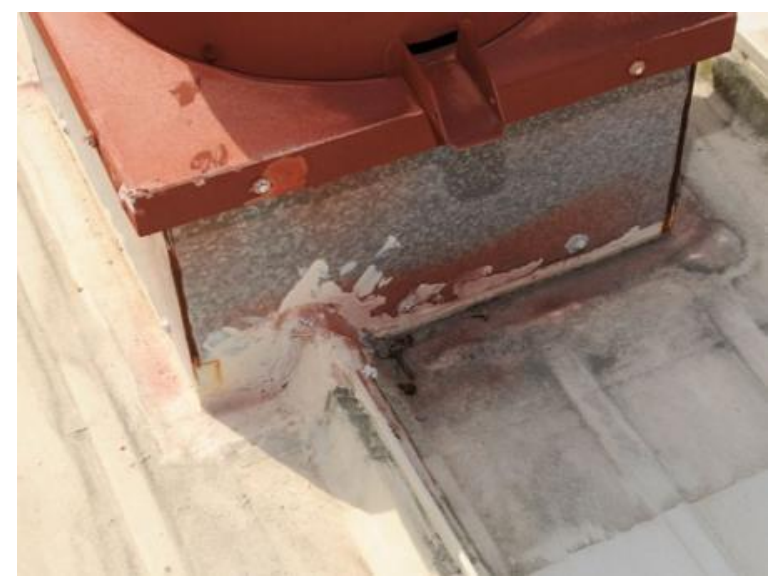

FR-M-1: Flashing patch, which appears to be performing a waterproofing function, appears to be watertight but requires a more permanent repair.

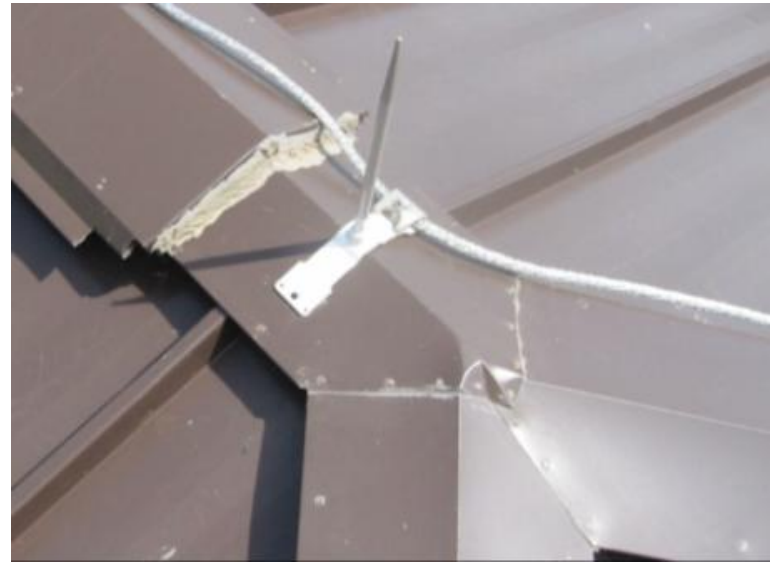

FR-M-1: Flashing patch, which appears to be performing a waterproofing function, appears to be watertight but requires a more permanent repair.

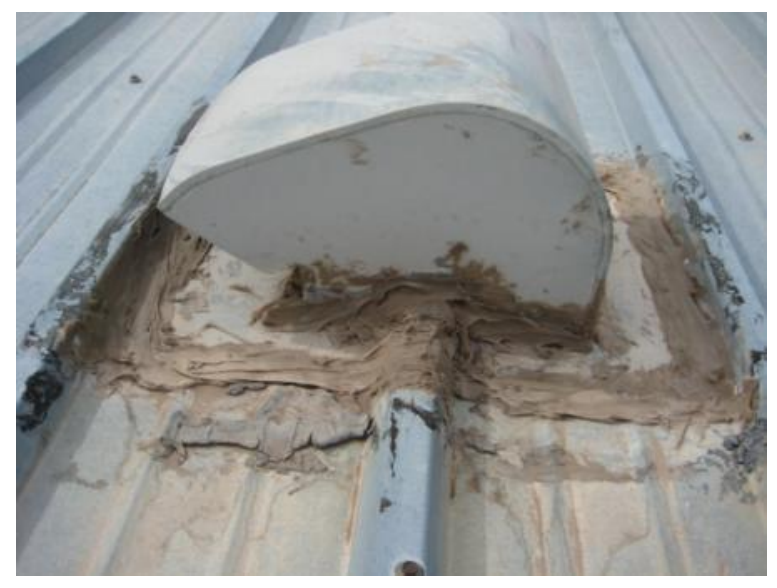

FR-M-1: Flashing patch, which appears to be performing a waterproofing function, appears to be watertight but requires a more permanent repair. 


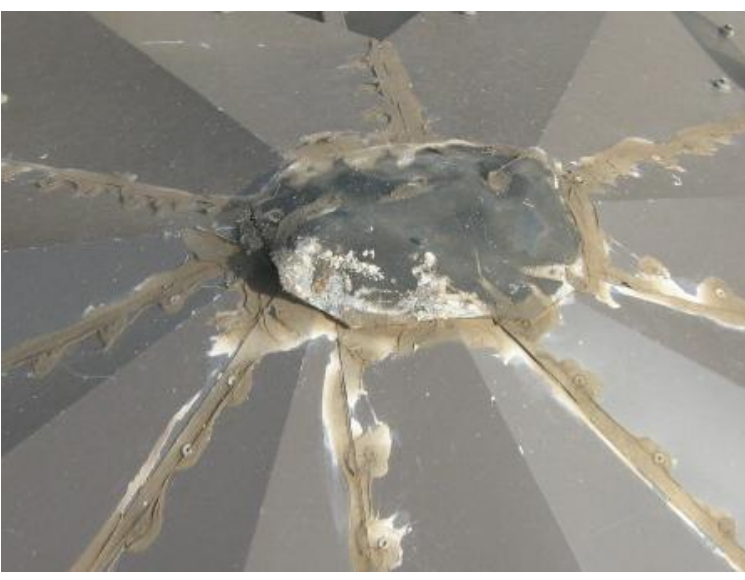

FR-H-1: Flashing patch is allowing water to penetrate the roofing system.

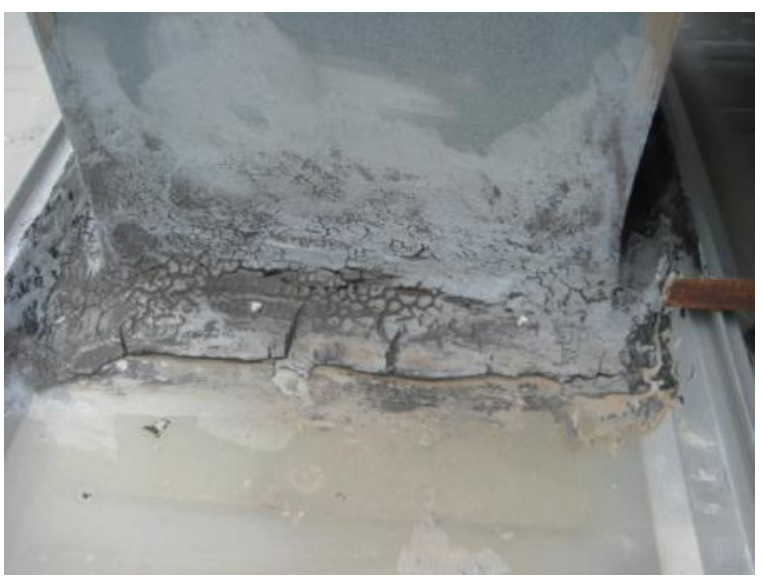

FR-H-1: Flashing patch is allowing water to penetrate the roofing system. 


\section{Metal Panel Distresses}

\section{Section-Wide Surface Deterioration (SW)}

\section{Description}

Degradation of factory-applied finish on the panel, such as colored paint, clear coat, anodized finish; degradation of the field-applied coating; or metal corrosion. This defect should be used to characterize an entire roof section. For localized areas of surface deterioration, use the Localized Surface Deterioration distress.

\section{Severity levels}

Low

1. Applied finish exhibits chalking, fading, or scratching over the entire roof section, but underlying corrosion is not apparent.

\section{Medium}

1. Base metal or applied finish exhibits chalking, fading, or scratching over the entire roof section, requiring a coating or surface treatment repair.

High

1. Base metal exhibits corrosion over the entire roof section, requiring a roof replacement.

\section{Measurement}

By definition, count the square feet of the entire area of the roof section.

\section{Density}

By definition, count the entire area of the roof section. 


\section{SW reference photographs}

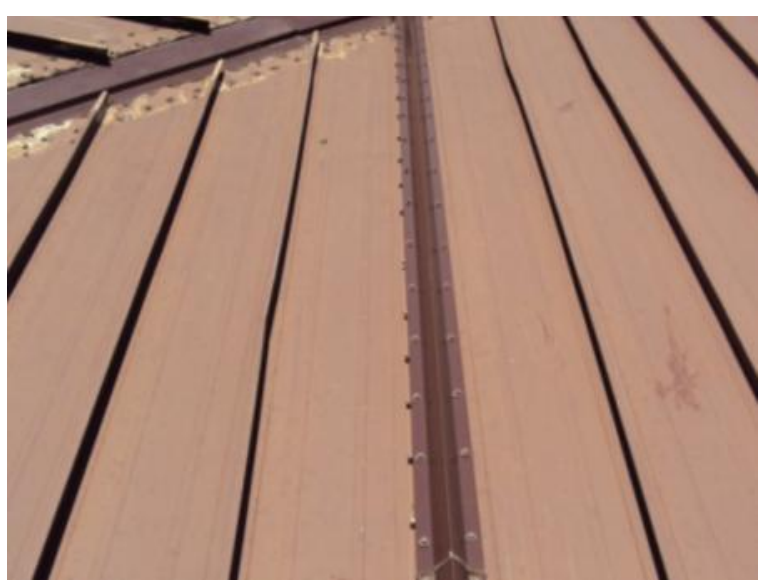

SW-L-1: Applied finish exhibits chalking, fading, or scratching over the entire roof section, but underlying corrosion is not apparent.

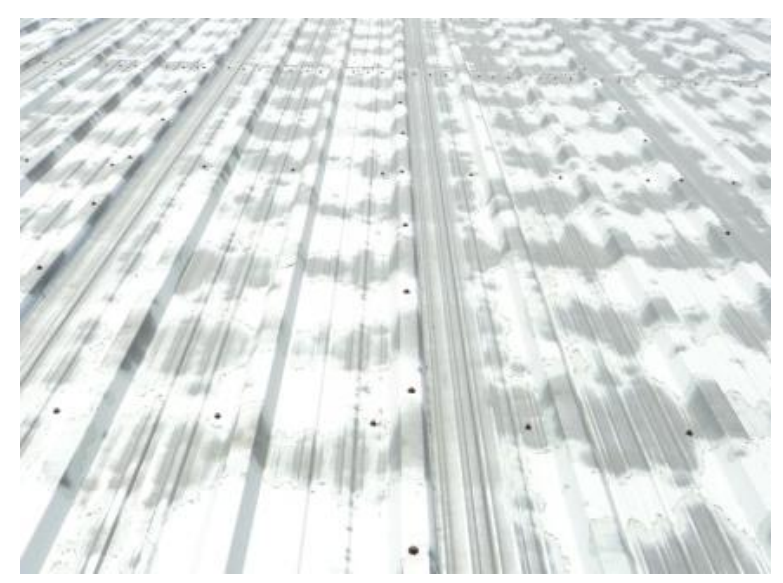

SW-M-1: Base metal or applied finish exhibits chalking, fading, or scratching over the entire roof section, requiring a coating or surface treatment repair.

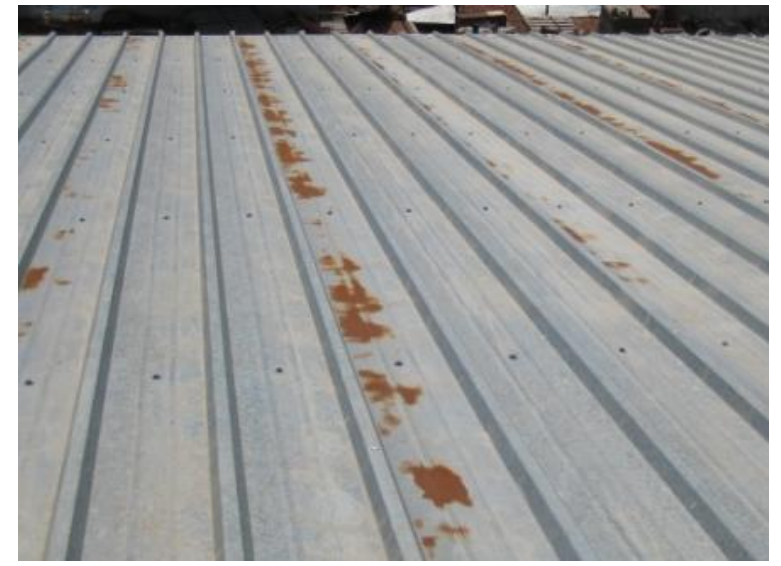

SW-M-1: Base metal or applied finish exhibits chalking, fading, or scratching over the entire roof section, requiring a coating or surface treatment repair.

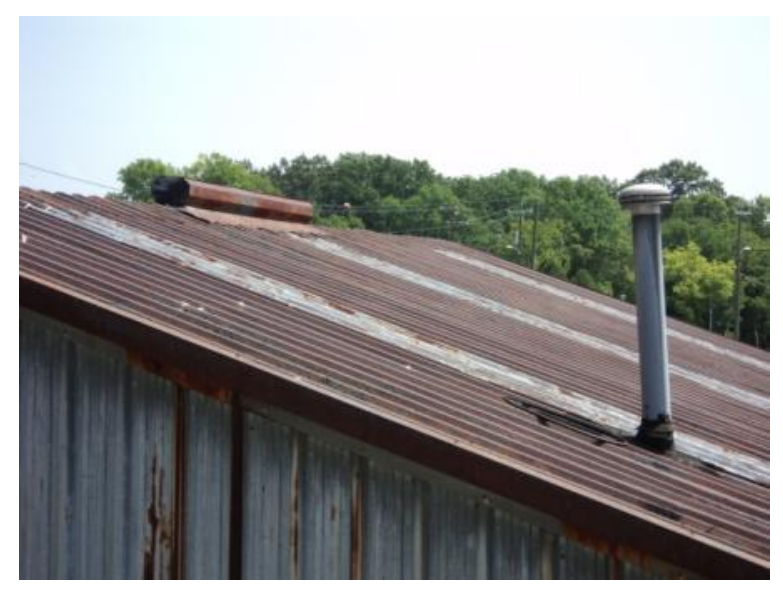

SW-H-1: Base metal exhibits corrosion over the entire roof section requiring a roof replacement. 


\section{Localized Surface Deterioration (SD)}

\section{Description}

Degradation of factory-applied finish on the panel, such as colored paint, clear coat, anodized finish; degradation of the field-applied coating; or metal corrosion

\section{Severity levels}

\section{Medium}

1. Localized loss of applied finish or localized metal corrosion.

2. Metal panel finish exhibits degradation caused by grease, solvent, or oil drippings.

High

1. For panel system that has mechanically interlocked seams, panel has corrosion holes that require localized repair.

2. Metal panel finish exhibits degradation caused by grease, solvent or oil drippings that require panel replacement.

Note: Once any panel has a distress that requires panel replacement, do not count other distresses on that same panel.

Note: Due to mechanical seaming, mechanically interlocked panels are typically difficult to replace, and localized repairs would likely be made in lieu of panel replacement.

\section{Measurement}

For M-1, M-2, and H-1 defects, measure the square feet of defective panel area.

For $\mathrm{H}-2$ defect, measure the square feet of each entire defective panel. (Repair requires replacement of the entire panel.)

When large quantities of this problem are present, especially on large roofs, the representative sampling technique can be used. 


\section{Density}

$$
\text { Problem Density }=\frac{A}{B} \times 100
$$

$A=$ Area of surface deterioration or area of defective panels ( $\mathrm{sq} \mathrm{ft}$ ).

$\mathrm{B}=$ Total area of roof section being rated (sq $\mathrm{ft}$ ).

Note: The problem density is calculated for each observed severity level.

\section{SD reference photographs}

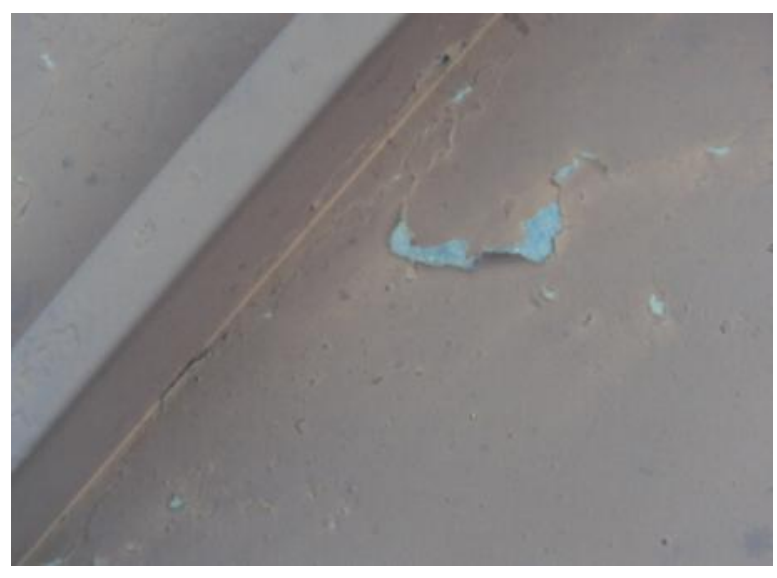

SD-M-1: Localized loss of applied finish or localized metal corrosion.

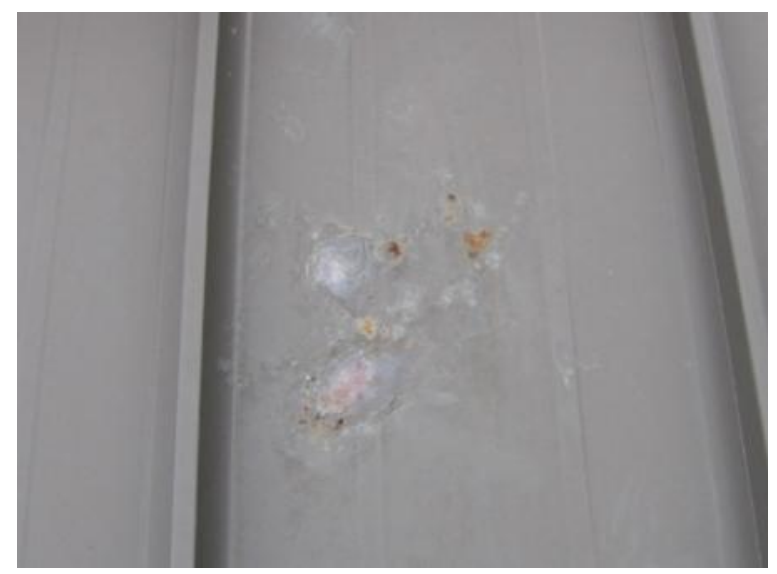

SD-H-1: For panel system that has mechanically interlocked seams, panel has corrosion holes that require localized repair.

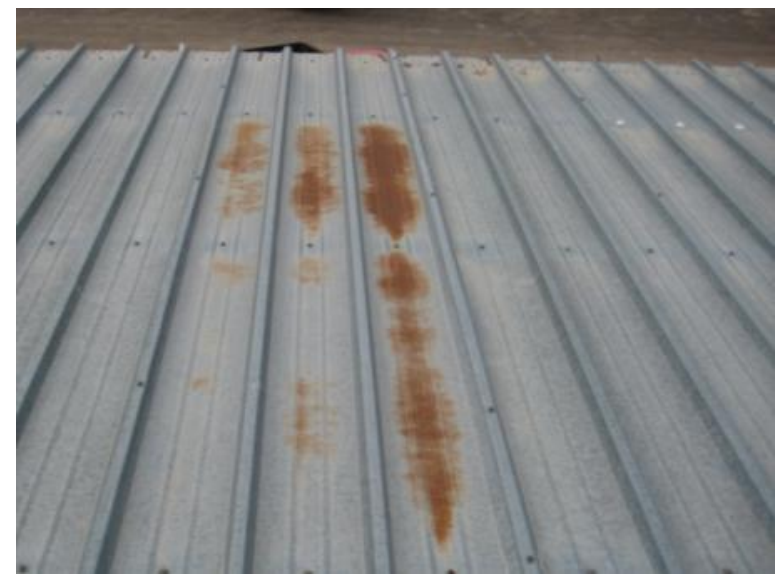

SD-M-1: Localized loss of applied finish or localized metal corrosion. 


\section{Panel Fastener Defect (PF)}

\section{Description}

This defect pertains to fasteners that penetrate any part of the panel. Fasteners can be screws that may have gaskets and/ or washers, or various types of rivets and nails. All fasteners with the fastener head or washer against flashing metal and the fastener not penetrating the panel are accounted for as flashing fastener distress.

\section{Severity levels}

\section{Medium}

1. Fastener has no flexible gasket (where one was originally installed) or has a flexible gasket that is deteriorating but appears to be watertight; or fastener is corroded, improperly seated, or has a sealant repair but appears to be watertight.

\section{High}

1. Fastener, flexible gasket (where one was originally installed) and/or metal washer is loose, deteriorated, or missing; allowing water to penetrate the roofing system; or fastener has an enlarged hole that is allowing water to penetrate the roofing system.

\section{Measurement}

Count the total number of defective fasteners.

\section{Density}

$$
\text { Problem Density }=\frac{A}{B} \times 100
$$

A = Number of defective fasteners (count) for separate cap, integral cap, and mechanically interlocked seam systems.

$\mathrm{B}=$ Total area of roof section being rated (sq ft).

For lap seam systems

$\mathrm{B}=$ Total number of panel fasteners (count). 
Note: The problem density is calculated for each observed severity level.

\section{PF reference photographs}

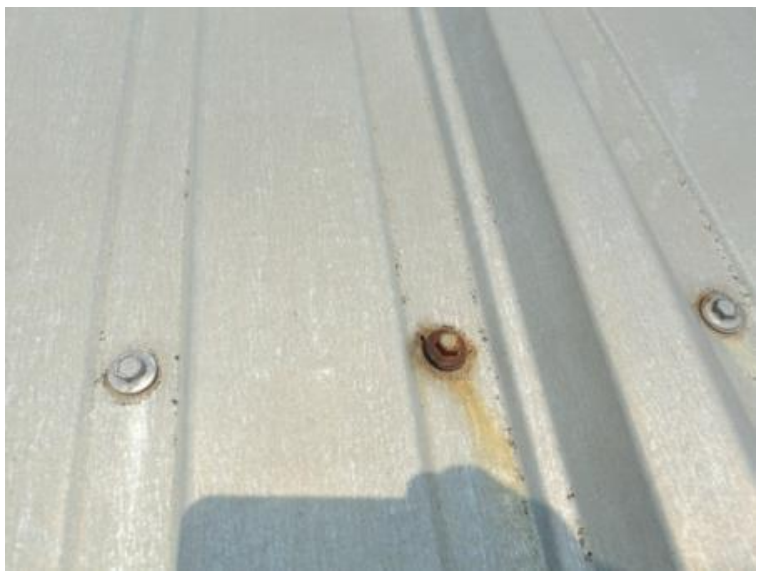

PF-M-1: Fastener has no flexible gasket (where one was originally installed) or has a flexible gasket that is deteriorating but appears to be watertight; or fastener is corroded, improperly seated, or has a sealant repair but appears to be watertight.

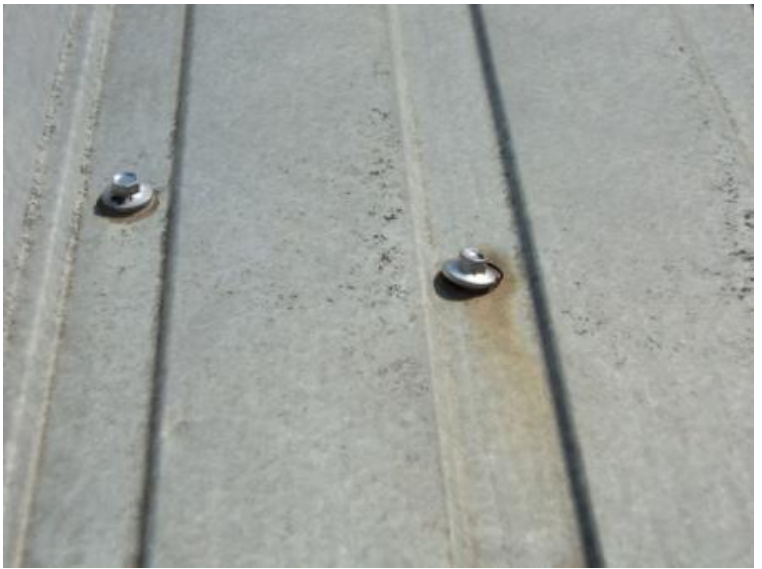

PF-H-1: Fastener, flexible gasket (where one was originally installed) and/or metal washer is loose, deteriorated or missing; allowing water to penetrate the roofing system; or fastener has an enlarged hole that is allowing water to penetrate the roofing system. 


\section{Damaged Panel (DP)}

\section{Description}

Dented deformed or kinked panel; or holes, splits, or tears in the panel.

Note: Oil canning of the panel is not considered a defect because it is primarily an aesthetic issue and does not require repair.

\section{Severity levels}

Low

1. Panel is dented, deformed, or kinked with no deformation of the seam, no loss of coating, and no corrosion; appears to be watertight.

\section{Medium}

1. Panel is dented, deformed or kinked, allowing ponding water and/ or corrosion.

\section{High}

1. For panel system that has mechanically interlocked seams, panel has holes, splits, or tears that require localized repairs.

2. For panel system that does not have mechanically interlocked seams, panel has holes, splits, or tears that require panel replacement.

Note: Once any panel has a distress that requires panel replacement, do not count other distresses on that same panel.

Note: Due to mechanical seaming, mechanically interlocked panels are typically difficult to replace, and localized repairs would likely be made in lieu of panel replacement.

\section{Measurement}

For L-1, M-1, and H-1 defects, measure the square feet of affected panel area. If the distance between holes, splits, or tears are less than $1 \mathrm{ft}$, count them as one defect.

For H-2 defect, measure surface area of each entire distressed panel. (Repair requires replacement of entire panel.) 


\section{Density}

$$
\text { Problem Density }=\frac{A}{B} \times 100
$$

$\mathrm{A}=$ Area of damaged panel or area of defective panels (sq $\mathrm{ft}$ ).

$\mathrm{B}=$ Total area of roof section being rated (sq $\mathrm{ft}$ ).

Note: The problem density is calculated for each observed severity level.

\section{DP reference photographs}

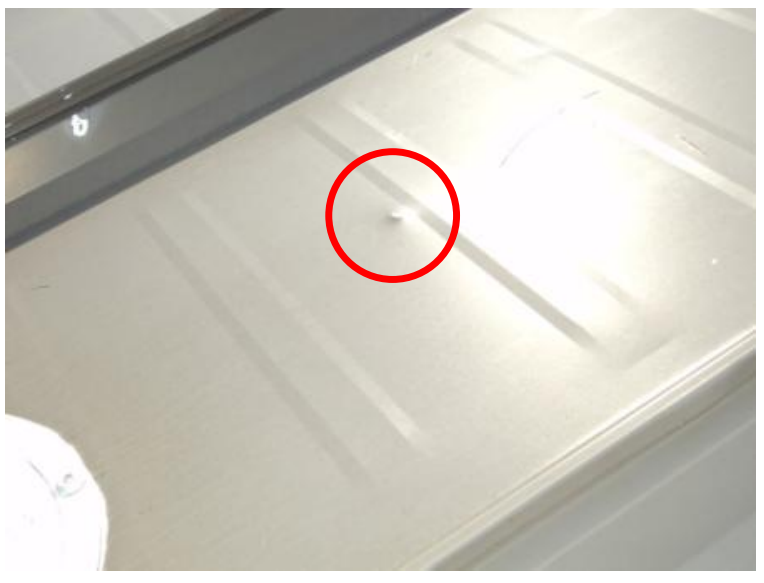

DP-L-1: Panel is dented, deformed, or kinked with no deformation of the seam, no loss of coating, and no corrosion; and appears to be watertight.

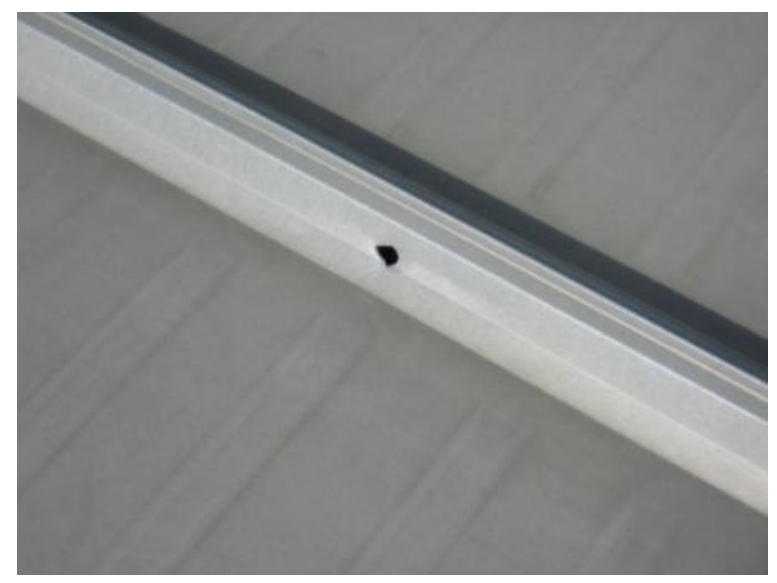

DP-H-1: For panel system that has mechanically interlocked seams, panel has holes, splits, or tears that require localized repairs.

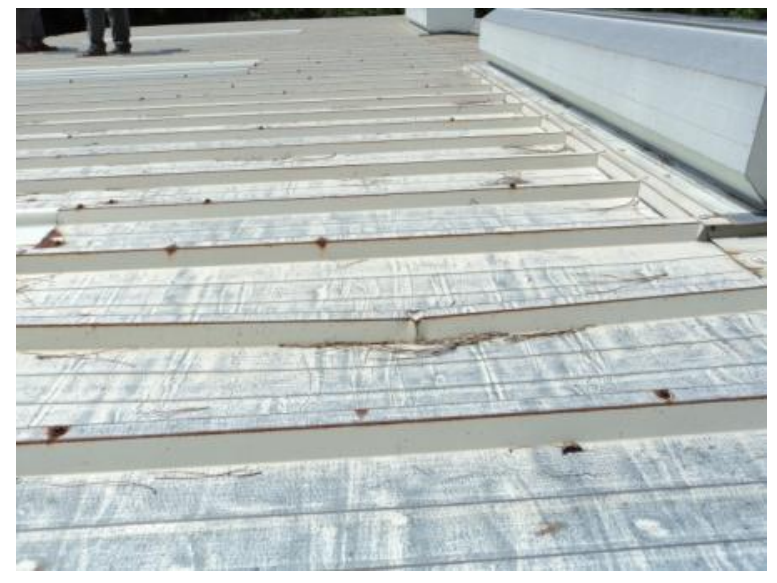

DP-M-1: Panel is dented, deformed or kinked, allowing ponding water and/or corrosion.

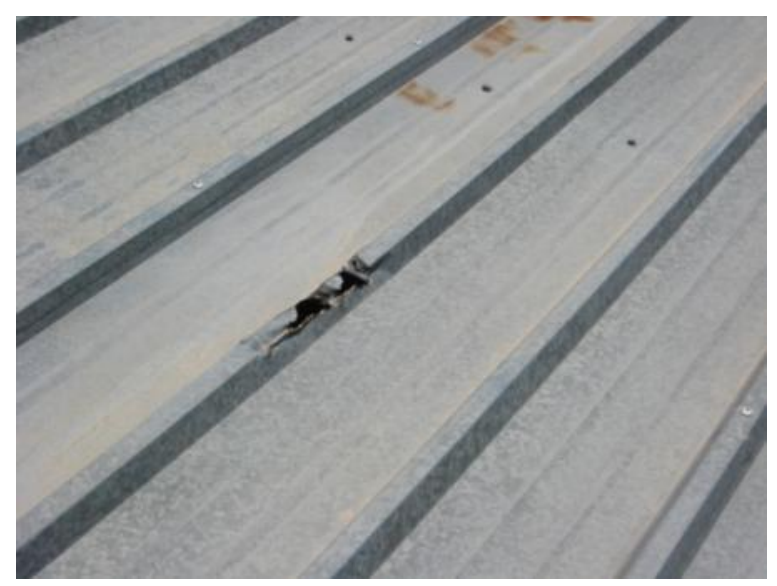

DP-H-2: For panel system that does not have mechanically interlocked seams; panel has holes, splits, or tears that require panel replacement. 


\section{Displaced Panel (DL)}

\section{Description}

Displaced or missing panels.

\section{Severity levels}

High

1. Panel is loose or displaced and requires repositioning and resecurement.

2. Panel is missing and requires replacement.

Note: Once any panel has a distress that requires panel replacement, do not count other distresses on that same panel.

\section{Measurement}

Measure the square feet of the area of each entire distressed panel.

\section{Density}

$$
\text { Problem Density }=\frac{A}{B} \times 100
$$

$\mathrm{A}=$ Area of displaced panels (sq $\mathrm{ft}$ ).

$\mathrm{B}=$ Total area of roof section being rated (sq $\mathrm{ft}$ ).

Note: The problem density is calculated for each observed severity level.

\section{DL reference photograph}

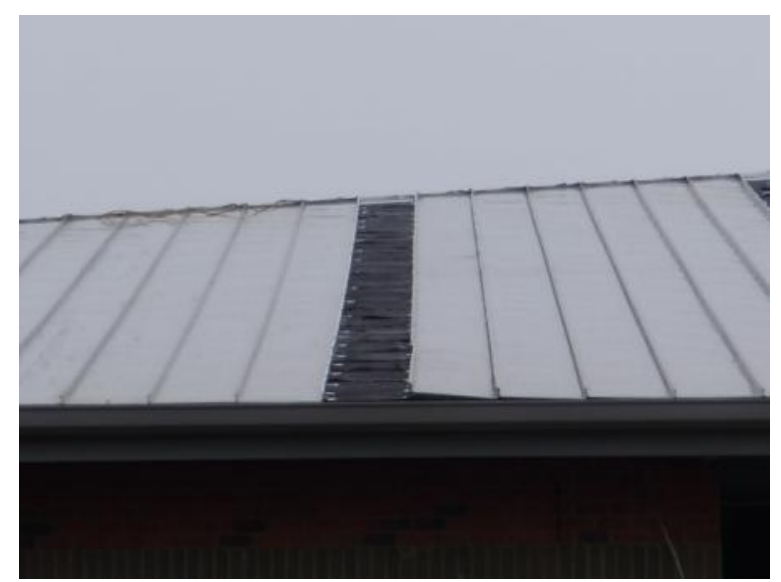

DL-H-2: Panel is missing and requires replacement. 


\section{Panel Patch (PA)}

\section{Description}

Post-construction application of material applied to the metal panel that is intended as a repair. Topical application of sealant that is not performing a waterproofing function is not considered a panel patch. Random application of sealant is not considered as patching.

Note: A replacement panel with the same profile, same materials, and same construction as the existing metal panel system is not considered a panel patch.

Note: A fastener that penetrates a panel that has sealant repair is counted as a panel fastener distress.

\section{Severity levels}

Low

1. Panel patch appears to be watertight, and does not require a more permanent repair.

\section{Medium}

1. Panel patch appears to be watertight and requires a more permanent repair.

\section{High}

1. Panel patch is allowing water to penetrate the roofing system.

\section{Measurement}

Measure the square feet of the panel patch.

When large quantities of this problem are present, especially on large roofs, a representative sampling technique can be used.

\section{Density}

$$
\text { Problem Density }=\frac{A}{B} \times 100
$$



$\mathrm{A}=$ Area of patching (sq ft).
$\mathrm{B}=$ Total area of roof section being rated (sq $\mathrm{ft}$ ).

Note: The problem density is calculated for each observed severity level.

\section{PA reference photographs}

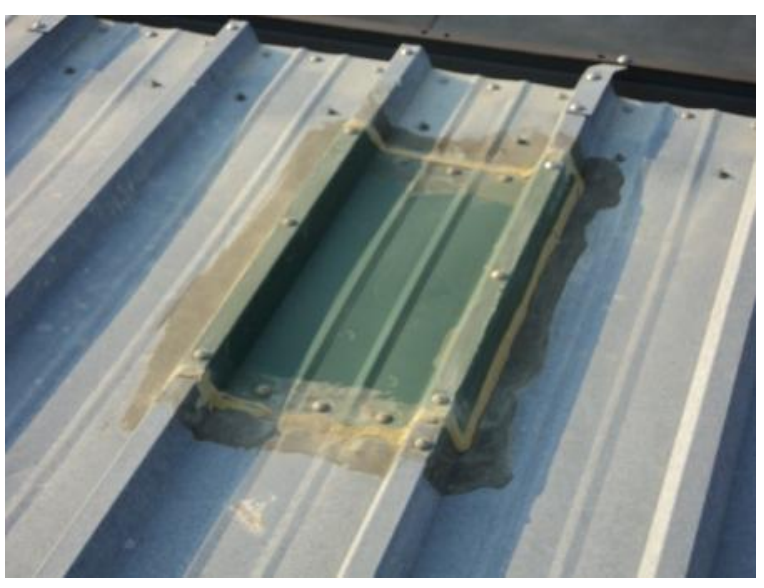

PA-L-1: Panel patch appears to be performing a waterproofing function, appears to be watertight, and does not require a more permanent repair.

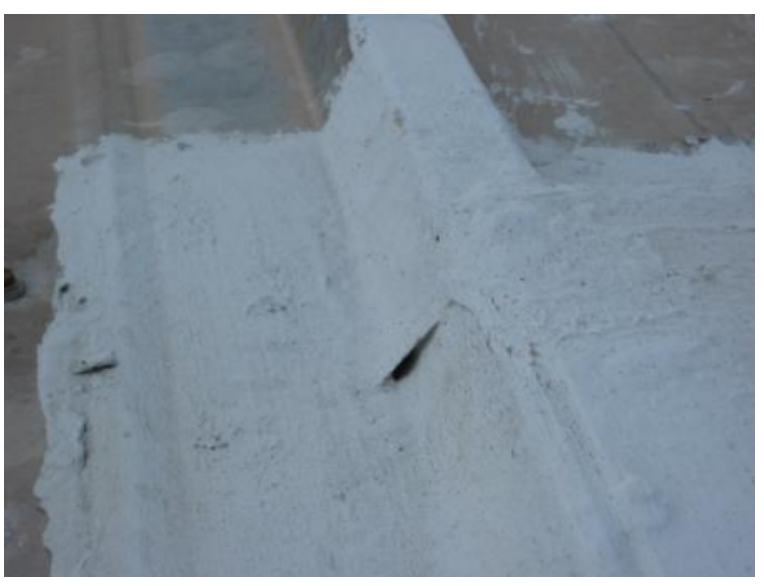

$\mathrm{PA}-\mathrm{H}-1$ : Panel patch is allowing water to penetrate the roofing system. 


\section{Debris and Vegetation (DV)}

\section{Description}

The accumulation of debris on the roof including foreign objects, vegetation that is growing on the roof, or grease, solvent or oil that is on the surface of the roof. Algae growth and related staining that does not affect the finish is not considered a defect because it does not affect performance, and is primarily an aesthetic problem.

Note: Grease, solvent, or oil drippings that have caused deterioration of the metal panel finish are considered to be panel surface deterioration defects.

\section{Severity levels}

\section{Medium}

1. A collection of foreign objects or vegetation not removed from the roof during the inspection; or grease, solvent, or oil drippings on the roof that cause no degradation of the panel's applied finish.

2. Evidence of tree branches making contact with the roofing system.

\section{Measurement}

Measure the square feet of the affected area. Each isolated case of debris and vegetation of less than $1 \mathrm{sq} \mathrm{ft}$ in area should be counted as $1 \mathrm{sq} \mathrm{ft}$.

\section{Density}

$$
\text { Problem Density }=\frac{A}{B} \times 100
$$

$\mathrm{A}=$ Area of debris and vegetation (sq ft).

$\mathrm{B}=$ Total area of roof section being rated (sq ft).

Note: The problem density is calculated for each observed severity level. 


\section{DV reference photographs}

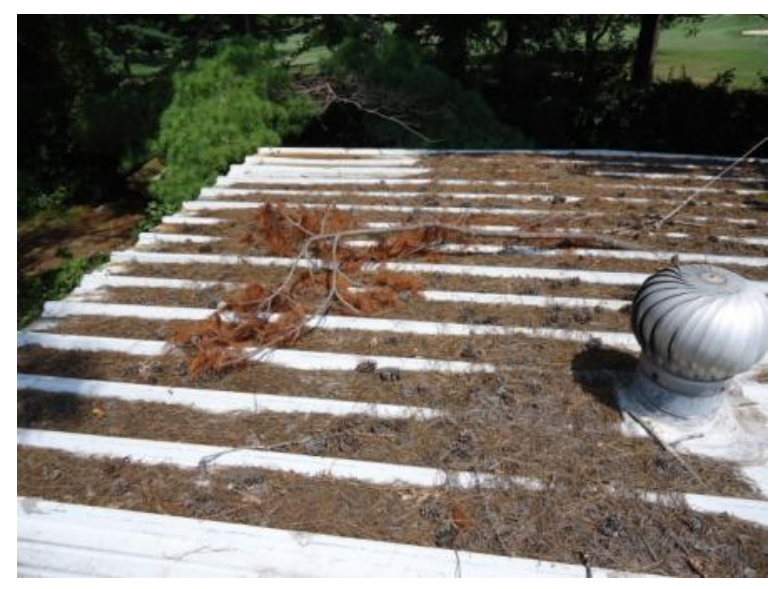

DV-M-1: A collection of foreign objects or vegetation not removed from the roof during the inspection; or grease, solvent, or oil drippings on the roof that cause no degradation of the panel's applied finish.

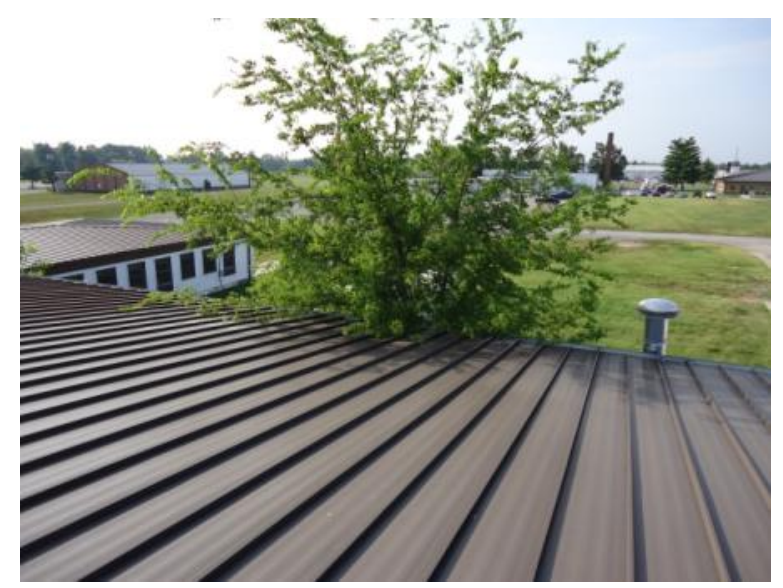

DV-M-2: Evidence of tree branches making contact with the roofing system.

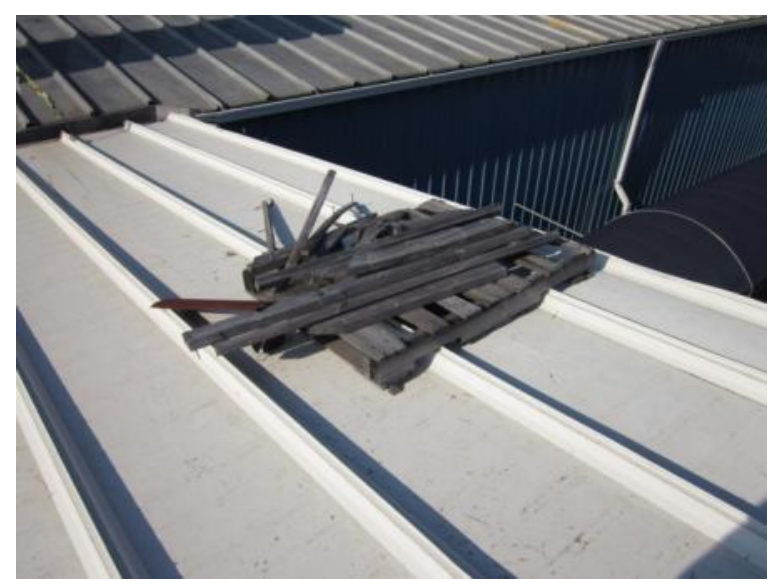

DV-M-1: A collection of foreign objects or vegetation not removed from the roof during the inspection; or grease, solvent, or oil drippings on the roof that cause no degradation of the panel's applied finish. 


\section{Improper Equipment Supports (EQ)}

\section{Description}

Improper equipment supports can includes pipe, conduit, and mechanical equipment supports (wood sleepers, channels, etc.) that are placed directly on the roof surface and/ or anchored to the roof with penetrating fasteners.

Note: Equipment supports that are appropriately clamped to the seams and not to the flat of the panel are not considered improper equipment supports.

\section{Severity levels}

Low

1. All improper equipment supports are rated low severity as a minimum due to the maintenance problems associated with them.

\section{Medium}

1. The equipment support is bolted or fastened through the metal panel seam flashing and the bolt(s) appear to be sealed and watertight.

2. The equipment support has caused damage to surrounding panels but appears to be watertight.

High

1. The equipment support is bolted or fastened through the metal panel seams or flashing and allowing water to penetrate the roofing system.

2. The equipment support has caused damage to surrounding panels and is allowing water to penetrate the roofing system.

\section{Measurement}

Measure square feet of each improper equipment support. The minimum dimension for length and width of a support shall be $1 \mathrm{ft}$.

\section{Density}

$$
\text { Problem Density }=\frac{A}{B} \times 100
$$




\section{$\mathrm{A}=$ Area of improper equipment supports (sq $\mathrm{ft}$ ). \\ $\mathrm{B}=$ Total area of roof section being rated (sq $\mathrm{ft}$ ).}

Note: The problem density is calculated for each observed severity level.

\section{EQ reference photographs}

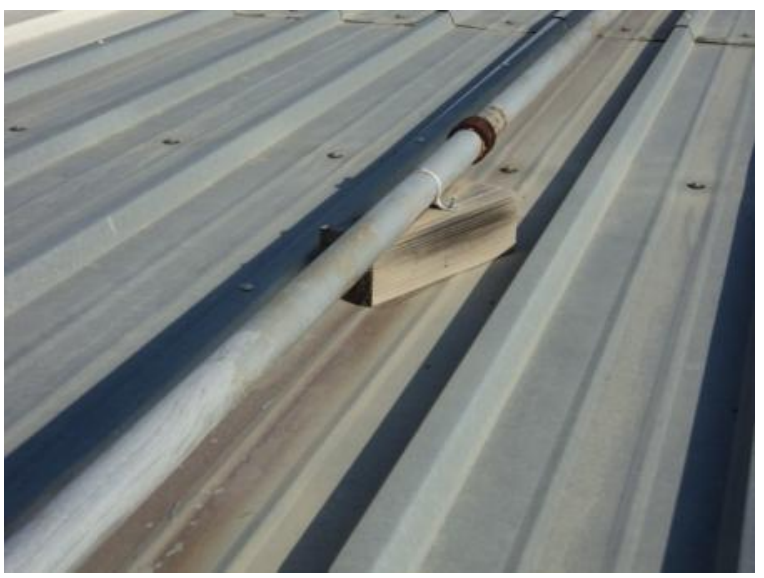

EQ-L-1: All improper equipment supports are rated low severity as a minimum due to the maintenance problems associated with them.

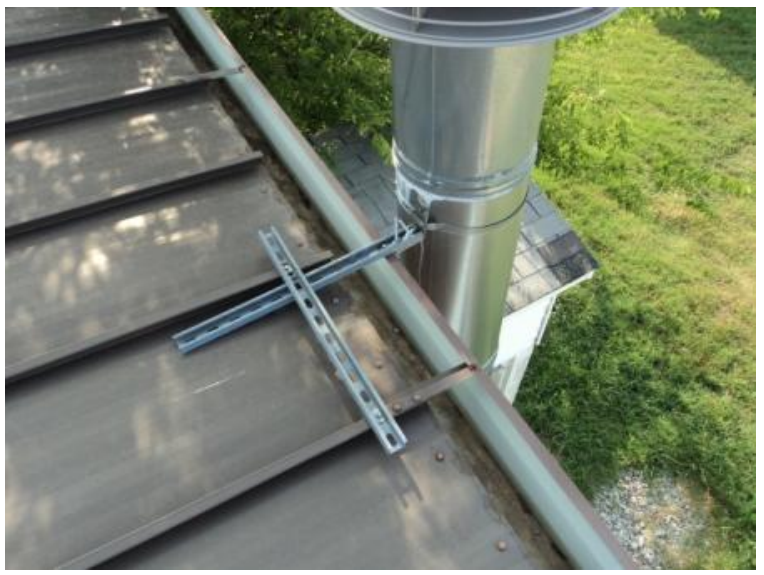

EQ-H-1: The equipment support is bolted or fastened through the metal panel seams or flashing and allowing water to penetrate the roofing system.

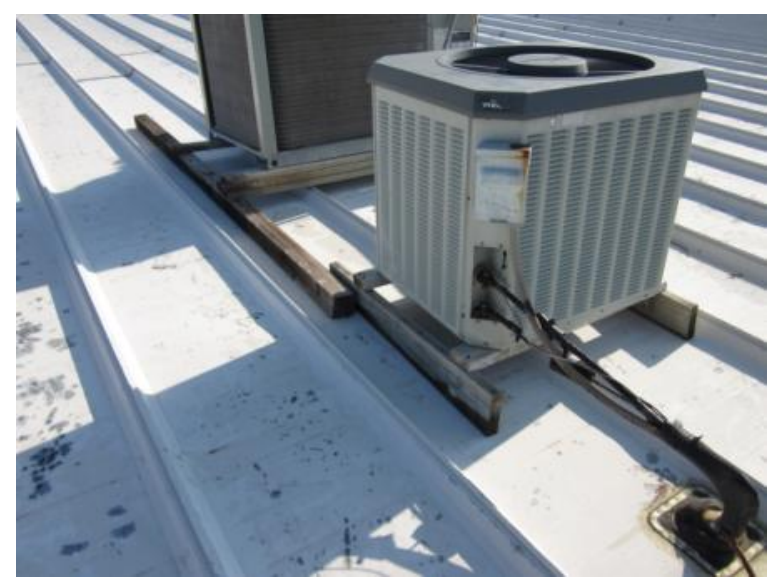

EQ-L-1: All improper equipment supports are rated low severity as a minimum due to the maintenance problems associated with them.

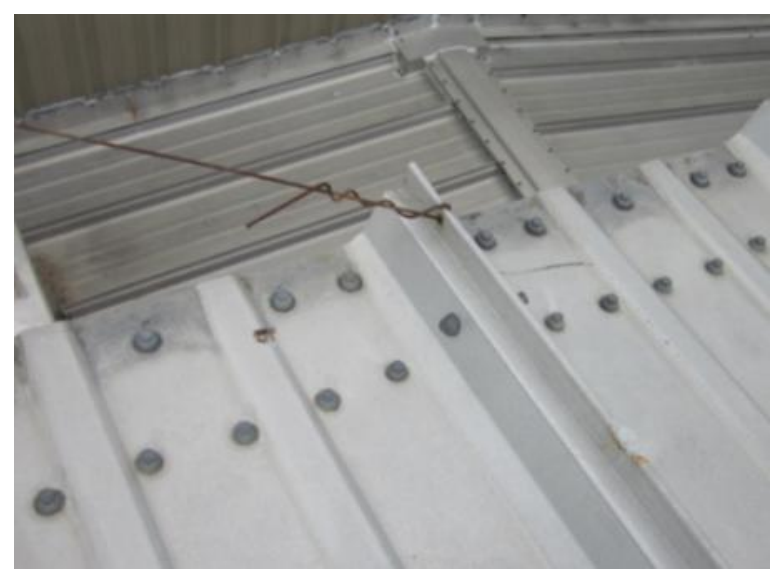

EQ-H-1: The equipment support is bolted or fastened through the metal panel seams or flashing and allowing water to penetrate the roofing system. 


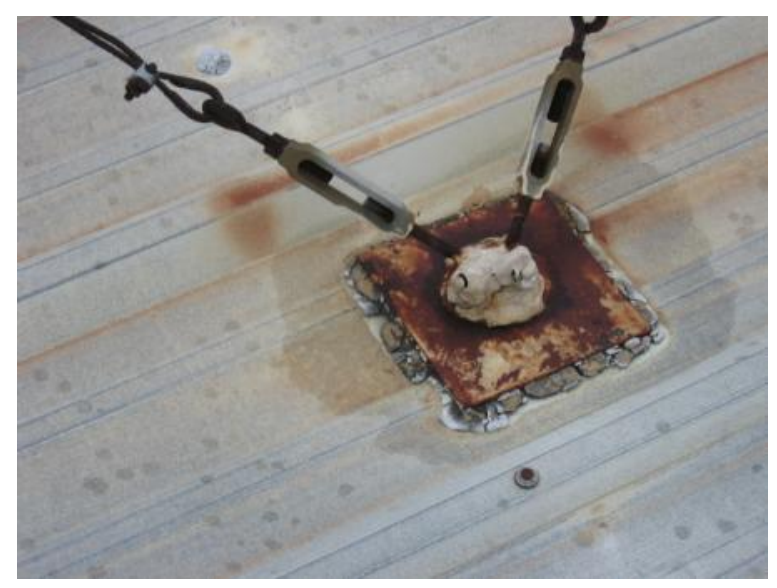

EQ-H-2: The equipment support has caused damage to surrounding panels and is allowing water to penetrate the roofing system. 


\section{Mechanically Interlocked Seam Defect (MS)}

\section{Description}

For mechanically interlocked seams, the seam is damaged or has become disengaged.

\section{Severity levels}

Low

1. Seam is deformed or flattened but appears to be watertight.

High

1. Seam is open or allowing water to penetrate the roofing system; or seam is disengaged.

\section{Measurement}

Measure the lineal feet of defective seam.

Density

$$
\text { Problem Density }=\frac{A}{B} \times 100
$$

$A=$ Length of defective seams (lf).

$\mathrm{B}=$ Total area of roof section being rated (sq ft). 


\section{MS reference photographs}

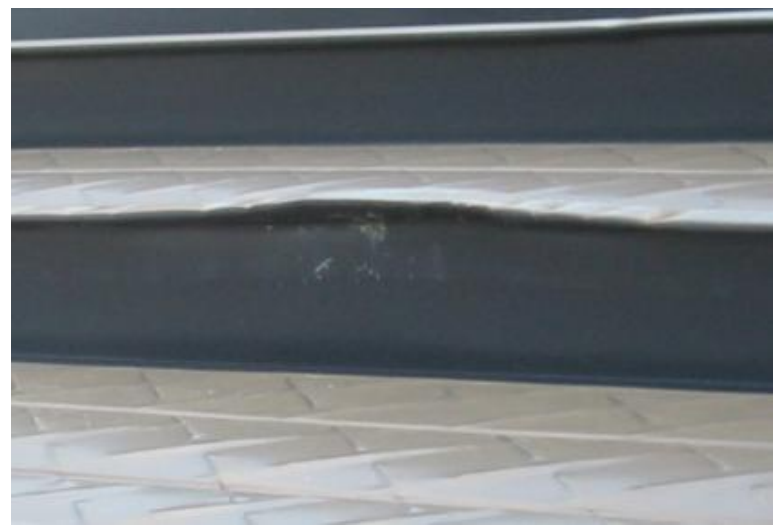

MS-L-1: Seam is deformed or flattened but appears to be watertight.

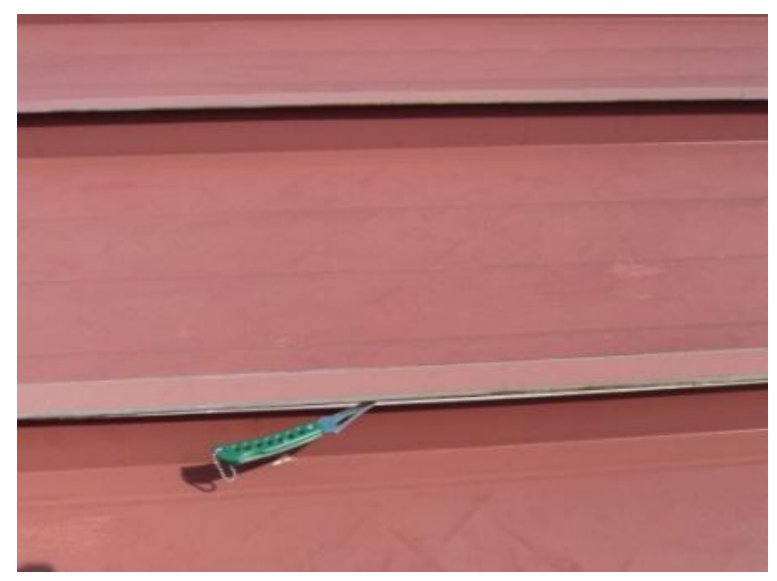

MS-H-1: Seam is open or allowing water to penetrate the roofing system; or seam is disengaged.

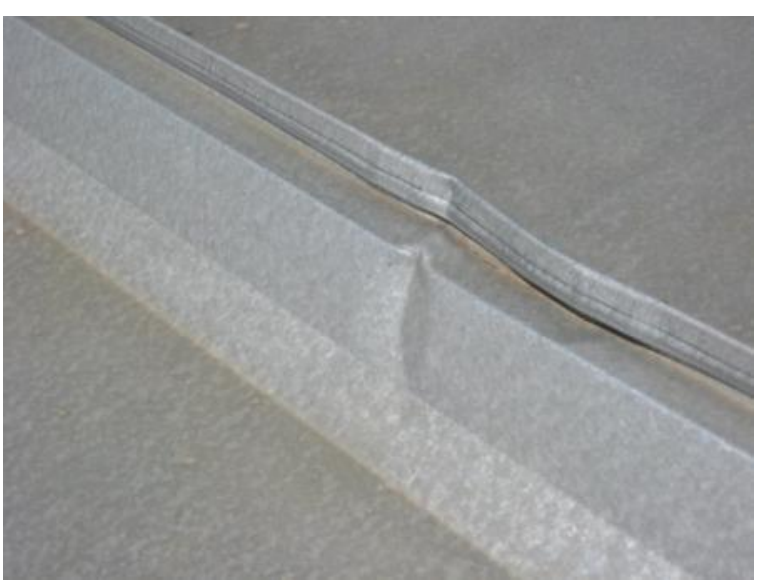

MS-L-1: Seam is deformed or flattened but appears to be watertight.

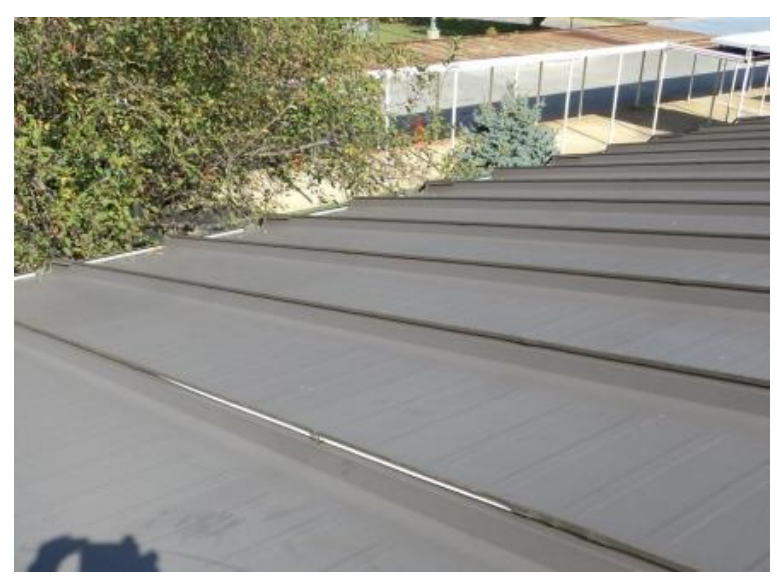

MS-H-1: Seam is open or allowing water to penetrate the roofing system; or seam is disengaged. 


\section{Integral Cap Seam Defect (IC)}

\section{Description}

For integral cap seams, the seam is damaged or has become disengaged.

\section{Severity levels}

Low

1. Seam is deformed or flattened, but still engaged and appears to be watertight.

High

1. Seam is disengaged and requires localized repair.

2. Seam is disengaged due to panel deformation and requires panel replacement.

Note: Once any panel has a distress that requires panel replacement, do not count other distresses on that same panel.

\section{Measurement}

For L-1 and H-1 defects, measure the lineal feet of defective seams. If the distance between defects is less than 1 foot, include the length between defects

For H-2 defect, measure the square feet of the entire area of the affected panel. (Repair requires replacement of entire panel.)

\section{Density}

$$
\text { Problem Density }=\frac{A}{B} \times 100
$$

$A=$ Length of defective seams (lf) or area of defective panels (sq ft).

$\mathrm{B}=$ Total area of roof section being rated (sq ft).

Note: The problem density is calculated for each observed severity level. 


\section{Separate Cap Seam Defect (SC)}

\section{Description}

For separate cap seam, the seam is deformed, flattened, has not been sufficiently locked to cleat, or has become disengaged; or cap is missing.

\section{Severity levels}

Low

1. Seam is deformed or flattened, but still engaged and appears to be watertight.

High

1. Seam is disengaged, requiring localized repair.

2. Seam is damaged or missing, requiring cap replacement.

3. Panel is damaged at seam location, requiring panel and cap replacement.

Note: Once any panel has a distress that requires panel replacement, do not count other distresses on that same panel.

\section{Measurement}

For L-1, H-1 and H-2 defects, measure the lineal feet of defective seams. If the distance between defects is less than 1 foot, include the length between defects.

For H-3 defect, measure the square feet of the entire area of both adjacent panels. (Repair requires replacement of entire panel.)

\section{Density}

$$
\text { Problem Density }=\frac{A}{B} \times 100
$$

A = Length of defective seams (lf) or area of defective panels (sq ft).

$\mathrm{B}=$ Total area of roof section being rated (sq ft).

Note: The problem density is calculated for each observed severity level. 


\section{Lap Seam Defect (LS)}

\section{Description}

Lap seam is open or deformed.

\section{Severity levels}

High

1. Seam is open with no panel deformation, requiring localized repair.

2. Seam is open due to panel deformation, requiring panel replacement.

Note: Once any panel has a distress that requires panel replacement, do not count other distresses on that same panel.

Note: If seam is open due to misalignment of the panel, the defect should be counted as a displaced panel.

\section{Measurement}

For H-1 defect, measure the lineal feet of defective seams. If the distance between defects is less than 1 foot, include the length between defects.

For H-2 defect, measure the square feet of the entire area of the panels. (Repair requires replacement of entire panel.)

\section{Density}

$$
\text { Problem Density }=\frac{A}{B} \times 100
$$

$A=$ Length of defective seams or area of defective panels (sq $\mathrm{ft}$ ).

$\mathrm{B}=$ Total area of roof section being rated (sq $\mathrm{ft}$ ).

Note: The problem density is calculated for each observed severity level. 


\section{LS reference photographs}

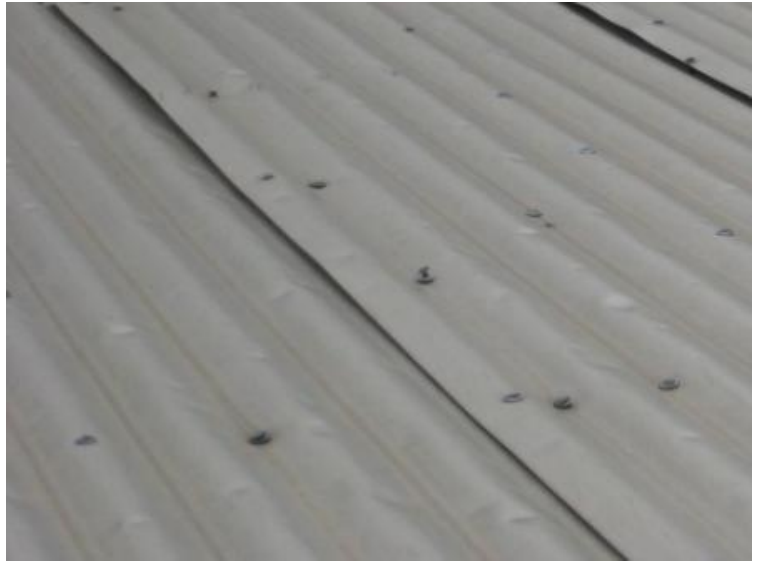

LS-H-1: Seam is open with no panel deformation, requiring localized repair.

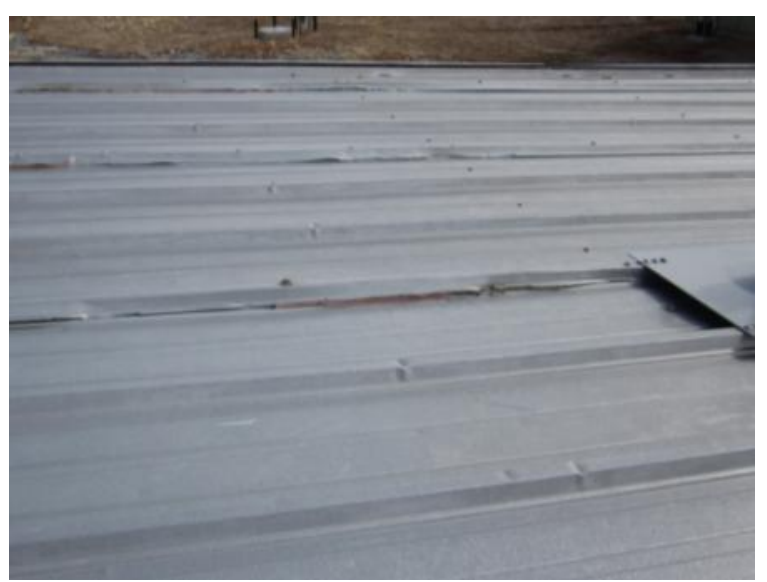

LS-H-2: Seam is open due to panel deformation, requiring panel replacement. 


\section{Transverse Panel Lap Defect (PL)}

\section{Description}

Defects in the panel end laps. Panel laps are transverse seams in the field of the panel or at the roof edge.

\section{Severity levels}

Medium

1. For cleated end lap, panel is disengaged from the cleat.

2. End lapjoint between panels has failed sealant or open fishmouths.

High

1. Transverse panel lap is bucking water.

\section{Measurement}

Determine the lineal feet of defect by counting the total number of defective panel end laps and multiplying by the panel width.

\section{Density}

$$
\text { Problem Density }=\frac{A}{B} \times 100
$$

A = Length of defective transverse panel end laps (lf).

$\mathrm{B}=$ total area of roof section being rated (sq ft).

Note: The problem density is calculated for each observed severity level. 


\section{PL reference photographs}

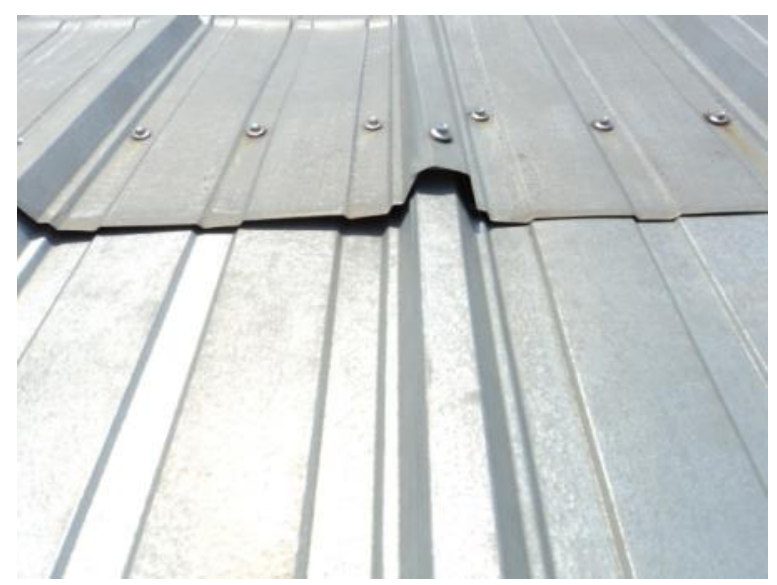

PL-M-2: End lap joint between panels has failed sealant or open fishmouths. 


\section{Integrated Skylight Panel Defect (SP)}

\section{Description}

Fiberglass skylights that are integrated into the roofing system. These panels typically have the same profile as the main roof panels and are installed in the same plane as the roof panels (not curbed). Integrated skylight panels are most often found in lap seam metal panel systems. Note that raised prefabricated skylights with curbs should be rated as flanged metal and raised curb flashings.

Note: These skylight panels can be very dangerous and should not be stepped on regardless of the age or condition of the panels. If no skylight cages are in place, enter a comment at visual inspection.

\section{Severity levels}

Low

1. Integrated skylight panels are rated low severity as a minimum due to their shorter service life as compared to the metal roofing system.

\section{Medium}

1. Skylight composite material exhibits visible fibers, significant discoloration, or other signs of degradation.

High

1. J oint between integrated skylight panel and adjacent metal panel is not watertight or is bucking water.

2. Integrated skylight panel has holes, splits, or tears, allowing water to penetrate the roofing system.

\section{Measurement}

Measure the square feet of the entire area of the integrated skylight panel.

\section{Density}

$$
\text { Problem Density } p=\frac{A}{B} \times 100
$$



$\mathrm{A}=$ Area of defective integrated skylight panels (sq ft).
$\mathrm{B}=$ Total area of roof section being rated (sq $\mathrm{ft}$ ).

Note: The problem density is calculated for each observed severity level.

\section{SP reference photographs}

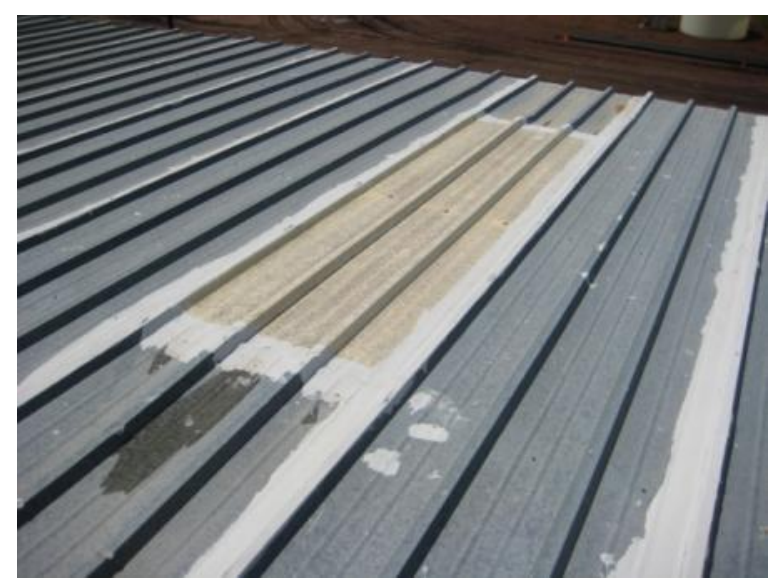

SP-L-1: Integrated skylight panels are rated low severity as a minimum due to their shorter service life as compared to the metal roofing system.

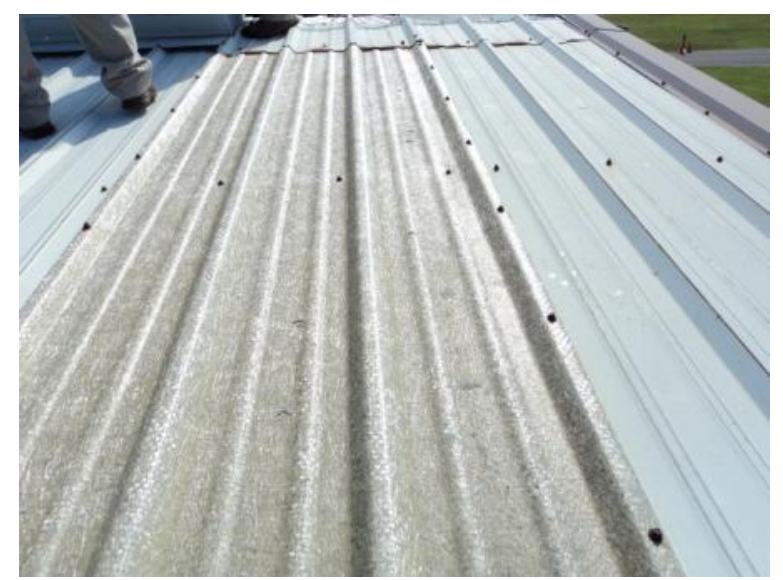

SP-M-1: Skylight composite material exhibits visible fibers, significant discoloration or other signs of degradation. 


\section{References}

Bailey, D.M. August 2003. MicroROOFER for Windows User Guide Version 2.0. ERDC/ CERL SR-03-8. Champaign, IL: US Army Engineer Research and Development Center, Construction Engineering Research Laboratory (ERDCCERL).

Bailey, D.M. December 1999. ROOFER: Steep Roofing Inventory Procedures and Inspection and Distress Manual for Asphalt Shingle Roofs, USACERL TR99/ 100/ADA378154. Champaign, IL: US Army Construction Engineering Research Laboratory (USACERL).

Bailey, D.M. March 2010. Membraneand Flashing Condition Indexes for Modified Bitumen Roofs. ERDC/ CERL Technical Report TR-10-5. Champaign, IL: ERDCCERL.

Bailey, D.M., D.E. Brotherson, W. Tobiasson, S. Foltz, and A. Knehans. April 1993. ROOFER: Membrane and Flashing Condition Indexes for Single-Ply Membrane Roofs - Inspection and Distress Manual. USACERL TR FM-93/ 11/ADA272573. Champaign, IL: USACERL.

Bailey, D.M., D. Brotherson, W. Tobiasson, and A. Knehans. December 1989. ROOFER: An Engineered Management System (EMS) For Bituminous Built-Up Roofs. USACERL TR M-90/ 04/ ADA218529. Champaign, IL: USACERL.

Shahin, M.Y., D. Bailey, and D. Brotherson. September 1978a. Membrane and Flashing Condition Indexes for Built-Up Roofs Volume I: Development of the Procedure, USACERL TR M-87/ 13/ ADA190367. Champaign, IL: USACERL.

Shahin, M.Y., D. Bailey, and D. Brotherson. September 1978b. Membrane and Flashing Condition Indexes for Built-Up Roofs Volume II: Inspection and Distress Manual, Technical ReportM-87/ 13/ ADA190368. Champaign, IL: USACERL. 


\section{Appendix A: Deduct Value Curves}
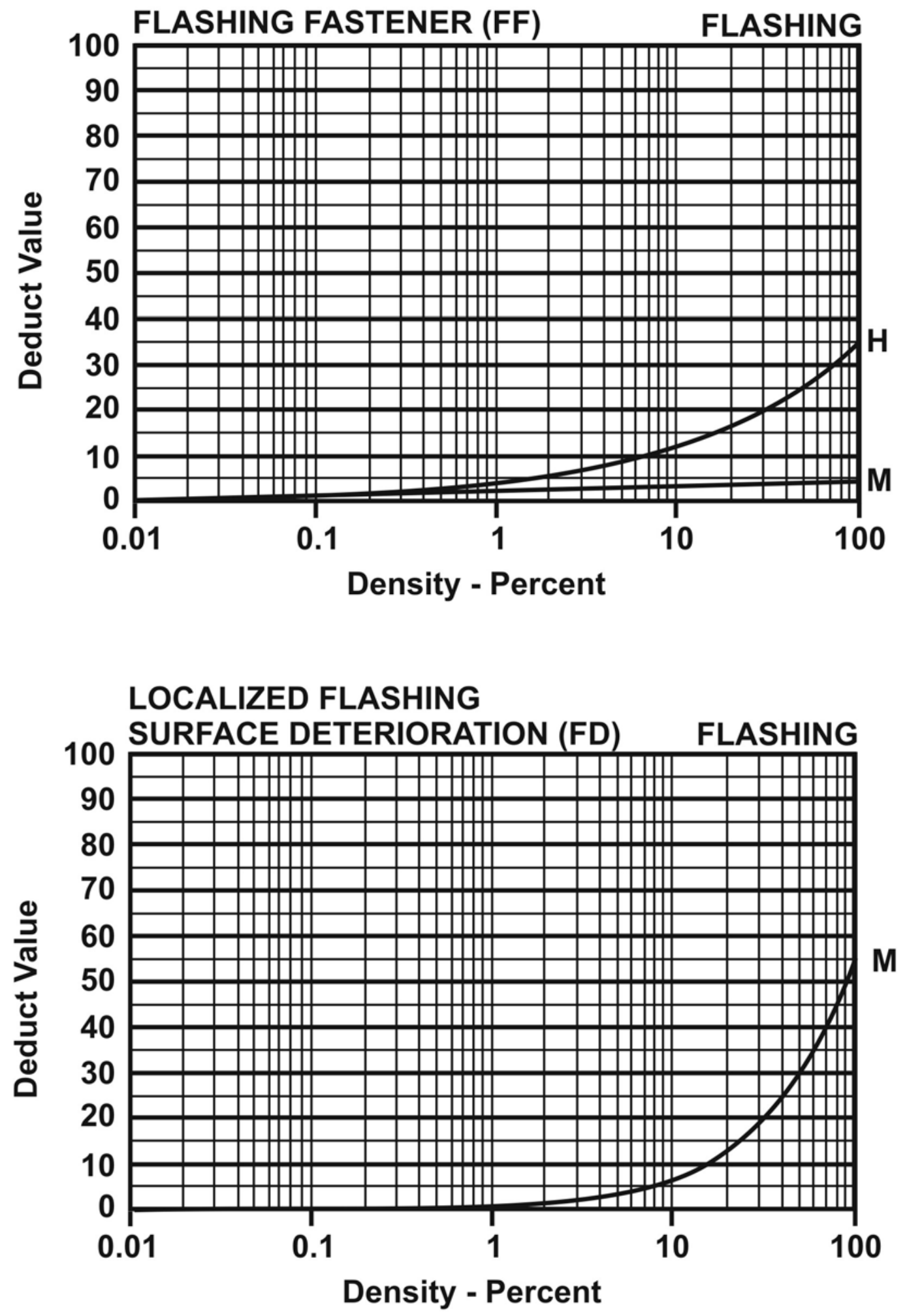

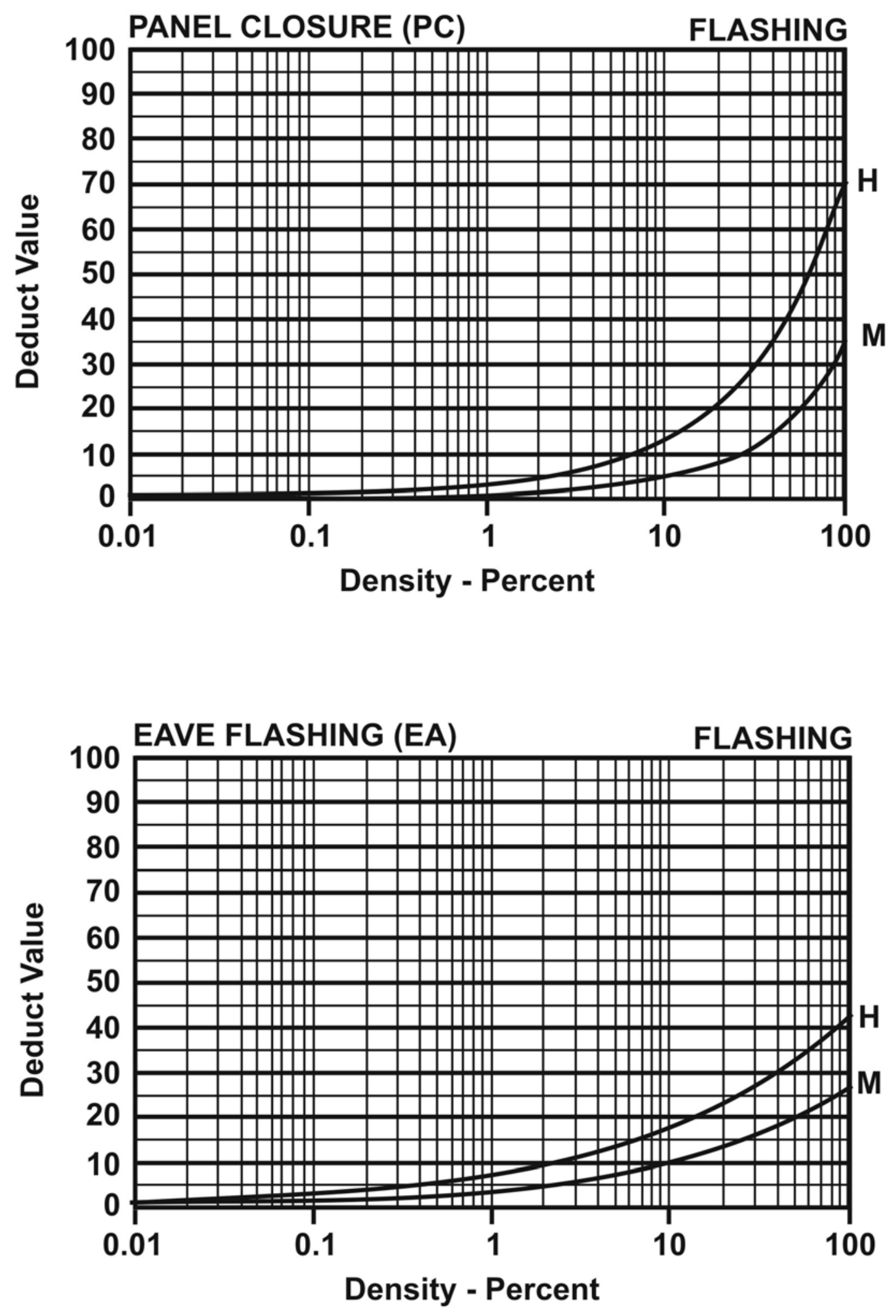

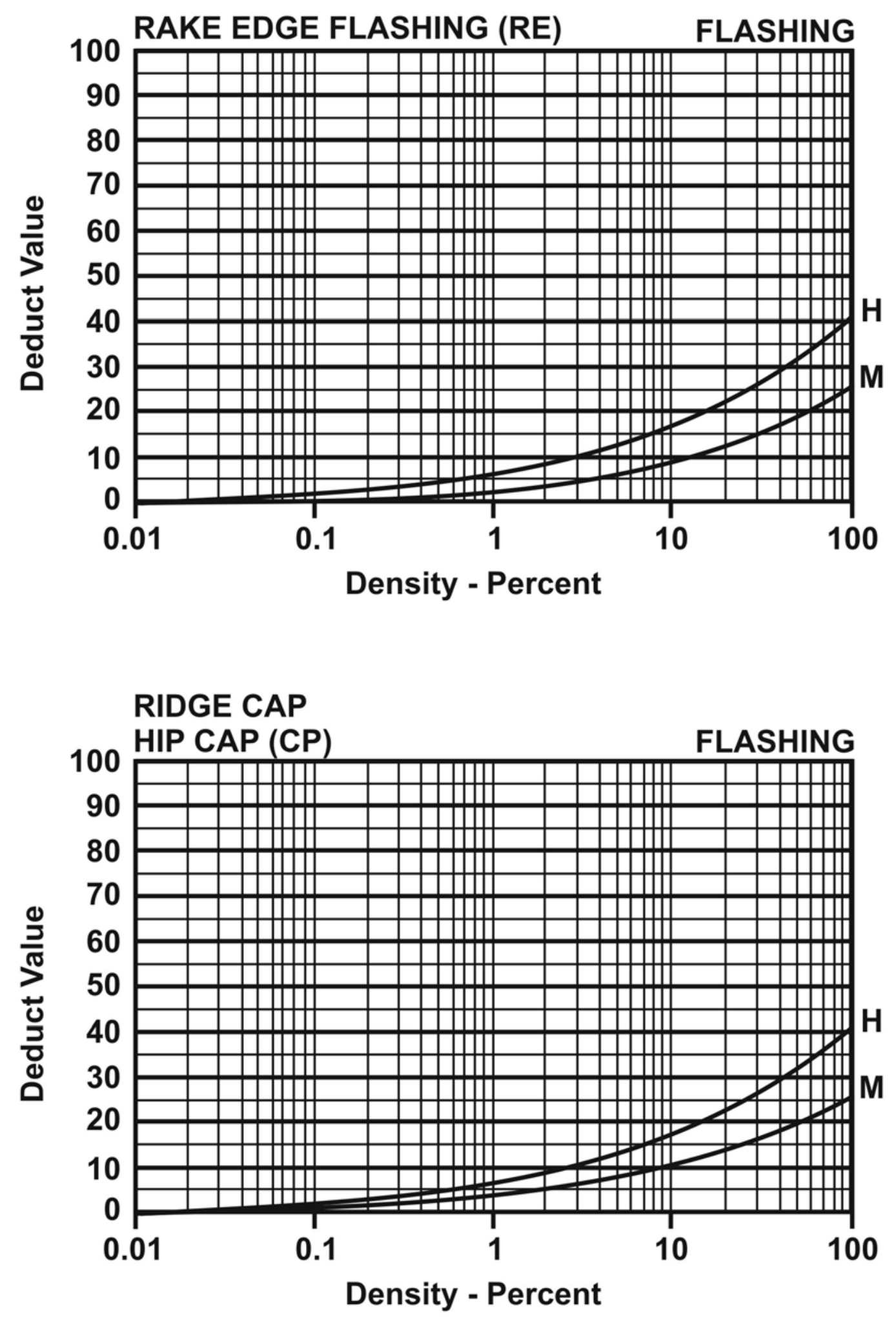

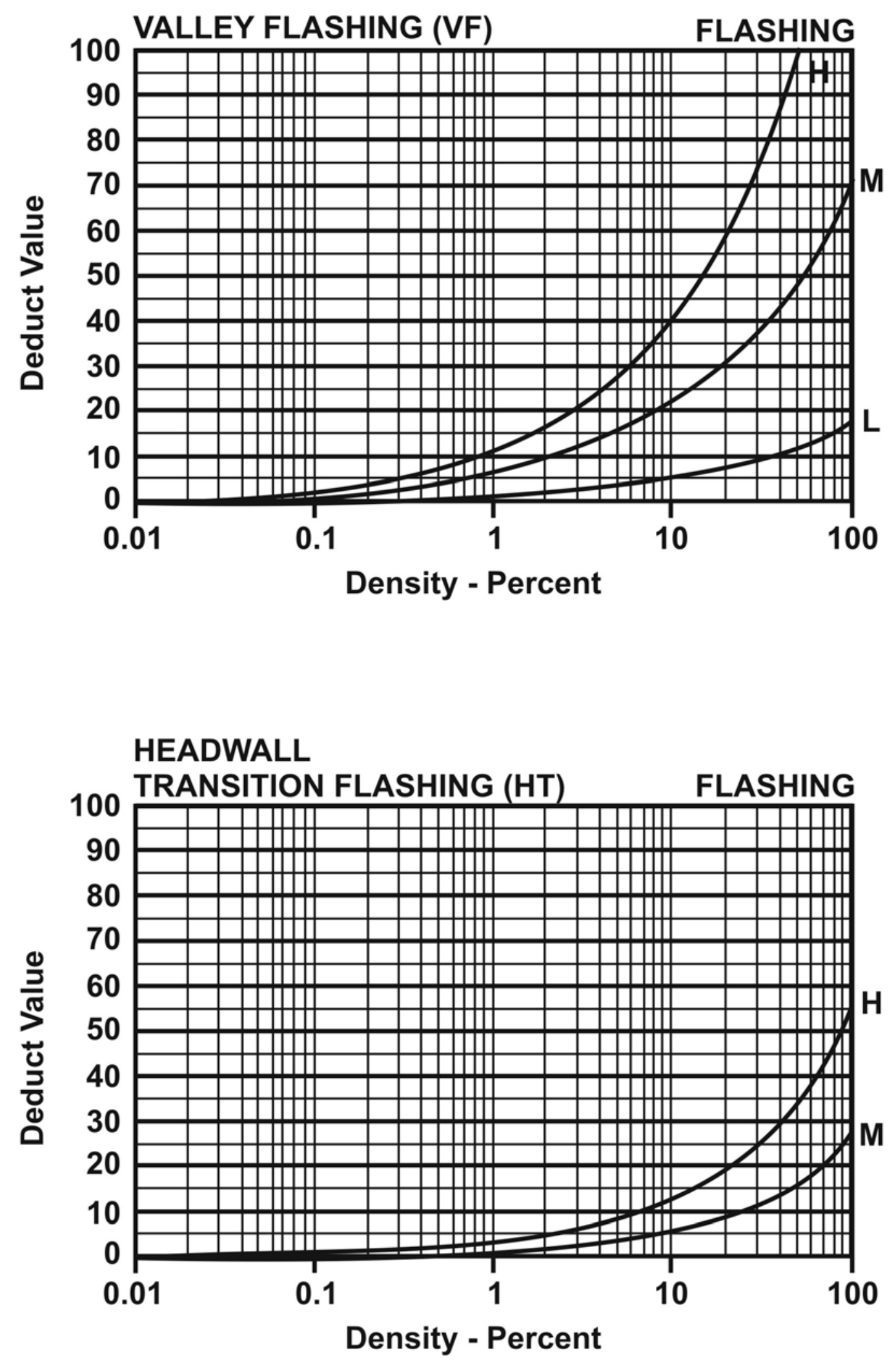

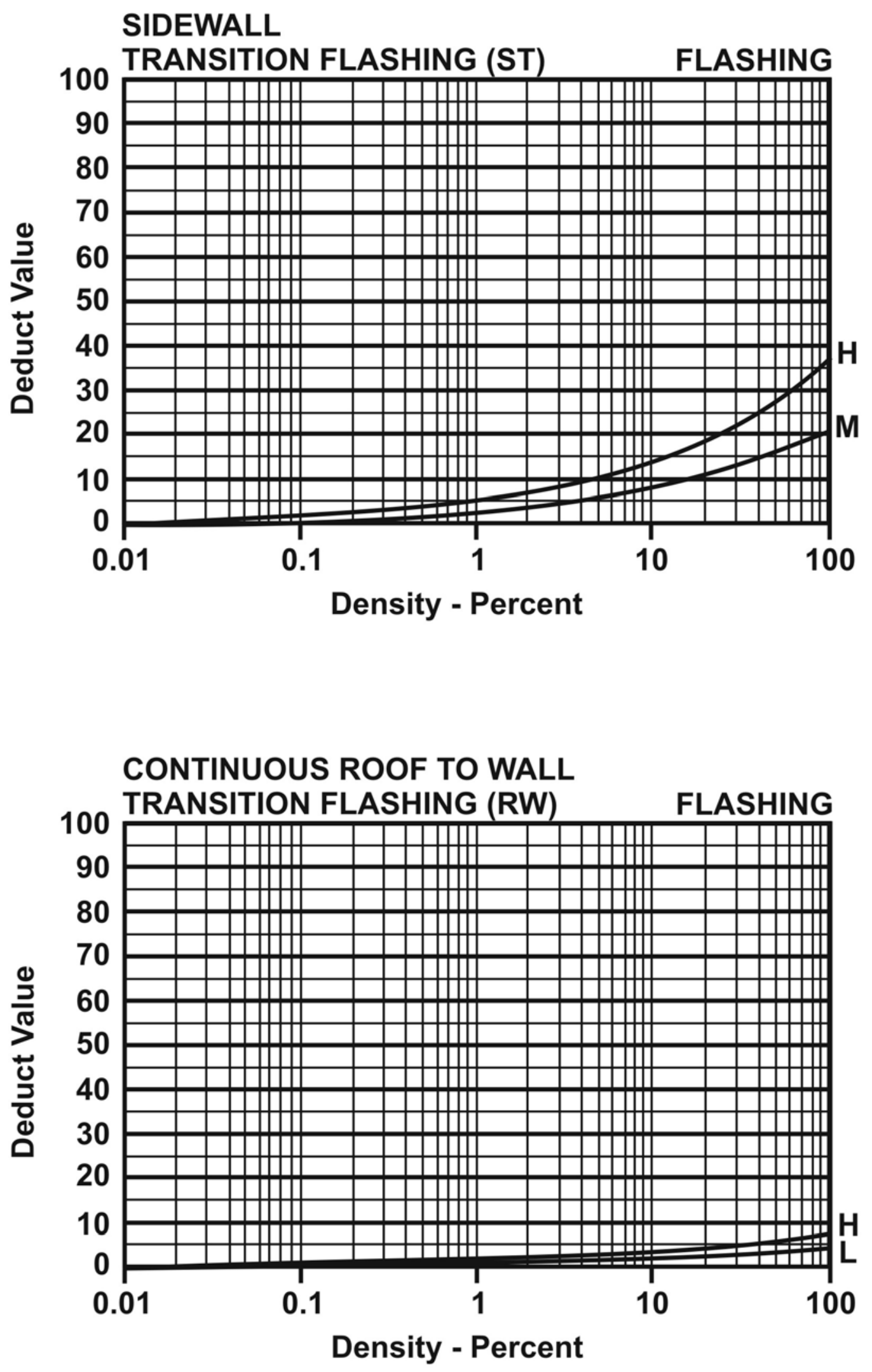


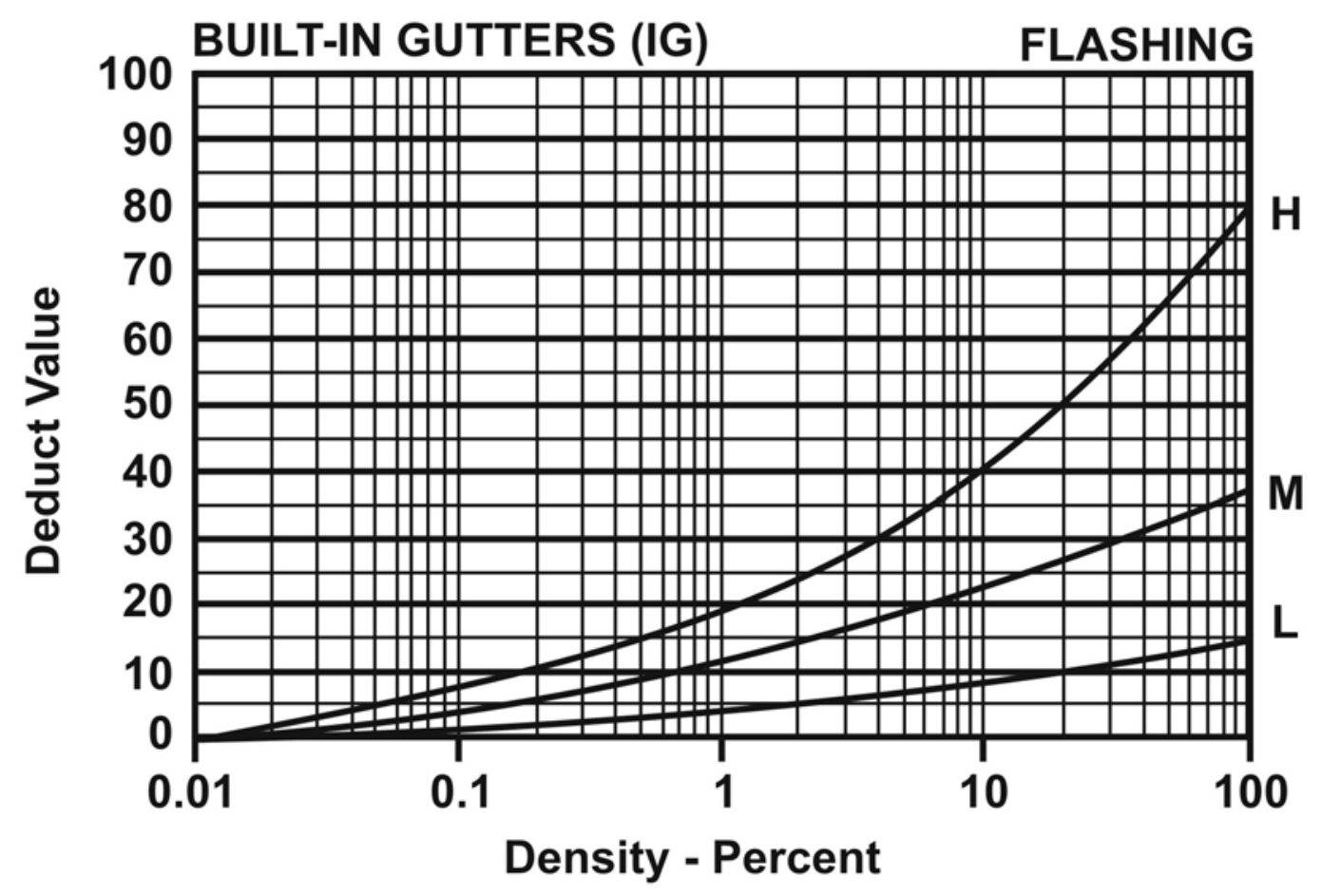

FLEXIBLE

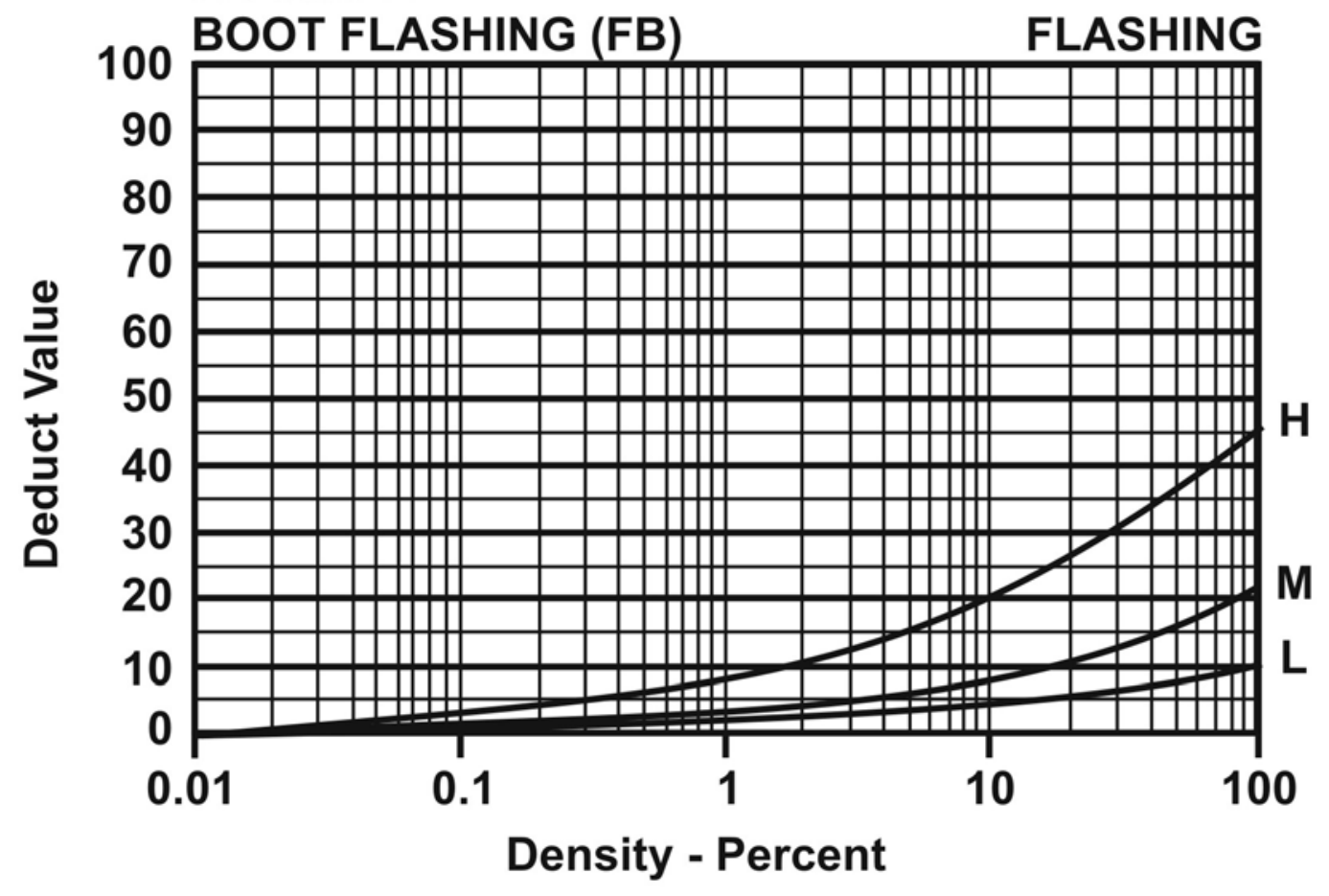



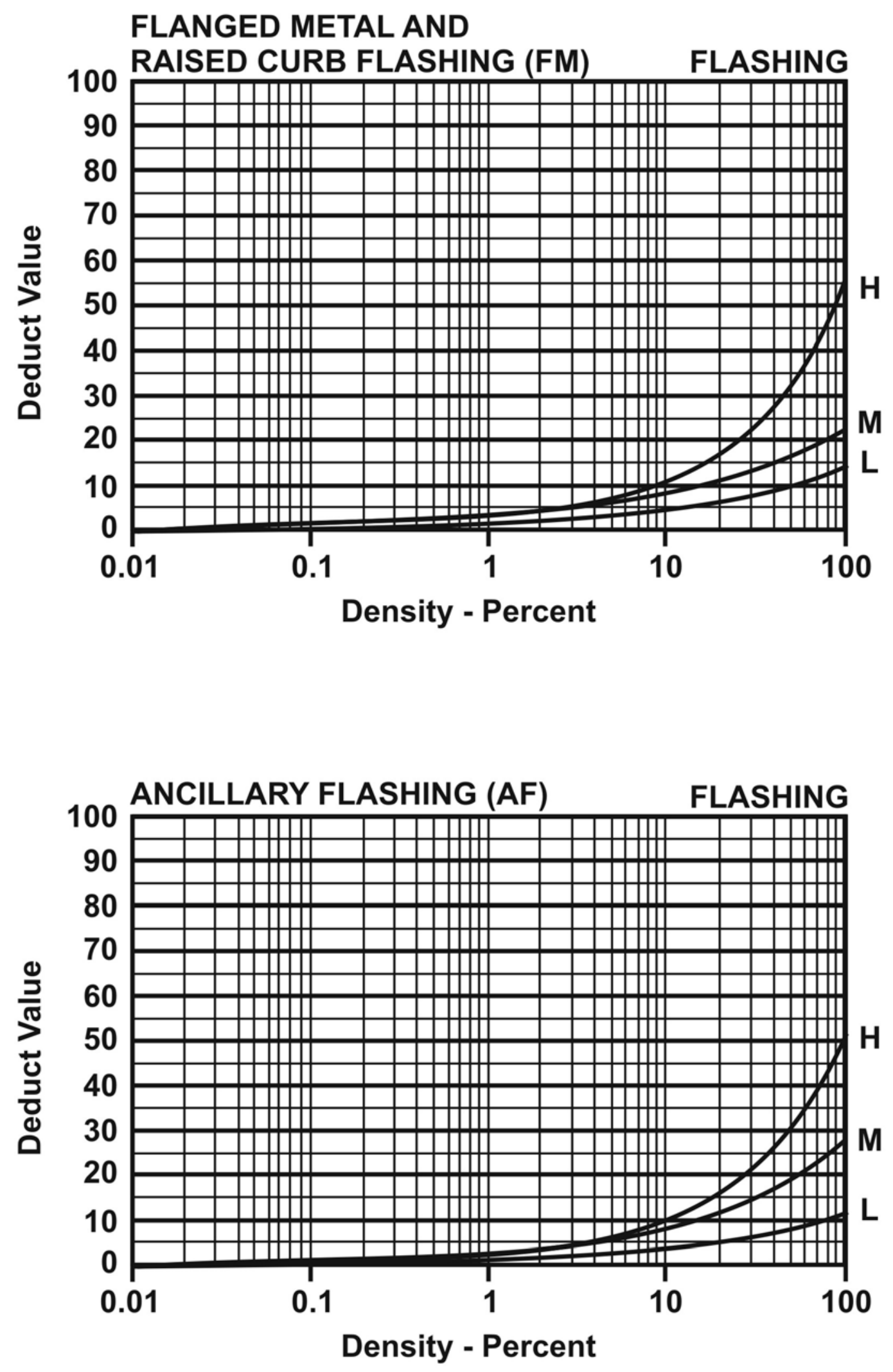

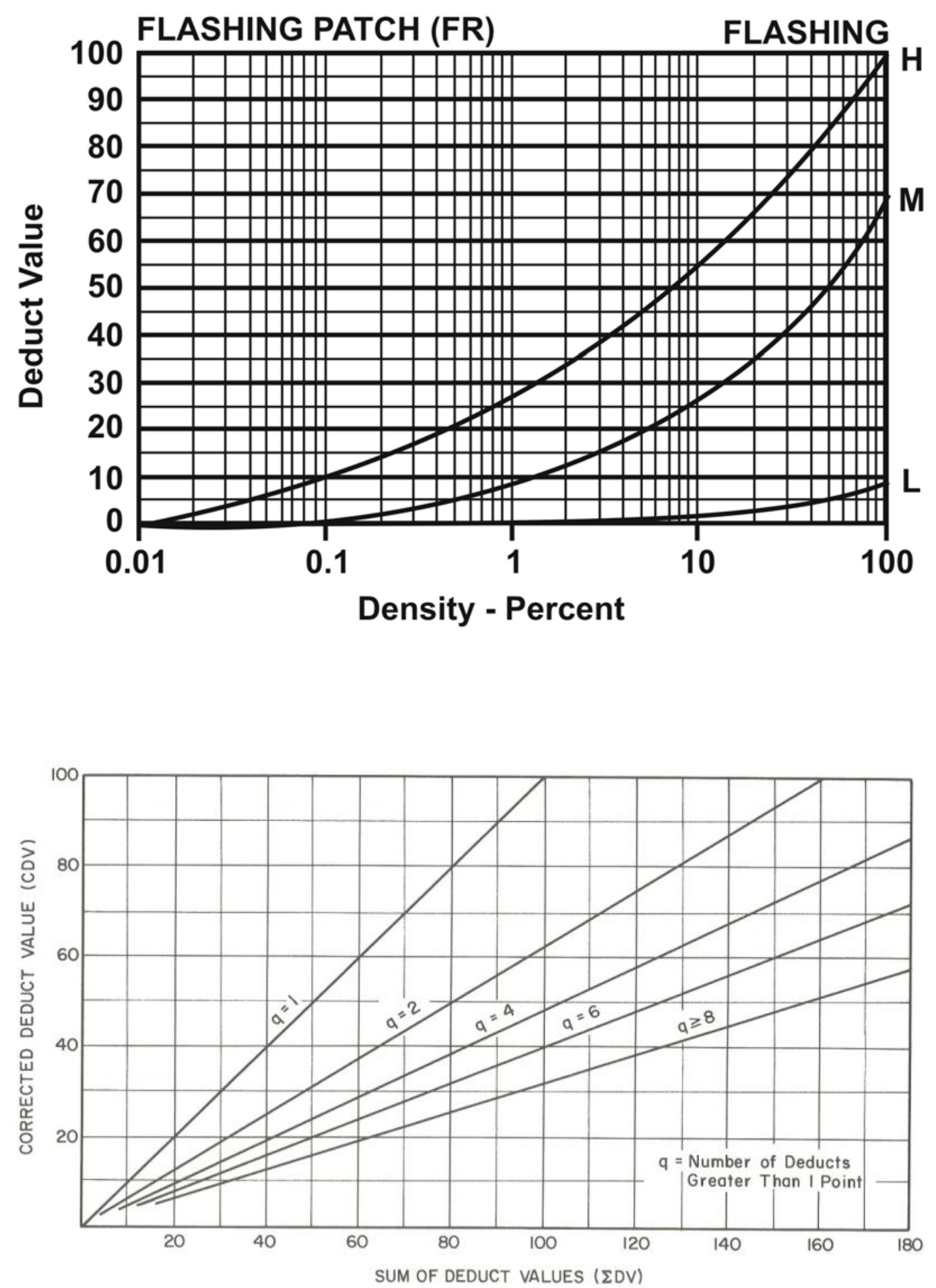

Corrected Deduct Values for Flashing. 

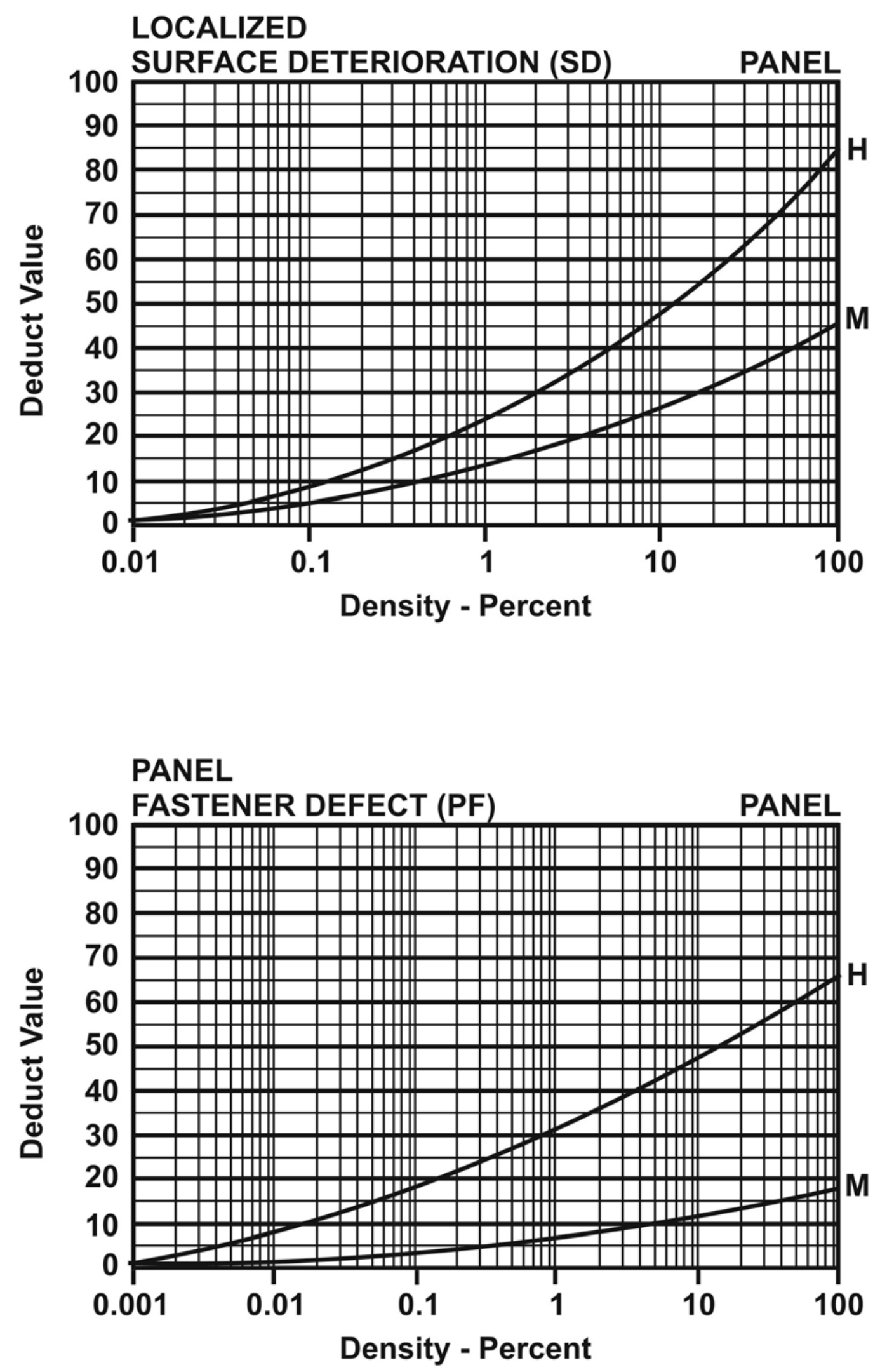

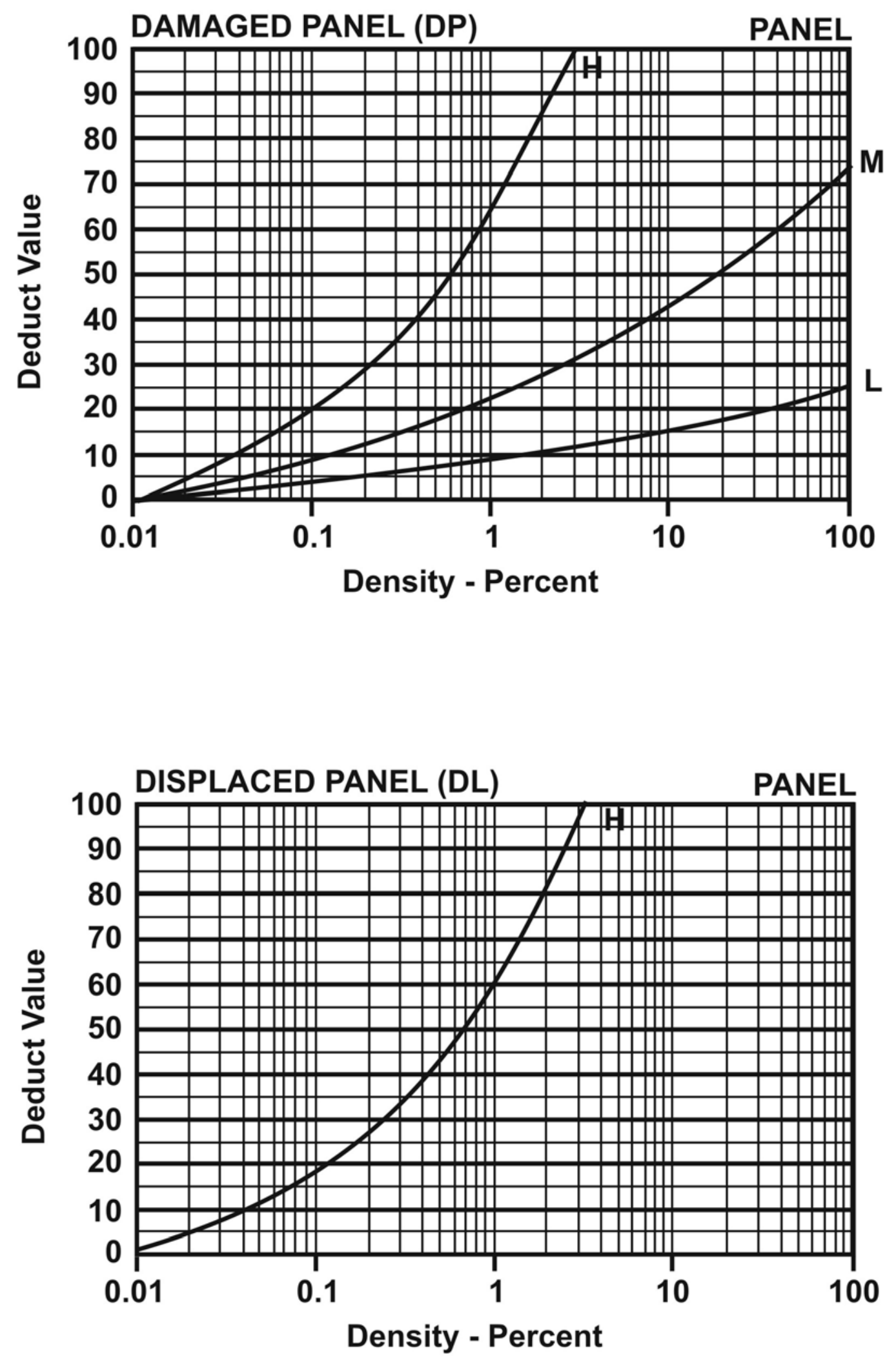

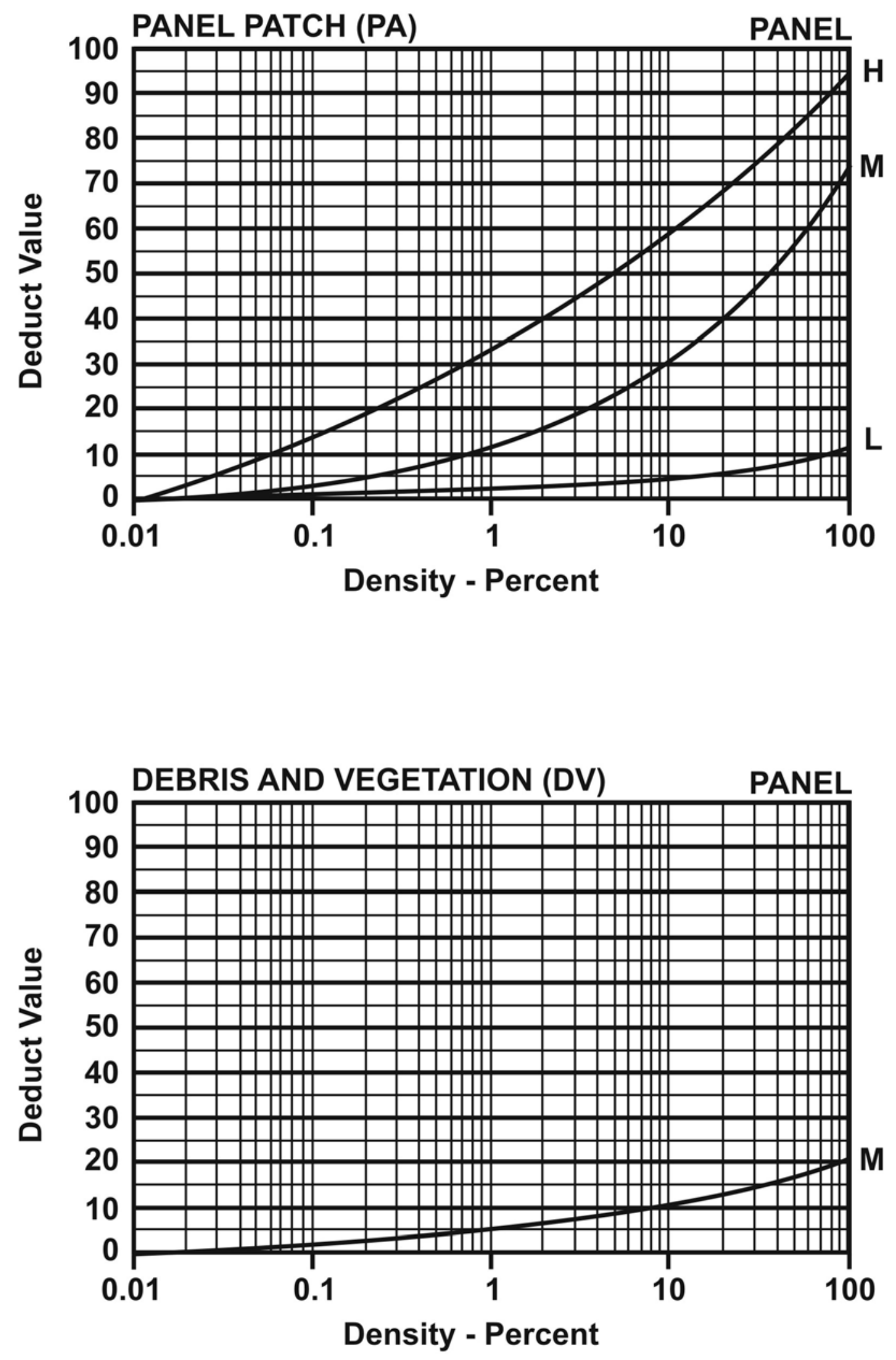

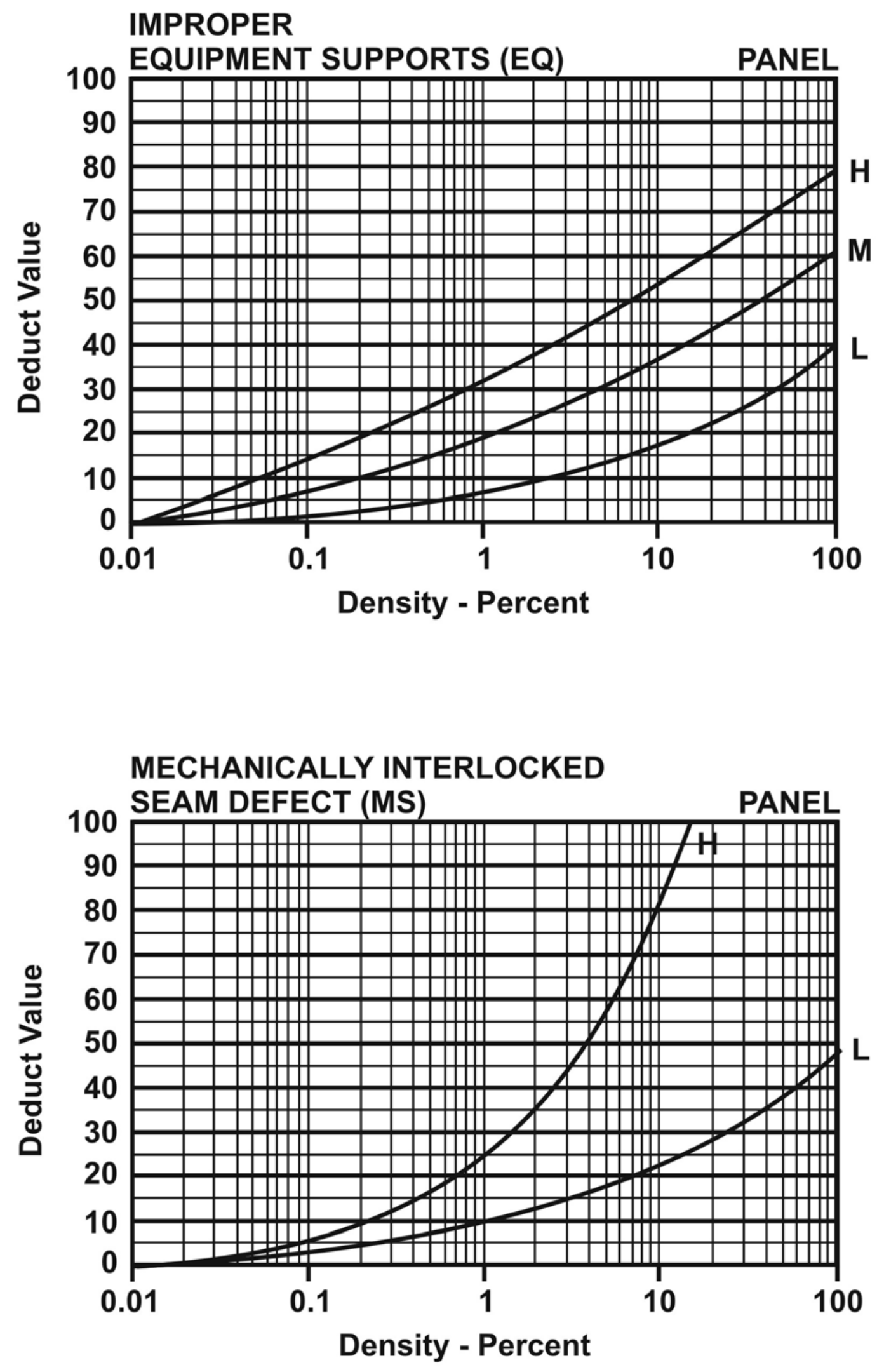

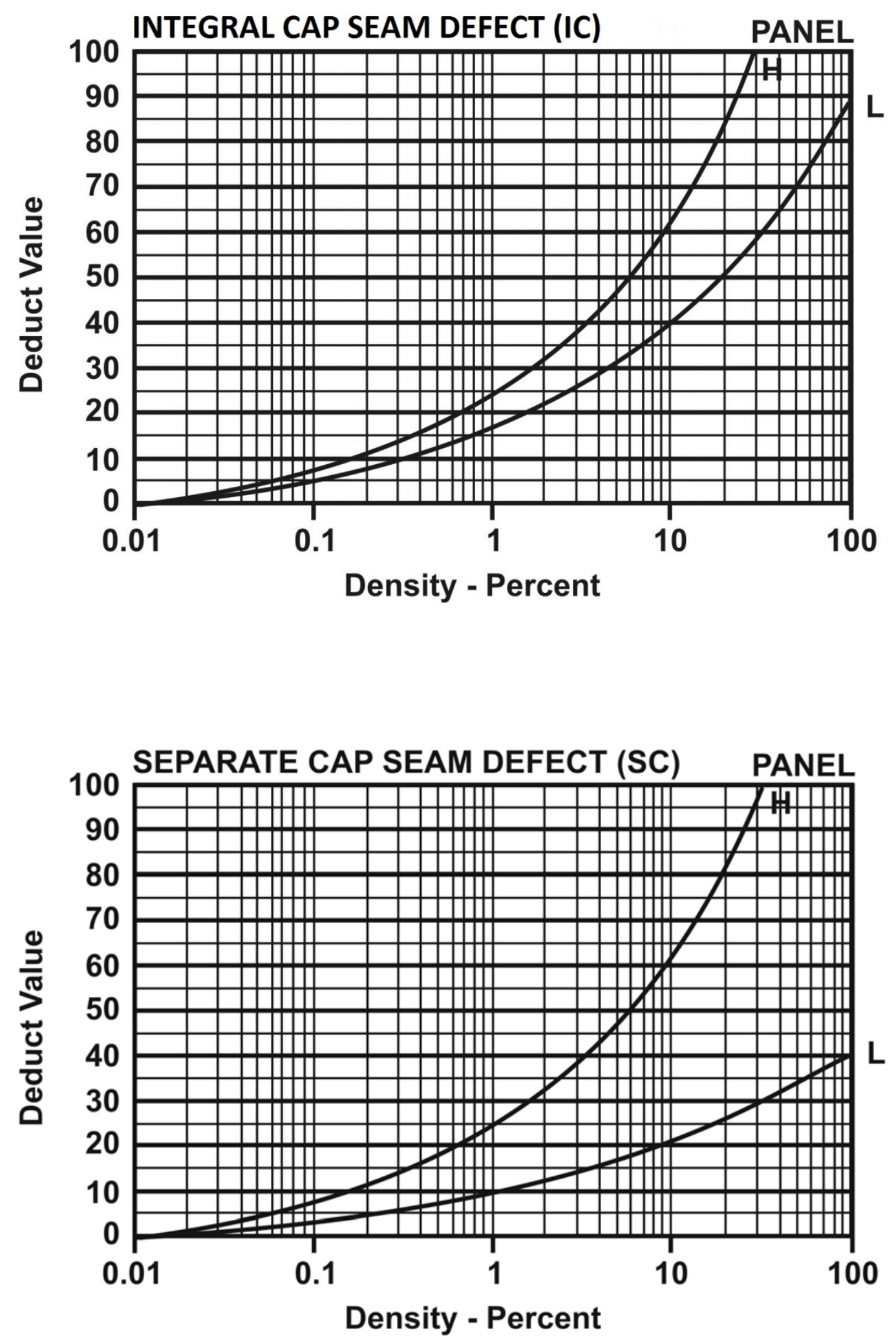

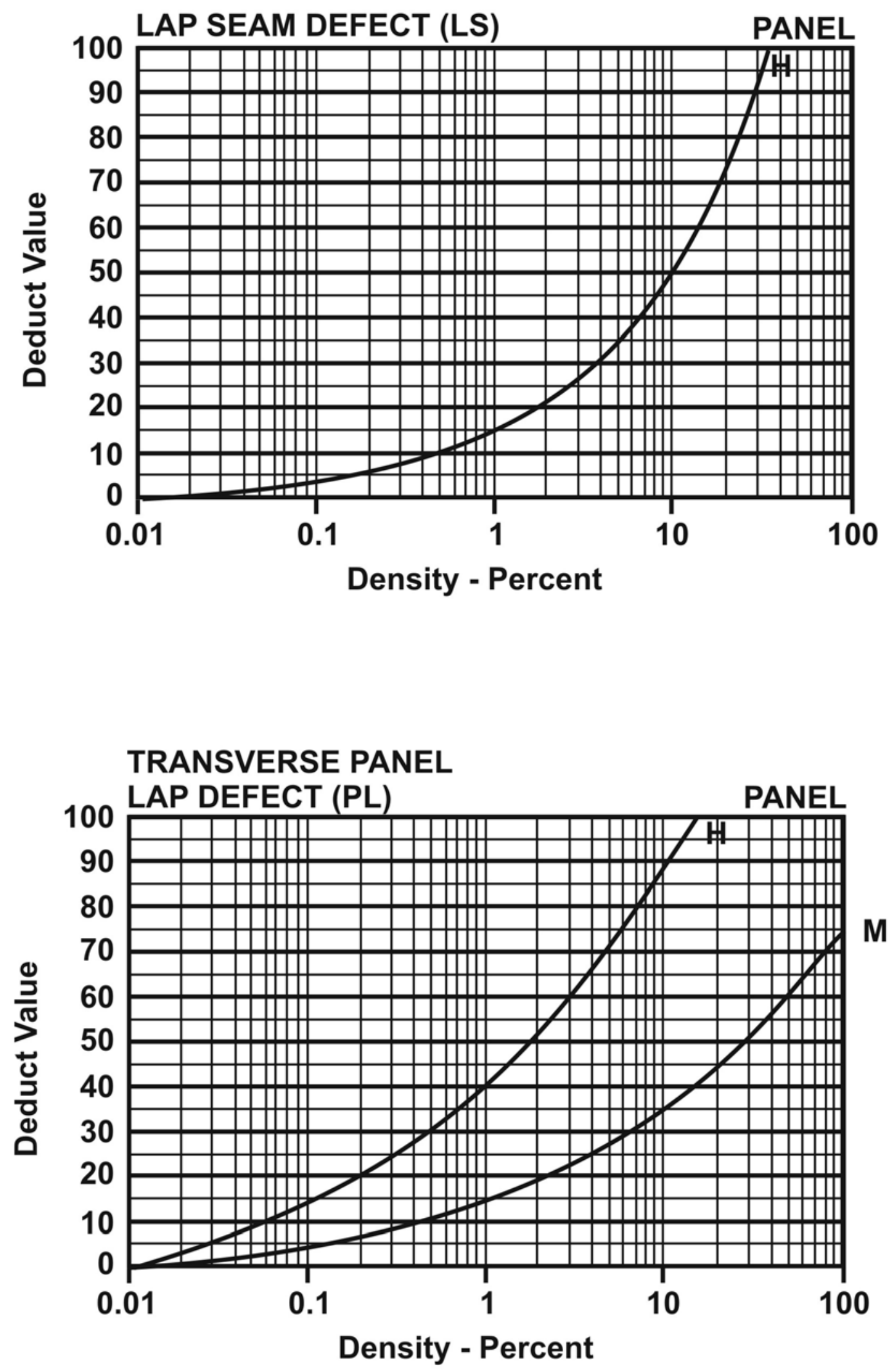

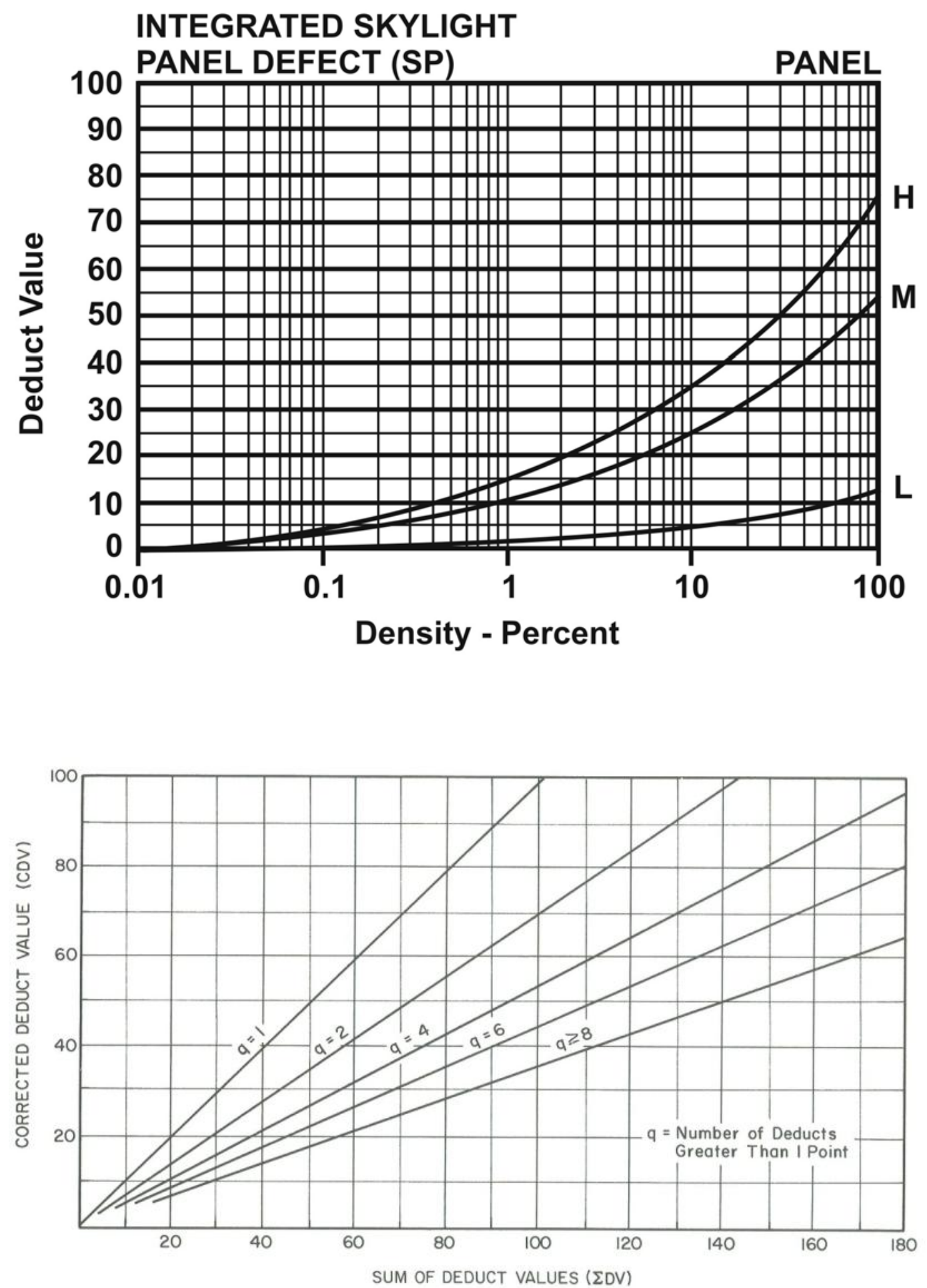

Corrected Deduct Values for Panels. 


\section{Appendix B: Condition Index Calculation Methodology}

The panel and flashing condition indexes and the overall roof condition index are computed by the web-based ROOFER application once the visual inspection data is entered into the database. To understand the condition index concept and methodology used in the calculations, the manual calculation process is described below.

\section{Determine deduct values}

Use information from the Roof Inspection Worksheet to complete the heading section of the Roof Section Rating Form. Transfer the quantities for each combination of distress type and severity level from the completed Roof Inspection Worksheet to the Roof Section Rating Form (see Figure B1 for the inspection data used for the presented example calculation). Flashing distresses are tabulated on the left side of the page and panel distresses on the right. Total the quantities for each severity of each distress, calculate each density using the equations in Chapters 4 and 5, and determine deduct values (DV) from the Deduct Value Curves in Appendix A. See Figure B2 for the completed Roof Section Rating Form using the example data.

\section{Determine corrected deduct values}

Tabulate flashing deduct values in descending order as shown below using the data obtained from Figure B1. Determine the sums of flashing deduct values $\left(\sum \mathrm{DV}\right)$ and the number of distresses with deduct values greater than 1 (q), then use these two values and the appropriate graph in Appendix A to determine corrected deduct values (CDV) for the flashing distresses. Circle the maximum value of CDV as shown. 


\begin{tabular}{|c|c|c|c|}
\hline DV & $\sum$ DV & $\mathrm{q}$ & $\mathrm{CDV}_{\text {flashing }}$ \\
\hline 14 & 14 & 1 & 14 \\
\hline 6 & 20 & 2 & 13 \\
\hline 2 & 22 & 3 & 13 \\
\hline & & & \\
\hline
\end{tabular}

For this example the Maximum $\mathrm{CDV}_{\text {flashing }}=14$

Repeat this process using the appropriate graph in Appendix A to determine the maximum corrected deduct value for the panels.

\begin{tabular}{|c|c|c|c|}
\hline DV & $\sum$ DV & q & CDV $_{\text {panels }}$ \\
\hline 15 & 15 & 1 & 15 \\
\hline 7 & 22 & 2 & 15 \\
\hline 7 & 29 & 3 & 17 \\
\hline 2 & 31 & 4 & 16 \\
\hline & & & \\
\hline
\end{tabular}

For this example the Maximum $\mathrm{CDV}_{\text {panel }}=17$

\section{Compute flashing and panel condition indexes}

Calculate flashing and panel condition indexes using the following equations:

$$
\text { FCI }=100-\text { Max. } \text { CDV }_{\text {flashing }}
$$




$$
\text { PCI }=100-\text { Max. } \text { CDV }_{\text {panels }}
$$

For this data, $\mathrm{FCI}=86$ and $\mathrm{PCI}=83$. Using Figure B3, determine the corresponding descriptive condition ratings for both the flashing and panel components.

\section{Compute roof condition index}

Each individual index (FCI, PCI) reflects the component's ability to provide its intended service and indicates MRR needs. Since the components must interact to function as a roof system, they are dependent on each other. The indexes, in total, provide an assessment of the condition of an metal panel roof section. By combining these indexes, a roof condition index (RCI) can be calculated. This single index is useful for evaluating the overall condition of a roof section and for comparing conditions between roof sections. The RCI allows the user to rank individual roof sections in accordance with their ability to perform.

This relationship is defined by the following equation:

$$
\mathrm{RCl}=(0.7 \times \text { lowest condition index })+(0.3 \times \text { remaining condition index })[\text { Eq 6] }
$$

The above equation give the greatest weight to the component with the lowest condition index and then modify it by adding "value" from the remaining index.

The following example illustrates how this relationship works:

Example: $\mathrm{FCI}=88 ; \mathrm{PCI}=91$

$$
\begin{aligned}
\text { RCI } & =(0.7 \times 88)+(0.3 \times 91) \\
= & 62+27 \\
= & 89
\end{aligned}
$$

A completed RCI Calculation Sheet is shown in Figure B4. 


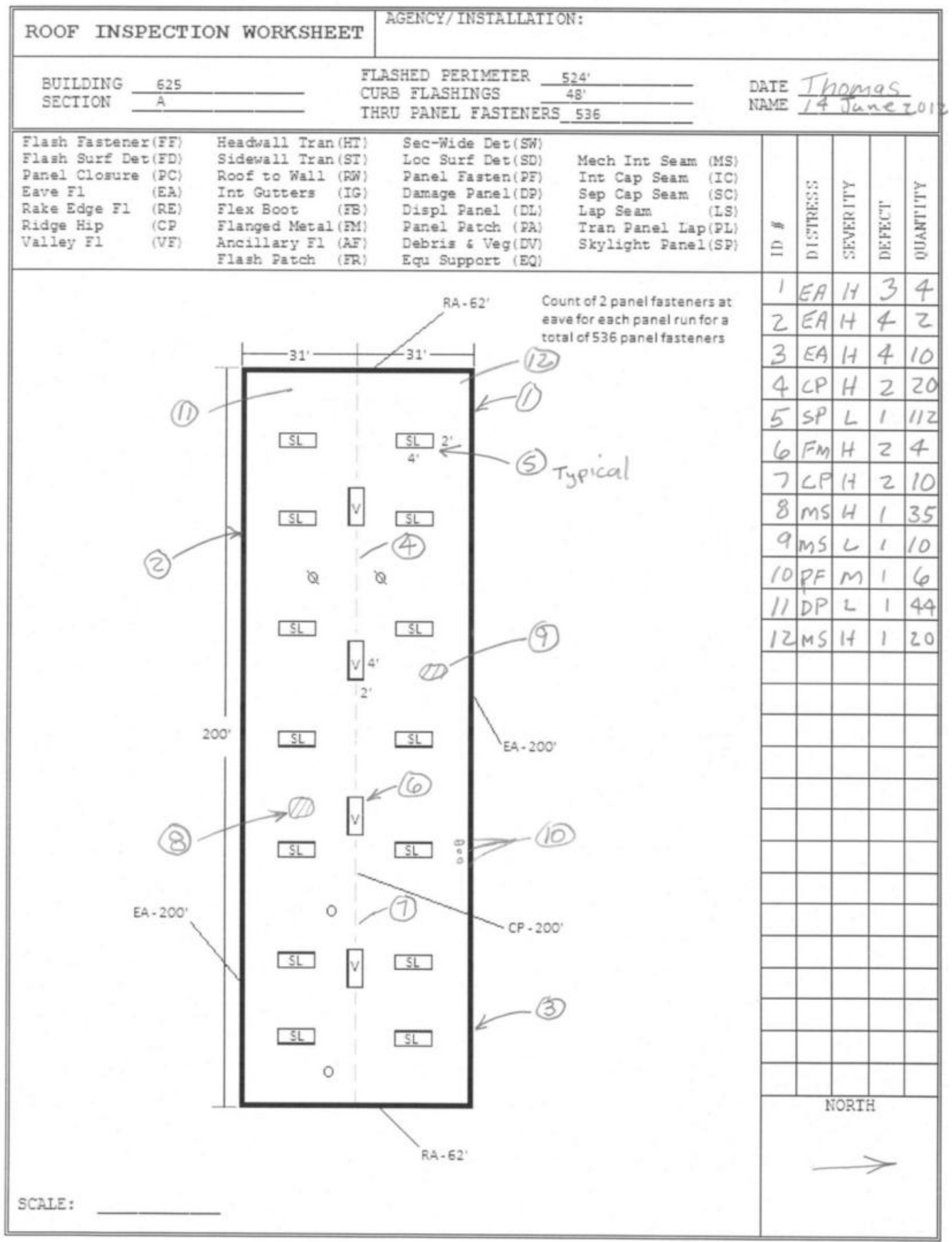

B 1. 


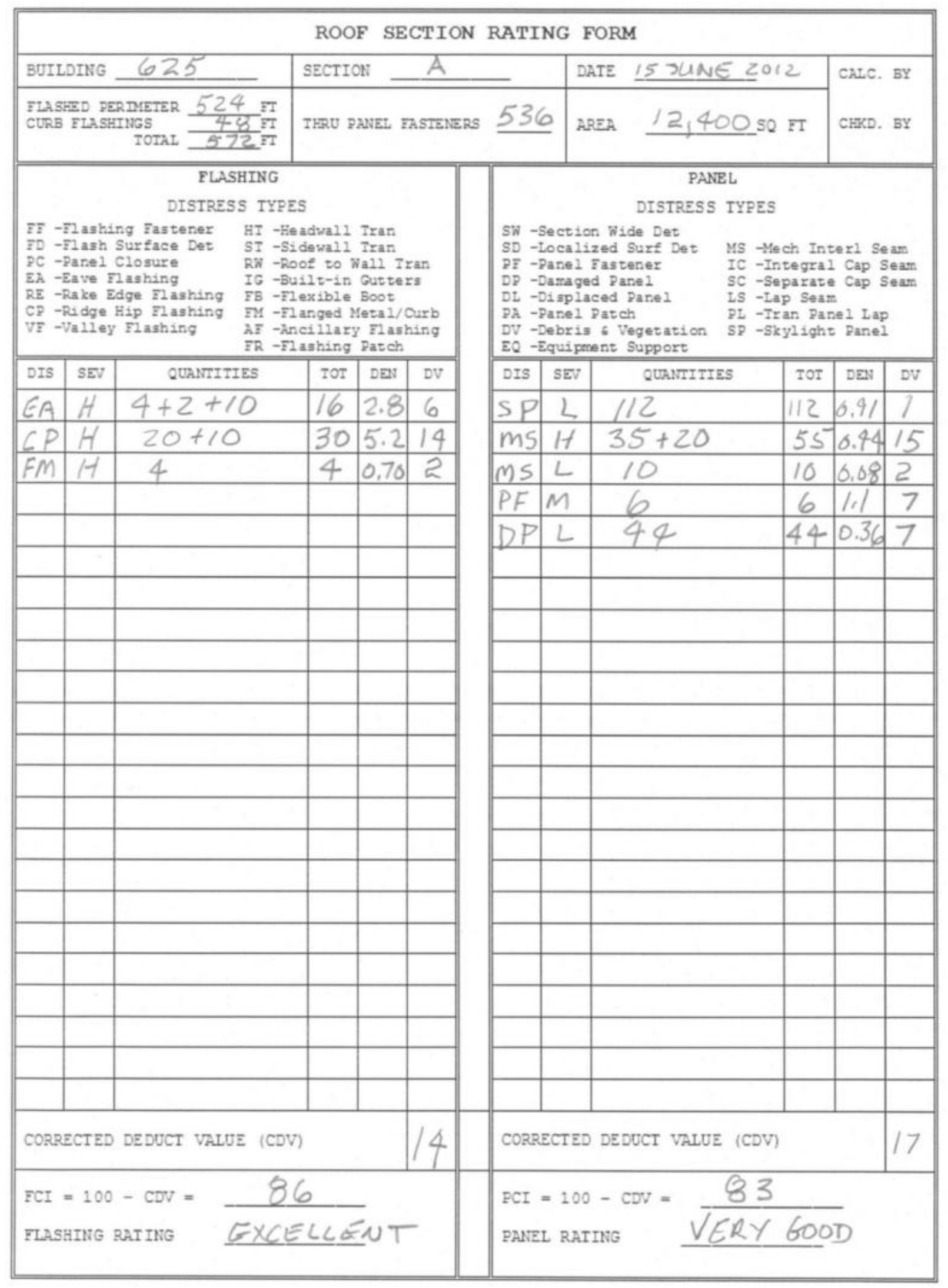

B 2. 


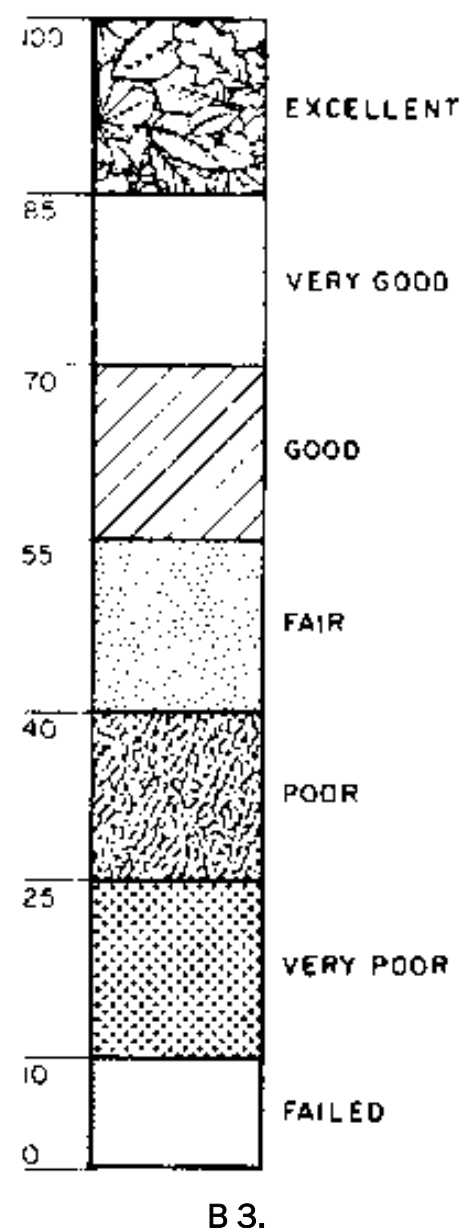




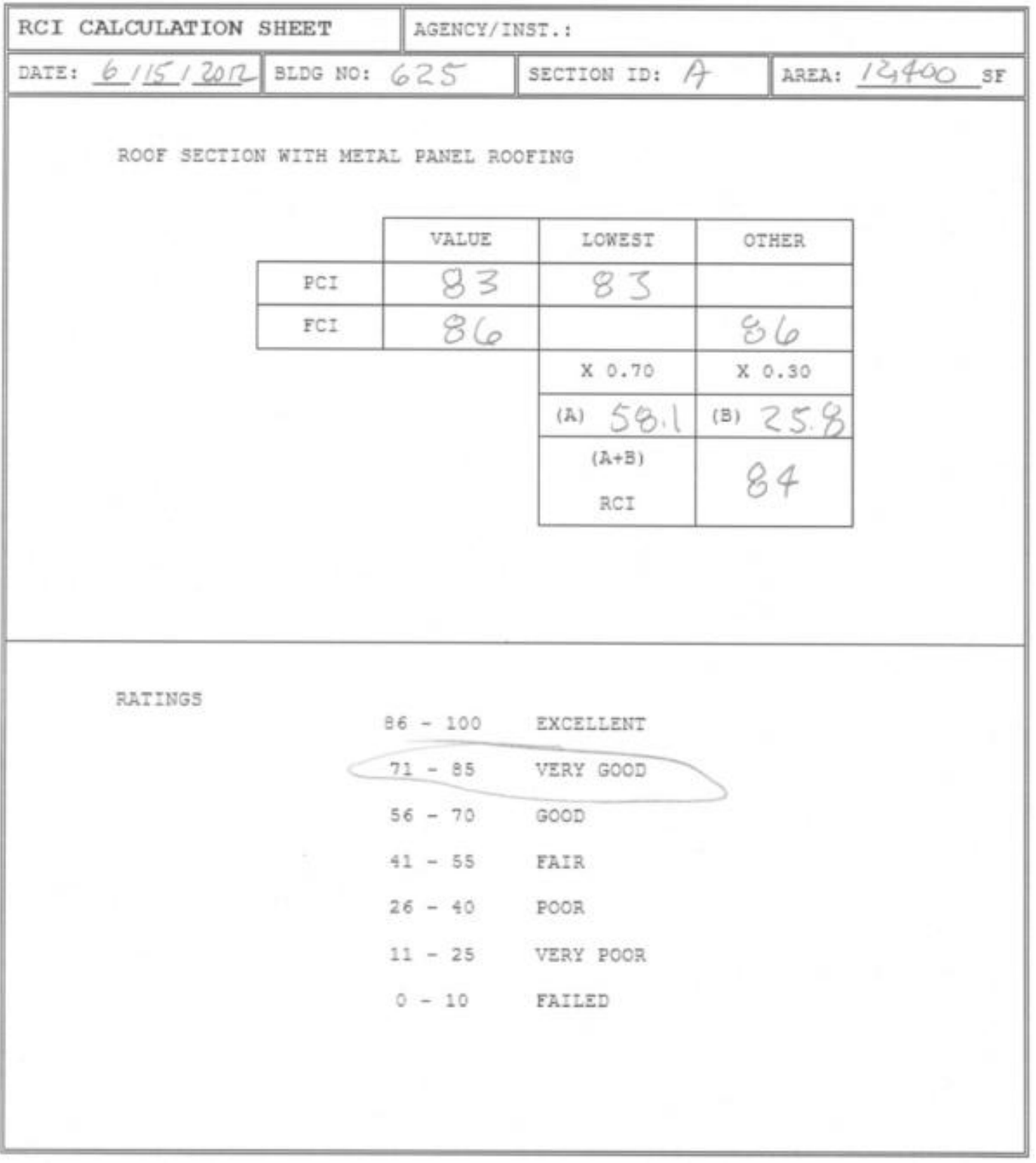

B 4. 


\section{Appendix C: Blank Worksheets}

The following pages contain facsimiles of all blank worksheets needed by an inspector performing a ROOFER steel panel roof evaluation. Photocopy them for use in the field.

Included at the end of the appendix is a field reference guide for flashing and panel distresses. 


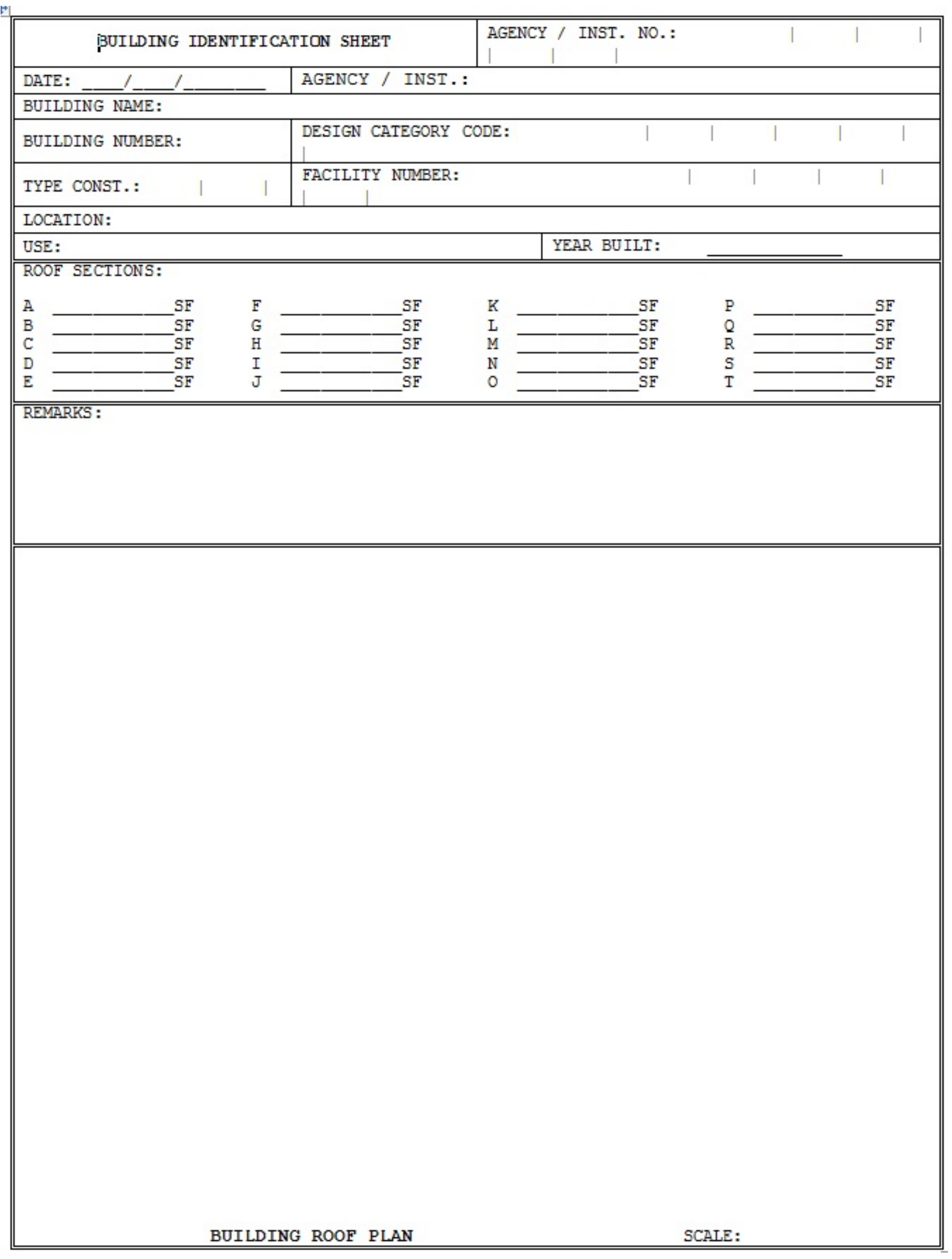




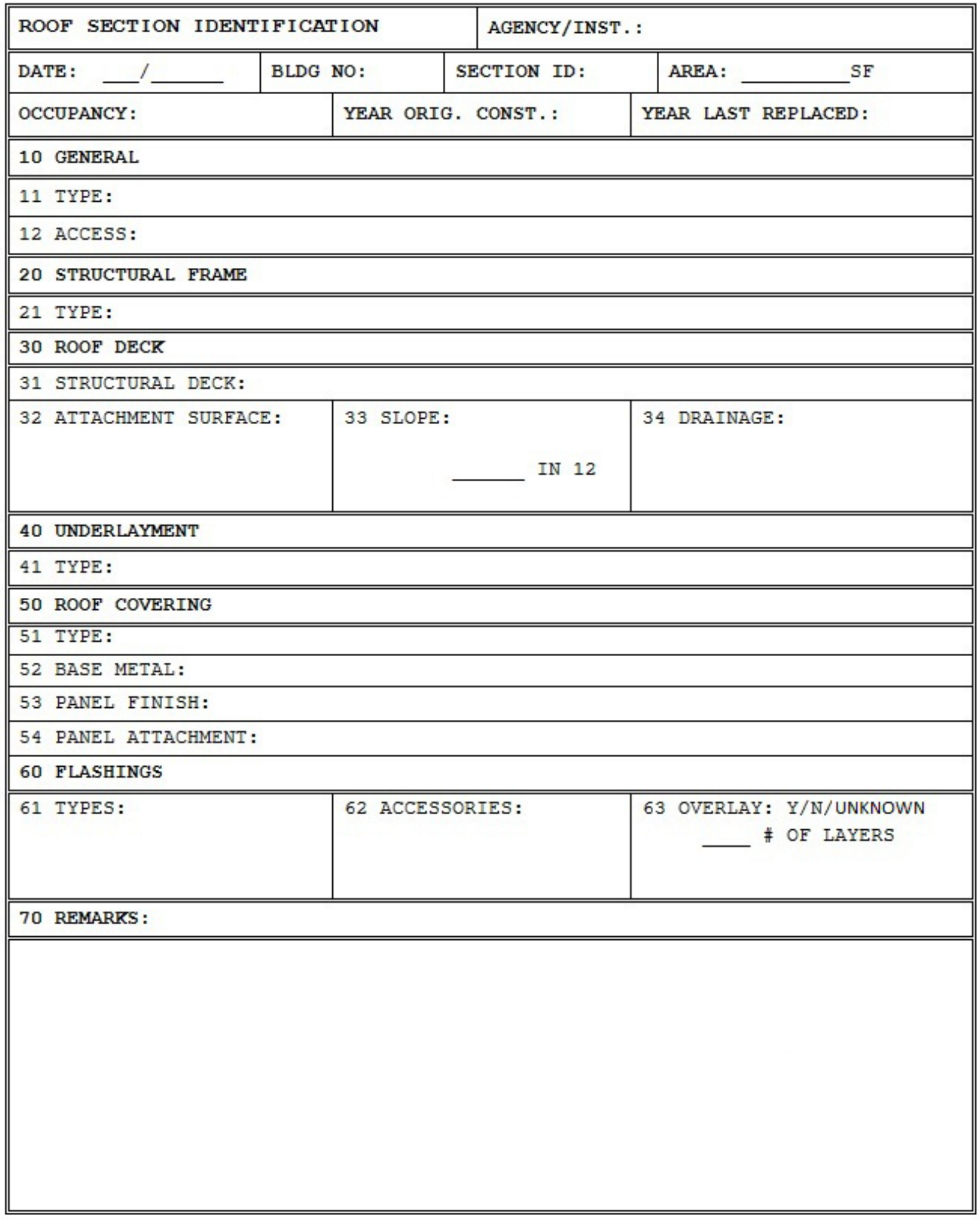




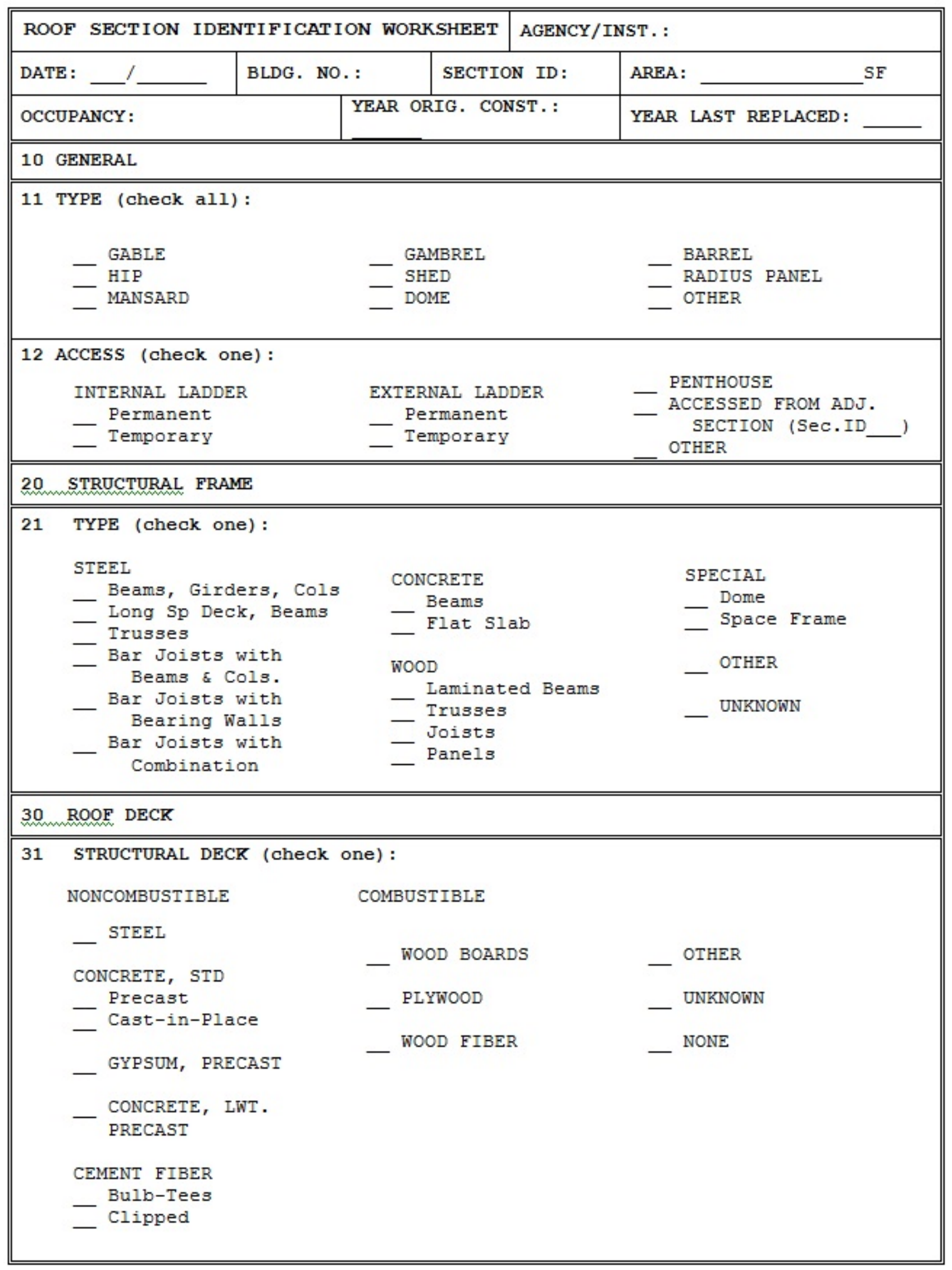




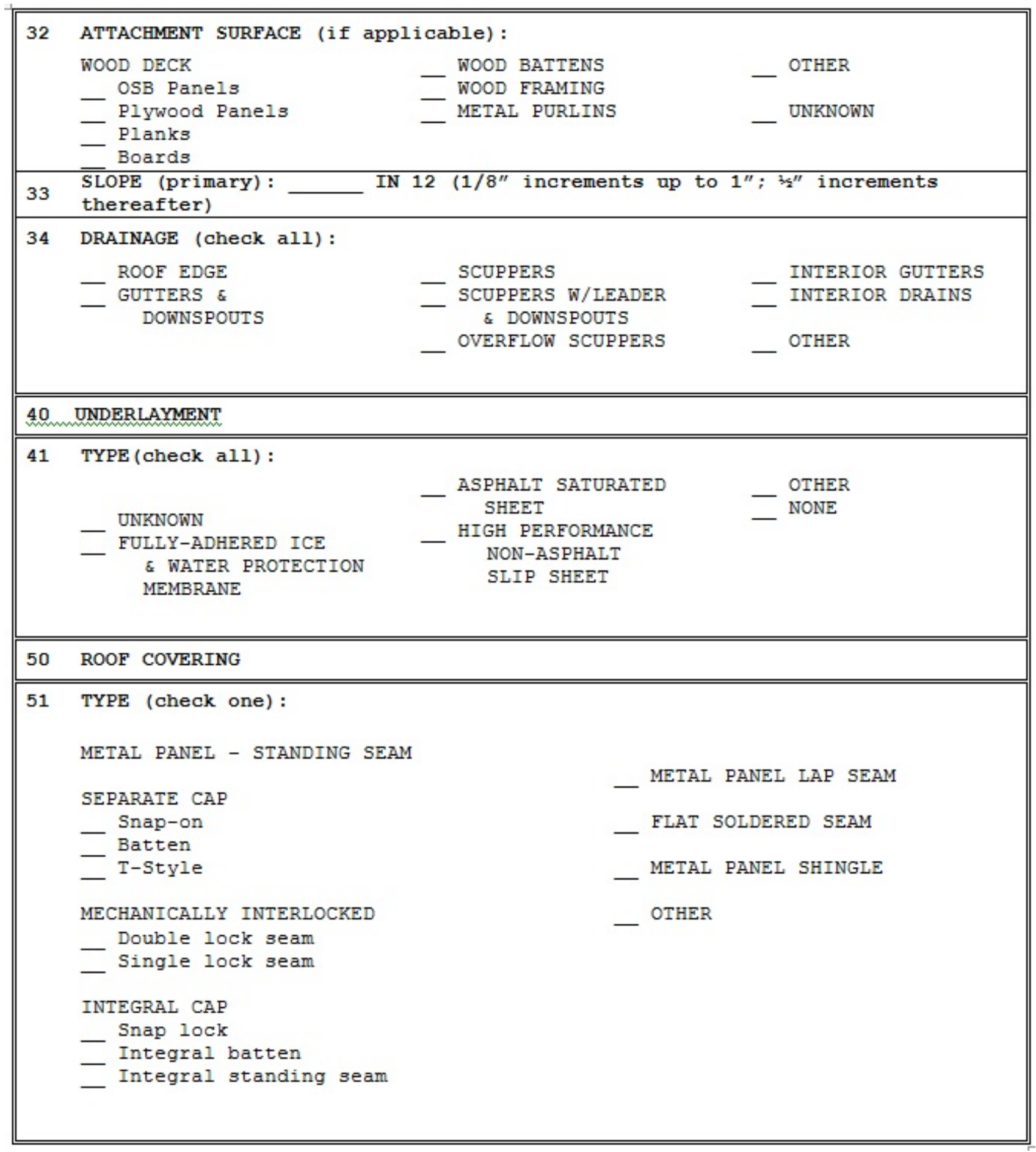


52 BASE METAL:

- ZINC COATED STEEL

- TERNE

- COPPER

- LEAD

(galvanized)

- STAInless STEEL

— LEAD COATED

ZINC-ALUMINUM

- ZINC

COPPER

COATED STEEL STEEL UNKNOWN

- ALUMINOM

53 PANEL FINISH:

_ FACTORY APPLIED SMOOTH

- FACTORY APPLIED STONE COATED

— maintenance coating

OTHER
- NONE
UNKNOWN

54 PANEL ATTACHMENT :

CONCEALED CLIPS

- EXPOSED FAsteners IN PANELS

- OTHER

60 FLASHINGS

61 TYPES (Record lineal

61 feet of each): EAVE

- RAKE EDGE

- RIDGE CAP

HIP CAP

V VALLEY

- HEADWALL TRANS.

- SIDEWALL TRANS.

CONTINUOUS ROOF TO WALL TRANSITION

INTERIOR GUTTERS

FLEXIBLE BOOT

FLANGED METAL

62 ACCESSORIES (check all):

— SNOW GUARDS

WALKWAYS PHOTOVOLTAICS

63 OVERLAY :

IS ROOF OVERLAYED ( $\mathrm{Y} / \mathrm{N} / \mathrm{UNKNOWN})$ \# OF LAYERS

70 REMARKS 


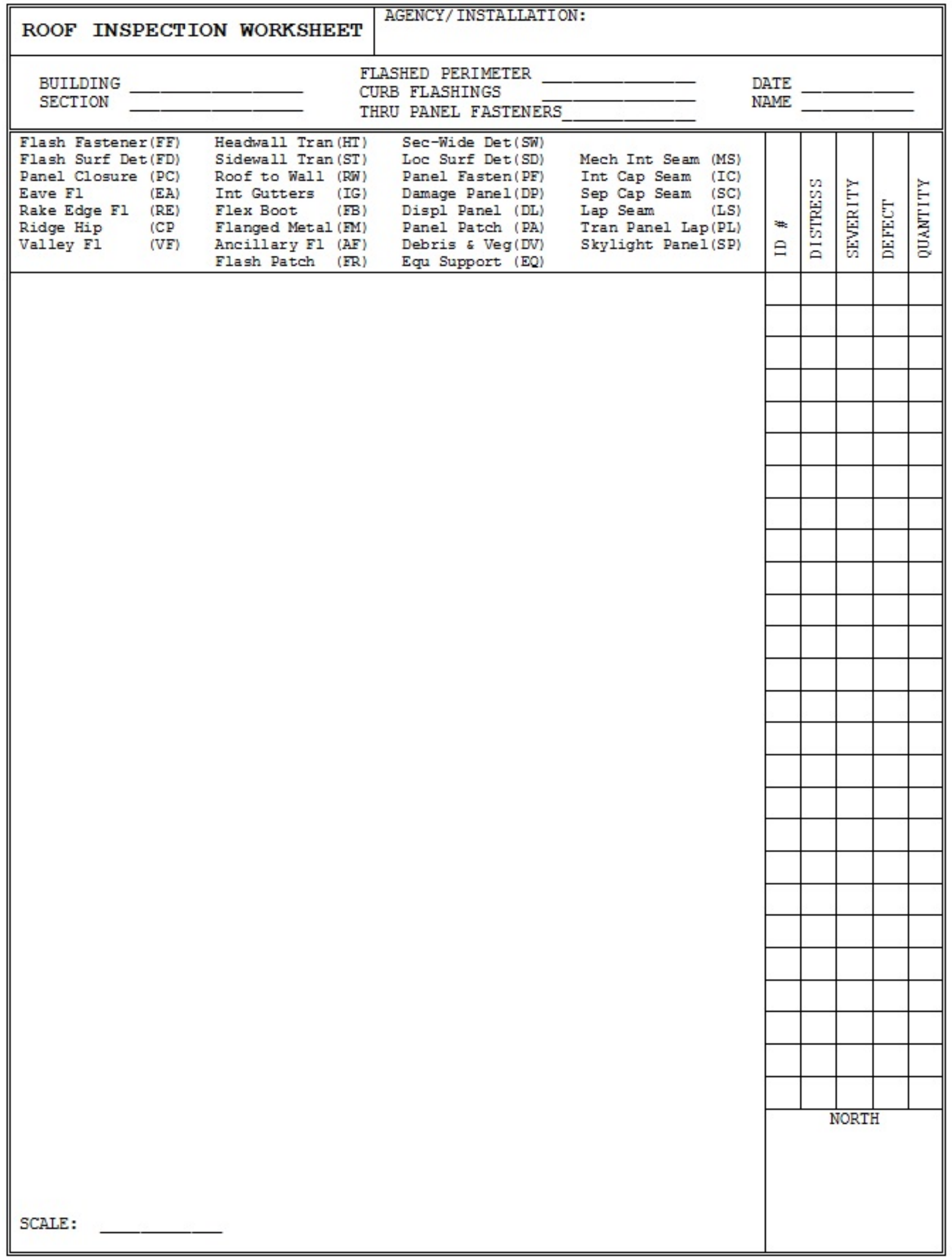




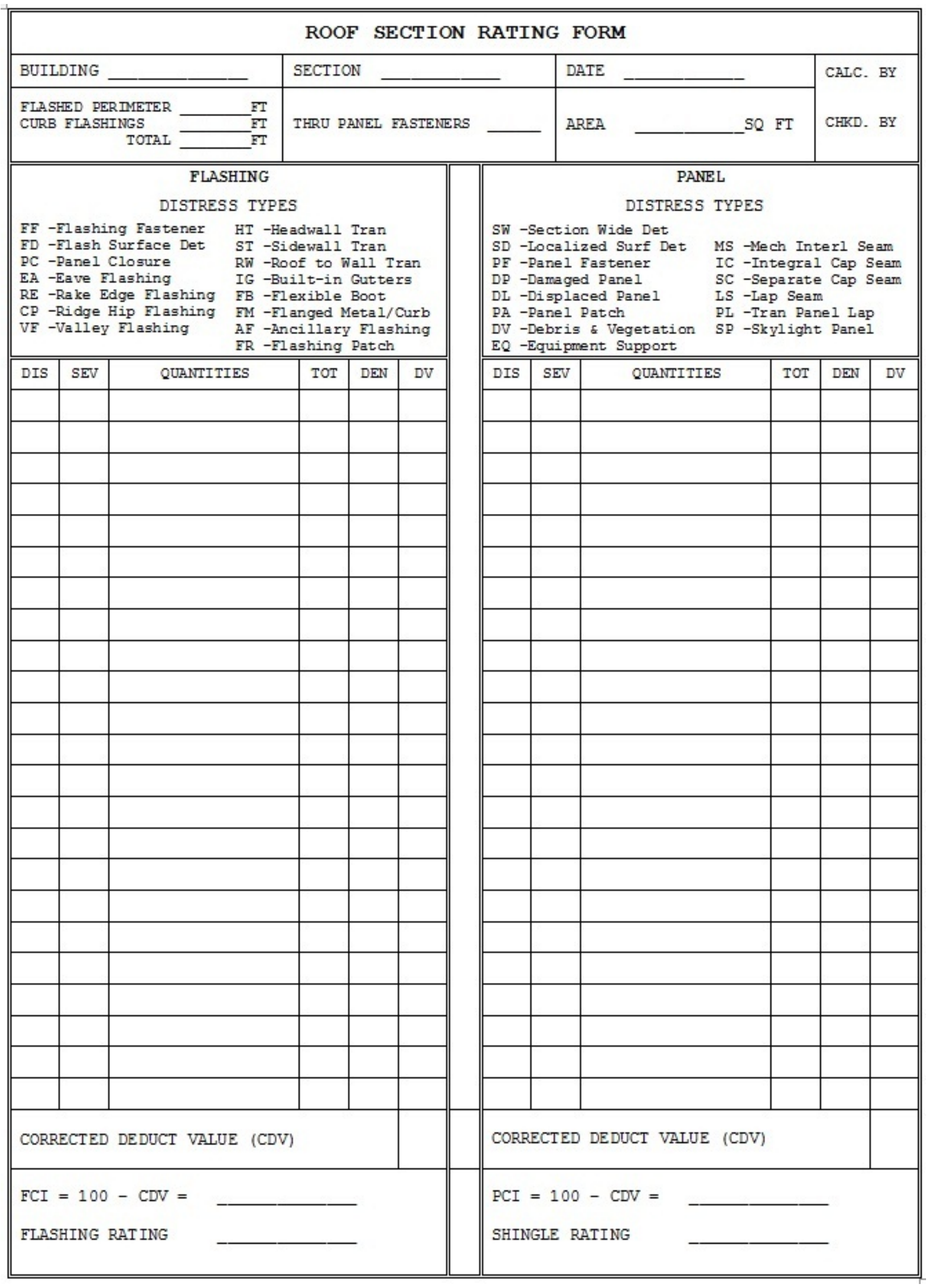




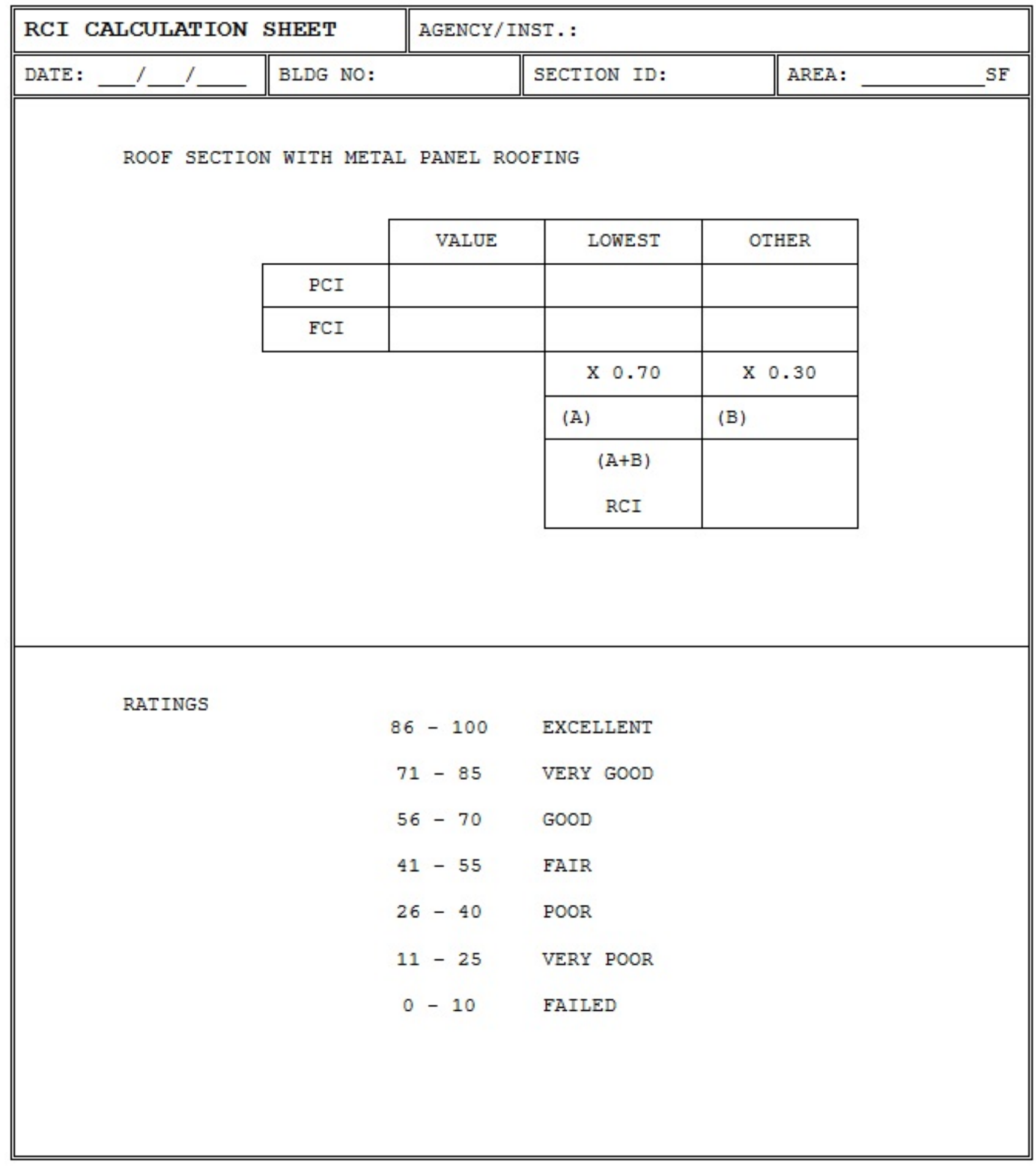


Flashing and Panel Distress Field Reference Card

\begin{tabular}{|c|c|c|c|c|c|}
\hline & & FLASHING DISTRESSES & & & FLASHING DISTRESSES (continued) \\
\hline & FF M 1 & $\begin{array}{l}\text { missing or deteriorated flexble gasket, or fastener is corroded, improperly } \\
\text { seated, or has a sealant repair but is watertight }\end{array}$ & & AF $L 1$ & $\begin{array}{l}\text { curb/coping cap flashing is deformed with ponding at a location not adjacent } \\
\text { to a lap or seam; or counterflashing is deformed }\end{array}$ \\
\hline Fasming Fastonirs & $\mathrm{FF} \mathrm{H} 1$ & fastener or flexible gasket is loose, deteriorated or missing or enlarged hole, & & $\overline{A F L}$ & elastomeric bellows expansion joint cover exists \\
\hline & & and allowing water to penetrate & & AF M 1 & holes on a vertical surface \\
\hline Flash Surface Det & FDM 1 & Dcalized loss of finish or metal corrosion & & AF M 2 & unflashed or impropenty flashed penetration passing through it but is \\
\hline & FCM 1 & misaligned but watortight & & & watertight \\
\hline & PC M 2 & pre-manufactured seam cap does not fit properly & & $\overline{A F H}$ & holes or severe deterioration on a horizontal surface \\
\hline Panel Closure & $\mathrm{PC}+\mathrm{H} 1$ & $\begin{array}{l}\text { non-metal panel closure is deformed, misaligned, damaged or missing. } \\
\text { allowing water to penetrate }\end{array}$ & & \begin{tabular}{|l|l|}
$\mathrm{AF} \mathrm{H} 2$ \\
$\mathrm{AF} \mathrm{H} 33$ \\
\end{tabular} & $\begin{array}{l}\text { missing or deformed; or ponding at a lap or seam } \\
\text { displaced }\end{array}$ \\
\hline & $\overline{P C H} 2$ & $\begin{array}{l}\text { metal panel closure is deformed, misaligned, or missing, allowing water to } \\
\text { penetrate }\end{array}$ & Ancilary Flashing & \begin{tabular}{|l|l|l|l}
$A F H 4$ \\
$A F H$
\end{tabular} & $\begin{array}{l}\text { failed soldered joint, an open joint, a butt joint, or missing joint covers } \\
\text { fioints that are bucking water }\end{array}$ \\
\hline & 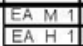 & 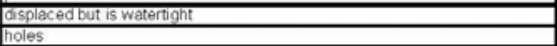 & & AF $H 6$ & $\begin{array}{l}\text { sealant at reglet, top of counterflashing or sealed joint is missing or no } \\
\text { longer functioning }\end{array}$ \\
\hline Eave Flashing & 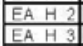 & $\begin{array}{l}\text { non-cloated eave is displaced and allowing wator to penetrate } \\
\text { cleated eave is displaced or disengaged }\end{array}$ & & AF $H 7$ & $\begin{array}{l}\text { counterllashing, exterior siding, or cladding does not extend over top of } \\
\text { transtion flashing }\end{array}$ \\
\hline & \begin{tabular}{|l|l|l}
$E A H 4$ \\
$E A H S$ \\
$E A H$
\end{tabular} & $\begin{array}{l}\text { open joints or butt joints } \\
\text { flashing is missing }\end{array}$ & & AF $\mathrm{H} 8$ & $\begin{array}{l}\text { curb/coping cap has unflashed or improperly flashed penetration passing } \\
\text { through it that is allowing water to penetrate }\end{array}$ \\
\hline & RE M 1 & Lose or displaced but watertight and does not compromise panel & & \begin{tabular}{|l|l|l}
$A F$ \\
\end{tabular} & top of transition flashing is not properfy countertlashed of terminated \\
\hline & 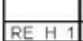 & \begin{tabular}{|l} 
securement \\
holes
\end{tabular} & & $F R \perp 1$ & $\begin{array}{l}\text { patch appears to be to be watertight and does not require a permanent } \\
\text { repair }\end{array}$ \\
\hline Rake Edgo Flashing & $\mathrm{RE} \mathrm{H}_{2}$ & $\begin{array}{l}\text { loose, displaced or missing and is allowing water to penetrate and/or } \\
\text { compromises panel securement }\end{array}$ & Flashing Patch & FR M 1 & patch appears to be watertight and does require a more permanent repair \\
\hline & $\mathrm{RE} \mathrm{H}_{3}$ & installed so that water is running against lap & & ER H 1 & Datch is allowing water to penetrate \\
\hline & $\mathrm{RE} H \mathrm{H}$ & ogen ioint or butt joints & & & \\
\hline & $C P M 1$ & disengaged but is watertight & & & PANEL DISTRESSES \\
\hline & $\mathrm{CP}+\mathrm{H} 1$ & holes & & SW L 1 & applied finish exhibits chalking. fading or scratching over the entire roof \\
\hline & $\mathrm{CPH} 2$ & deformed or disengaged and allowing water to penetrate; or evidence of & & & section, but no underyying corrosion \\
\hline Ridge Cap, Hip Cap & \begin{tabular}{|l|l|l} 
& \\
$C P H$ & 3 \\
\end{tabular} & ponding at a lap or seam & $\begin{array}{l}\text { Section-Wide } \\
\text { Surface Deterioration }\end{array}$ & SW M 1 & $\begin{array}{l}\text { base metal or applied finish exhibits challang, fading or scratching over the } \\
\text { entire roof section; requiring a coatting or surface treatment }\end{array}$ \\
\hline & 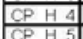 & $\begin{array}{l}\text { Joints that are bucking water } \\
\text { open joints or buttionts }\end{array}$ & & SW & base metal exhibits corrosion over the entire roof section, requiring a roof \\
\hline & VF $L 1$ & Tastener is located in the valley but is watertight & & SOM & freplacement \\
\hline & VF L 2 & patch is watertight & & SD M 2 & panel finish exhibits degradation caused by grease, solvent or oil drippings \\
\hline & VF M 1 & Tastener has missing or deteriorated flexible gasket but watertight; or & & & \\
\hline & \begin{tabular}{|l|l|l} 
& \\
$V F H 1$
\end{tabular} & $\begin{array}{l}\text { fastener is corroded, improperly seated, or temp repair } \\
\text { fastener or flexible gasket is loose. deteriorated or missing and is allowing }\end{array}$ & Detenioration & $\mathrm{SOH}$ & $\begin{array}{l}\text { for mech interlocked seams, panel has corrosion holes, requiring localized } \\
\text { repair }\end{array}$ \\
\hline Valley Flashing & & water to penetrate. or fastener has an enlarged hole & & $\overline{S O H} 2$ & panel finish exhibits degraderion caused by grease, solvent or ofl drippings \\
\hline & $\mathrm{VF} \mathrm{H}_{2}$ & holes & & & \\
\hline & \begin{tabular}{|l|l|} 
VF $\mathrm{H}_{3}$ \\
VF $\mathrm{H} 4$ \\
\end{tabular} & $\begin{array}{l}\text { open joints or butt joint, or joints that are bucking water } \\
\text { panel end that terminatos in valey has become disengaged }\end{array}$ & Panel Fastener & PF M 1 & $\begin{array}{l}\text { Fastener has missing or deteriorating flexible gasket or fastener is } \\
\text { corroded, improperly seated, or has a sealant repair but is watertight }\end{array}$ \\
\hline & 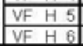 & \begin{tabular}{|l|l|} 
patch is allowing water to penetrate or is inappropriate \\
missing
\end{tabular} & Dofect & PF $\mathrm{H} 1$ & $\begin{array}{l}\text { fastener, flexible gasket and/or metal washer is loose, deteriorated or } \\
\text { missing or has large hole around it allowing water to penetrate }\end{array}$ \\
\hline & \begin{tabular}{|l|l|} 
HIM 11 \\
HT $\mathrm{H} 1$ \\
\end{tabular} & $\begin{array}{l}\text { Oissengaged or loose but wratertight } \\
\text { holes }\end{array}$ & & DPL L & $\begin{array}{l}\text { panel Is dented, deformed, or knked whth no deformation of the seam, no } \\
\text { loss of coating and no corrosion, and is watertight }\end{array}$ \\
\hline $\begin{array}{l}\text { Headwall Transition } \\
\quad \text { Flashing }\end{array}$ & 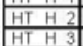 & $\begin{array}{l}\text { disengaged or loose and allowing water to penetrate } \\
\text { missing or deformed and allowing water to penetrate }\end{array}$ & & DP M 1 & $\begin{array}{l}\text { panel is dented, deformed or kinked, allowing ponding water and/or } \\
\text { corrosion }\end{array}$ \\
\hline & HT $\mathrm{H} 4$ & open joints or butt joints, or joints that are bucking water & Damaged Panel & $\mathrm{DP}+\mathrm{H} 1$ & for mech. Interlocked panel system, panel has holes, splits or tears. \\
\hline & ST M 1 & disengaged or looso but appears to be watertight & & & requiring localized repairs \\
\hline Sidewall Transtion & 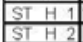 & $\begin{array}{l}\text { flashing has holes } \\
\text { disengaged or loose and is allowing water to penetrate }\end{array}$ & & $\mathrm{DPH2}$ & $\begin{array}{l}\text { for non-mech interlocked systems, panel has holes, splits or tears that } \\
\text { require panel replacement }\end{array}$ \\
\hline & 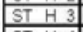 & gpen joints or butt joints, or joints that are bucking water & Displaced Panol & $\overline{D L} \quad \mathrm{H}$ & panel is loose or displaced, reguiring reposhtooning and re-securement \\
\hline & ST $\mathrm{H} 4$ & missing or deformed and dis allowing water to penetrate & Uisplaced Panel & $\mathrm{QL} \mathrm{H}$ & panel is missing and requires replacement \\
\hline $\begin{array}{l}\text { Continuous Roof to } \\
\text { Wall Panel Transtion }\end{array}$ & \begin{tabular}{|l|l|l|l|l}
$R W L$ & 1 \\
$R W$ & $H$ & 1 \\
\end{tabular} & \begin{tabular}{|l|} 
rated low-severity as a minimum \\
loose, deformed or missing seam cover
\end{tabular} & & $P A \perp 1$ & $\begin{array}{l}\text { patch appears to be watertight and does not require a more permanent } \\
\text { repair }\end{array}$ \\
\hline & $1 \mathrm{G} \quad \mathrm{L} 1$ & gutter is lined with elastomeric membrane or coening and is watertight & Panel Patch & $\overline{P A M} 1$ & panch appears to be watertight and requires a more permanent repair \\
\hline & IG M 1 & gutter is not lined with elastomencic membrane or costing and is watertight & & & \\
\hline & & & & PA H & patch is allowing water to penetrate \\
\hline Built-in Gutters & $16+1$ & $\begin{array}{l}\text { Interior gutter is not lined with elastomeric membrane or coating and has } \\
\text { holes, splits or open joints }\end{array}$ & $\begin{array}{l}\text { Debris and } \\
\text { Vegetation }\end{array}$ & $\overline{D V M}$ & $\begin{array}{l}\text { collection of foreign objocts or vegetation or grease, solvent or oil drippings } \\
\text { on the roof which cause no degradation }\end{array}$ \\
\hline & $16 \mathrm{H}_{2}$ & gutter having elastomeric membrane or costing has holes splits or open & & $\mathrm{DV} \mathrm{M}_{2}$ & tree branches making contact with the roofing svstem \\
\hline & & joints & & $E Q L$ & rated low severity as a minimum \\
\hline & $\mid \mathrm{GH}$ & gutter or drain is clogged & & EQ M 1 & support is bolted or fastened through the metal panel seam flashing and \\
\hline & FB $L$ & rated low-severily as a minimum & & & the bolt(s) are watertight \\
\hline Flexible Boot & \begin{tabular}{|l|l|}
$F B$ M 1 \\
$F B H$
\end{tabular} & $\begin{array}{l}\text { bose, missing, corroded or misaligned drawband } \\
\text { boot is missing or has holes; or interferes with a panel seam and allowing } \\
\text { water to penetrate }\end{array}$ & $\begin{array}{l}\text { Improper Equipment } \\
\text { Support }\end{array}$ & \begin{tabular}{|l|l|l|l|l|l}
$E Q M_{2}$ \\
$E O H_{1}$
\end{tabular} & $\begin{array}{l}\text { support has caused damage to surrounding panels but is watertight } \\
\text { support is bolted or fastened through the metal panel seams of flashing and } \\
\text { allowing water to penetrate }\end{array}$ \\
\hline & 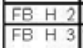 & \begin{tabular}{|l|} 
deformed securement ring that is allowing water to penetrate \\
falled or missing sealant around the drawband allowing water to penetrate
\end{tabular} & & $E Q H_{2}^{2}$ & $\begin{array}{l}\text { support has caused damage to surrounding panels and is allowing water to } \\
\text { penetrate }\end{array}$ \\
\hline & & & Mechanically & & seam is deformed or flattened but stli engaged and is watertight \\
\hline & FML 1 & rated low-severly as a minimum & Interlocked Soam & MSH & seam is open or allowing water to penetrate; or seam is disengaged \\
\hline & FM M 1 & flange on upslope side is mounted on top of panel, bucking water, but is & & $\overline{C C L}$ & seam is deformed or flattened but stil engaged and is watertight \\
\hline & & watertight & Integral Cap Seam & $\mathrm{IC} \mathrm{H} 1$ & seam is disengaged, requiring localized repair \\
\hline & 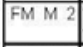 & $\begin{array}{l}\text { flange on downslope side is mounted below panel, bucking water, but is } \\
\text { watertight }\end{array}$ & Defect & $\mathrm{ICH} \mathrm{H}_{2}$ & seam is disengaged due to panel deformity, requining panel replacement \\
\hline & FM M 3 & sealent around umbrella is deteriorating. forn, or deformed, but is watertight & & \begin{tabular}{|l|l|}
$S C L$ & $L$ \\
$S C H$ & \\
\end{tabular} & seam is deformed or flattened but stil engaged, and is watertight \\
\hline & FM H 1 & Hlashing impedes dranage & Separate Cap Seam & \begin{tabular}{|l}
$\mathrm{SC} \mathrm{H}_{1}$ \\
$\mathrm{SC} \mathrm{H}_{2}$
\end{tabular} & $\begin{array}{l}\text { seam is disengaged, requiring localzed repair } \\
\text { seam is damaged or missing reguring cap replacement }\end{array}$ \\
\hline $\begin{array}{l}\text { Flanged Metal and } \\
\text { Rarsed Curb }\end{array}$ & FM H2 & holes & & $\mathrm{SCH}$ & panel is damagod at seam location, requiring panel and cap replacement \\
\hline Flashing & $\mathrm{FMH3}$ & joint has failed and is allowing water to penetrate & & & \\
\hline & FMH4 & flange on upslope side is mounted on top of panel and allowing water to & Lap Seam Defect & LS H 1 & seam is open with no panel deformity, requinnglocalized repair \\
\hline & & penetrate & & $\mathrm{LSH}$ & seam is open due to panel deformily, requining panel replacement \\
\hline & FM H 5 & $\begin{array}{l}\text { flange on downslope side is mounted below panel and is allowing water to } \\
\text { penetrate }\end{array}$ & Transverse Panel & 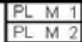 & $\begin{array}{l}\text { for cleated end lap, panel is disengaged from cleat } \\
\text { end lap joint befween panels has failed sealant or open fishmouths }\end{array}$ \\
\hline & FMHE & missing seam closure on downslope side & & $\mathrm{PL} \mathrm{H} 1$ & panel lap is bucking water \\
\hline & FMH 7 & fllange is open or unsealed & & SP L 1 & rated low severity as a minimum \\
\hline & 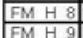 & $\begin{array}{l}\text { top of pipe flashing is open } \\
\text { sealsnt around umbrella is mis sing or is allowing water to penetrate }\end{array}$ & & SP M 1 & $\begin{array}{l}\text { composite material exhibits visible fibers, significant discoloration or other } \\
\text { signs of degradation }\end{array}$ \\
\hline & $F M A$ & Isealant around umbrella is missing or is allowing weter to penetrate & $\begin{array}{l}\text { Integrated Skylight } \\
\text { Panel Defect }\end{array}$ & SP $\mathrm{H} 1$ & $\begin{array}{l}\text { signs of degradation } \\
\text { joint between skybight panel and adjacent metal panel is not watertight or } \\
\text { bucking water }\end{array}$ \\
\hline & & & & $\mathrm{SP} \mathrm{H}_{2}$ & holes, splits or tears; allowing water to penetrate \\
\hline
\end{tabular}




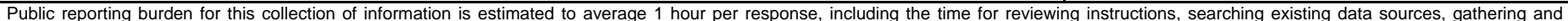

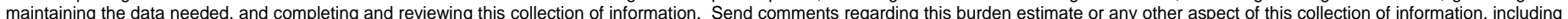

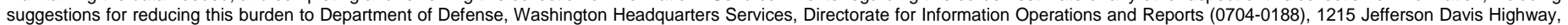

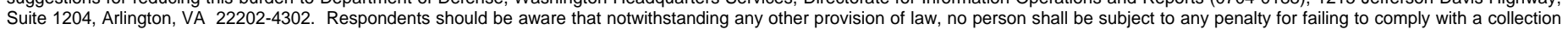
of information if it does not display a currently valid OMB control number. PLEASE DO NOT RETURN YOUR FORM TO THE ABOVE ADDRESS.

\begin{tabular}{l|l|l|l} 
1. REPORT DATE (DD-MM-YYYY) & 2. REPORT TYPE & 3. DATES COVERED (FrOm - To)
\end{tabular}

December 2012 Final

4. TITLE AND SUBTITLE

ROOFER Inventory Procedures and Inspection Manual for Metal Panel Roofing

5a. CONTRACT NUMBER

5b. GRANT NUMBER

5c. PROGRAM ELEMENT NUMBER

6. AUTHOR(S)

David M. Bailey, Joseph E. Karbarz, and Katharine E. Sweeton

5d. PROJECT NUMBER

5e. TASK NUMBER

5f. WORK UNIT NUMBER

7. PERFORMING ORGANIZATION NAME(S) AND ADDRESS(ES)

US Army Engineer Research and Development Center

Construction Engineering Research Laboratory

8. PERFORMING ORGANIZATION REPORT NUMBER

P.O. Box 9005

Champaign, IL 61826-9005

ERDC TR-12-15

9. SPONSORING I MONITORING AGENCY NAME(S) AND ADDRESS(ES)

Office of the Assistant Chief of Staff for Installation Management (ACSIM)

Facilities Branch (DAIM-ODF)

2511 Jefferson Davis Highway

Arlington, VA 22202
10. SPONSOR/MONITOR'S ACRONYM(S) ACSIM

11. SPONSOR/MONITOR'S REPORT NUMBER(S)

\section{DISTRIBUTION I AVAILABILITY STATEMENT}

Approved for public release; distribution is unlimited.

\section{SUPPLEMENTARY NOTES}

\section{ABSTRACT}

The US Army is responsible for maintaining millions of square feet of metal panel roofing on a wide variety of facilities. This type of roofing system shares a number of general characteristics with other types, but they use certain distinct types of materials that have their own specialized distress and degradation mechanisms.

Dedicated inspection guidance and condition index calculation methods are needed to quantify the condition of an installation's metal panel roofing assets in order to make the best use of Army maintenance and repair resources. This manual was developed to serve as a standard reference for performing inspections and calculating a flashing condition index (FCI) and panel condition index (PCI) for use in facility maintenance management activities. This guidance represents a new implementation of the widely used ROOFER Sustainment Management System.

\section{SUBJECT TERMS}

facilities, inspection, ROOFER, maintenance and repair (M\&R), metal panel roofing, Sustainment Management Systems (SMS)

\section{SECURITY CLASSIFICATION OF:}

\section{a. REPORT}

Unclassified

\section{b. ABSTRACT}

Unclassified c. THIS PAGE

Unclassified
17. LIMITATION OF ABSTRACT

\section{NUMBER} OF PAGES

132 19a. NAME OF RESPONSIBLE PERSON 19b. TELEPHONE NUMBER (include area code) 